\title{
LATENT CYSTEINE RESIDUES FROM POLYMERS PREPARED VIA FREE AND CONTROLLED RADICAL POLYMERIZATIONS
}

\author{
A Thesis \\ presented to \\ the Faculty of California Polytechnic State University, \\ San Luis Obispo
}

\author{
In Partial Fulfillment \\ of the Requirements for the Degree \\ Master of Science in Agriculture \\ by \\ Douglas Vincent Amato \\ June, 2013
}


(C) 2013

Douglas Vincent Amato

ALL RIGHTS RESERVED 
COMMITTEE MEMBERSHIP

TITLE:

Latent Cysteine Residues from Polymers Prepared via Free and Controlled Radical Polymerizations

AUTHOR:

Douglas Vincent Amato

DATE SUBMITTED:

May, 2013

COMMITTEE CHAIR:

Dr. Philip J. Costanzo, Professor

Chemistry and Biochemistry Department

COMMITTEE MEMBER:

Dr. Chad Immoos, Professor

Chemistry and Biochemistry Department

COMMITEE MEMBER: Dr. Derek Gragson, Professor

Chemistry and Biochemistry Department 


\begin{abstract}
Latent Cysteine Residues from Polymers Prepared via Free and Controlled Radical Polymerizations

Douglas Vincent Amato
\end{abstract}

One less commonly used "click" reaction is thiazolidine chemistry. Thiazolidine chemistry is a commonly used reaction used in biological systems because the reaction requires the presence of both cysteine (a common amino acid) and an aldehyde or ketone. If cysteine residues could be incorporated into a polymer then a variety of applications could be developed. Polymers containing free thiols (aka thiomers) have developed in the last decade to become great mucoadhesives. If there was a facile route to control the amount of free thiols along the polymer then more fine-tuned and potentially stronger adhesives could be made. For these reasons the attachment of cysteine residues in a facile way via reversible addition fragmentation chain transfer (RAFT) polymerization or small molecule synthesis was researched. The incorporation of latent cysteine residues into the polymer via post polymerization modification proved to be less successful. However protected cysteine molecules have been successfully ligated onto polymerizable monomers and have been show to be easily deprotected in the presence of an acid source. 


\section{ACKNOWLEDGMENTS}

As one goes through life, the people that we have around us and the people that we look up to, matter the most. I would like to thank Dr. Philip Costanzo for his guidance and development of me as both a chemist and a person. From my research with Dr. Costanzo I have learned that when presented with failure it is important to realize that there is always another way to reach your goal. Next I would like to thank my parents for instilling the belief that you can always do or be anything that you put your mind to, regardless of difficulty. I would like to thank the chemistry department for the role of developing me as a professional chemist. My life would not be what it is today without the people involved with the Polymer and Coatings program at Cal Poly. The program not only led me to an area of science that I love, but also led me to find love personally. My wife, Dahlia Amato, I would like to thank for her continued emotional support and drive to push through failure. I would like the thank Cal Poly-San Luis Obispo, for without whom I would not know where I would be without it. 


\section{TABLE OF CONTENTS}

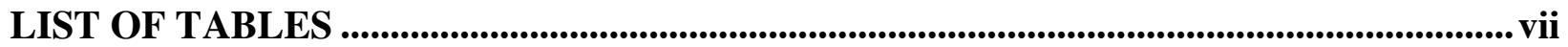

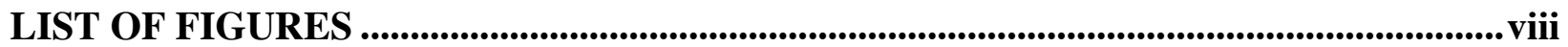

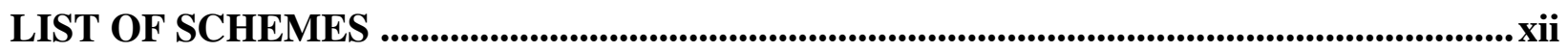

1. INTRODUCTION ................................................................................................................................... 1

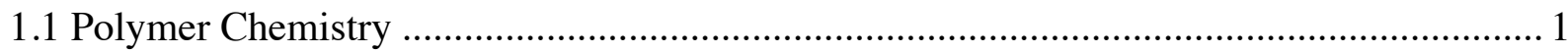

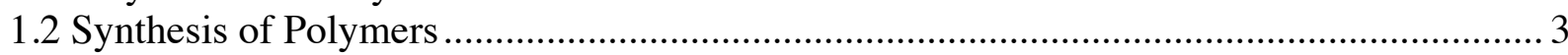

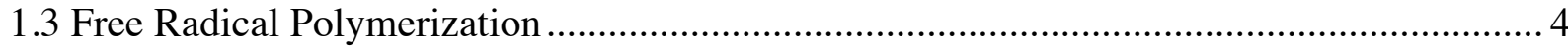

1.4 Controlled Radical Polymerization .............................................................................. 6

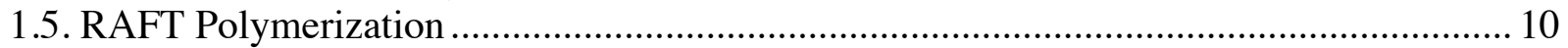

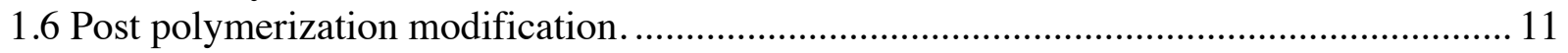

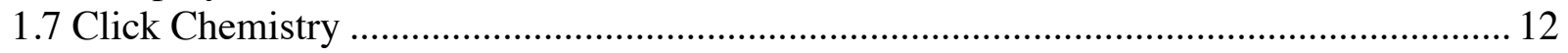

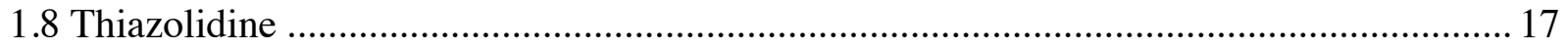

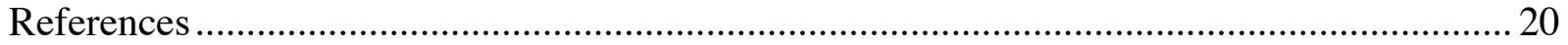

2. LATENT CYSTEINE RESIDUES FORMED VIA RAFT POLYMERIZATION ........... 23

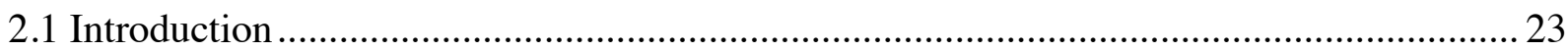

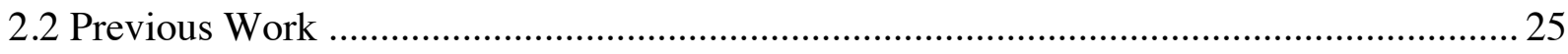

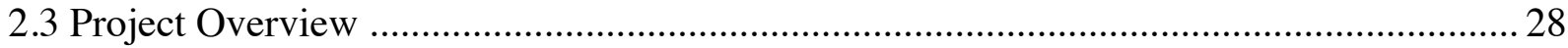

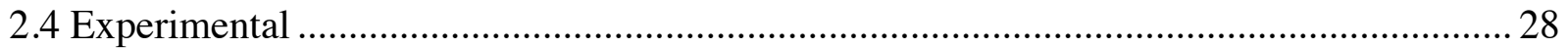

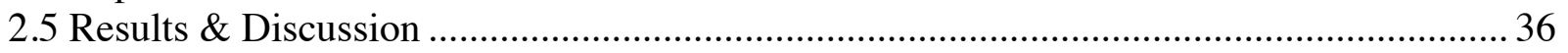

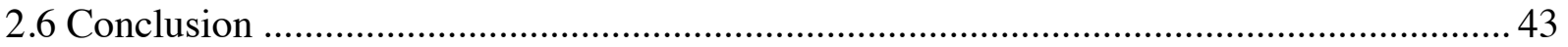

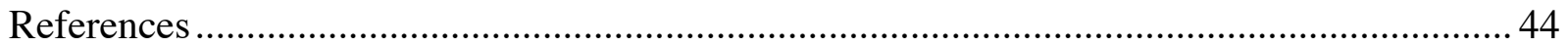

3. INCORPORATION OF A PROTECTED CYSTEINE INTO A POLYMER ................... 46

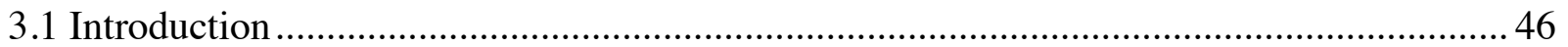

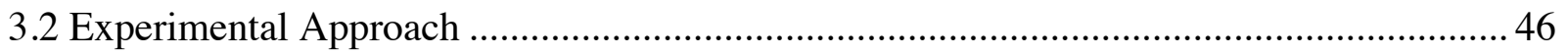

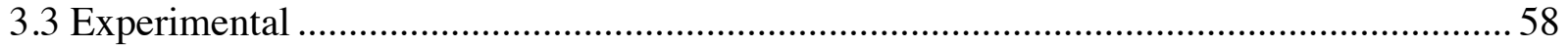

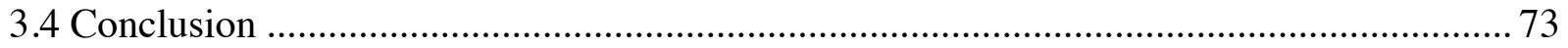

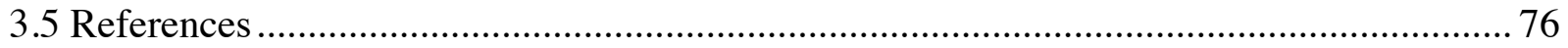

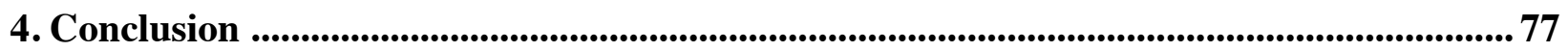

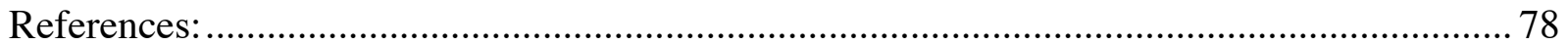




\section{LIST OF TABLES}

Tables

Page

1.4.1 Modes of propagation for NMP, ATRP, and RAFT 


\section{LIST OF FIGURES}

Figures

Page

1.1.1 Thermoset polymer with crosslinks in orange (left) and a thermoplatic polymer with reversible crosslinks (right).

1.1.2 Original polyvinylchloride balloon stent tested in a dog in 1976

1.1.3 Host reaction to a foreign body 3

1.3.1 Mechanism for radical generation for benzoyl peroxide (1)

$\begin{array}{ll}\text { and azobisisobutyronitrile (2) } & 4\end{array}$

1.3.2 Propagation, the second step in polymerization 5

1.3.3 Mechanism of chain growth polymerization. 5

1.3.4 The effect of decreasing monomer concentration on $\begin{array}{ll}\text { the molecular weight of polymers } & 6\end{array}$

1.4.1 The advantages of controlled radical polymerization $\quad 7$

1.4.2 The change in molecular weight for different $\begin{array}{ll}\text { mechanisms of polymerization } & 8\end{array}$

1.4.3 The difference in MW of polymers formed via FRP $(\triangleright \diamond$ top) and CRP $(\bigcirc$ bottom)

$\begin{array}{lll}\text { 1.4.4 Synthesis of a star polymer via ATRP } & 10\end{array}$

1.5.1 Base structure of a RAFT agent. Z represents an O-R, S-R, N-R , or other molecule. R can be a variety of structures but primarily has a secondary, tertiary, or quaternary $\alpha$-carbon with an $\mathrm{R}$ group attached to it.

1.5.2 Mechanism of RAFT polymerization showing the steps of initiation, propagation, reversible chain transfer (also known as preequilibrium, initialization), reinitiation, chain equilibration (also known as main equilibrium) and termination 
Figures

1.6.1 Facile synthesis of a biologically labeled polymer

1.7.1 Historical overview of the development of post-polymerization modification

1.7.2 Azide-alkyne click

1.7.3 Attachment of an azide onto a molecule

1.7.4 Synthesis of azide functionalized styrene via combination of ATRP and post-polymerization modification a) Styrene, $\mathrm{CuBr}_{2}, \mathrm{PMDETA}$. b) $\mathrm{NaN}_{3}$

1.7.5 Click of two different polymers to make a longer polymer

1.7.6 Optical micrograph of capillaries at various stages of functionalization filled with $\mathrm{H}_{2} \mathrm{O}$ containing fluorescein taken under UV conditions

1.8.1 Thiazolidine formation from an aldehyde (blue) and a cysteine residue (red).

2.1.1 Thiazolidine ring formation with an aldehyde (left) and

a 1,2-amino-mercapto terminated molecule

2.1.2 Aminolysis of a dithioester (left) resulting in a free thiol (right).

2.2.1 Potential side reactions from the direct reduction of PS-PAN with LAH. 26

2.2.2 Precursor to coupling experiments (black) with the subsequent experiments using a non-stoichiometric amount of isophthalaldehyde (blue) and a stoichiometric amount (red)

2.5.1 GPC trace of the homopolymerization of styrene with three transfer agents 37

2.5.2 Chain extension of polystyrene with acrylonitrile for three different transfer agents 38

2.5.3 Cleavage of the transfer agent for three different chain extended polymers 39

2.5.4 GPC analysis of polymeric dimers via thiazolidine coupling

2.5.5 A) The effect of solvent on the ratio of methanol:THF and

B) the effect of time on coupling efficiency

2.5.6 The effect of the amount of DTT on the coupling efficiency. 
Figures

Page

2.5.7 Effect of potassium carbonate on coupling efficiency 42

3.2.1 Azidolysis in water of 1,2-epoxides by sodium azide at $30{ }^{\circ} \mathrm{C} \quad 48$

3.2.2 ${ }^{1} \mathrm{H}$ NMR spectra of the conversion of styrene azide (top) to the alcohol-azide (middle) to the mesylated product 48

3.2.3 ${ }^{1} \mathrm{H}$ NMR of $\mathbf{1 1}$ in $d_{6}$ DMSO.

3.2.4 Kinetics of the reversibility of thiazolidine linkages in acid $d_{6}$ DMSO. $\quad 57$

3.4.1 Incorporation of thiazolidine chemistry as a way to functionalize

a photocleavable molecule. 74

3.4.2 Use of thiolyne click to create a dimer with a central protected thiazolidine. 75 


\section{LIST OF SCHEMES}

$\begin{array}{lll}\text { Schemes } & \text { Page }\end{array}$

2.2.1 Synthesis of poly(styrene)-block-poly(acrylonitrile) via RAFT 25

2.2.2 Aminolysis and protection of the produced thiol with MTS and the subsequent reduction of the nitrile with LAH 26

2.2.3 Coupling of the polymer via cleavage of MTS and subsequent $\begin{array}{ll}\text { thiazolidine formation with isophthalaldehyde } & 27\end{array}$

2.5.1 Synthesis of RAFT transfer agents 36

3.2.1 Synthesis of a cysteine residue from styrene 47

3.2.2 Synthesis of protected cysteine 49

3.2.3 Reduction of carboxylic acid with protected and unprotected cysteine $\begin{array}{ll}\text { to create a primary alcohol } & 50\end{array}$

3.2.4 Synthesis of hydrophobic thiazolidine cysteine residues 51

3.2.5 Formylation of protected cysteine 51

3.2.6 Esterification of $\mathbf{1 1}$ with vinyl-chlorobenzyl chloride (a) and propargyl chloride (b) 52

3.2.7 Carbodiimide coupling of $\mathbf{1 1}$. 53

3.2.8 Synthesis of an amide containing protected cysteines 54

3.2.9 Synthesis of 4-vinylbenzyl amine $\quad 54$

3.2.10 Ligation of a polymerizable monomer with the protected cysteine 55

3.2.11 Copolymerization of the $\mathbf{1 9}$ with styrene 56

$\begin{array}{ll}\text { 3.2.12 Click ligation strategy } & 57\end{array}$ 


\section{INTRODUCTION}

\subsection{Polymer Chemistry}

The discovery of man made synthetic polymers began in early 1907 with the invention of Bakelite. ${ }^{1}$ From two chemicals, phenol and formaldehyde, new materials made entirely by man ushered in an era termed the Age of Plastics. More man made materials were developed as they became less expensive and easier to mass-produce. From Tupperware to paint, polymer based materials that never existed previously on Earth became omnipresent in society.

Polymers can be divided into two categories, thermosets and thermoplastics. The major difference between the two is that a thermoplastic is a recyclable material that can melt when heated whereas a thermoset is a crosslinked material that does not melt when heated (see Figure 1). The properties differ between the two types and are therefore used in completely different applications. For example, thermosets are prominently utilized in coatings, adhesives, rubbers, insulation, where their non-conductive properties and heatresistance are essential. ${ }^{2,3}$ Thermoplastics are shapeable and can be melted or dissolved repeatedly as in CD cases, milk jugs, and plastic bags.
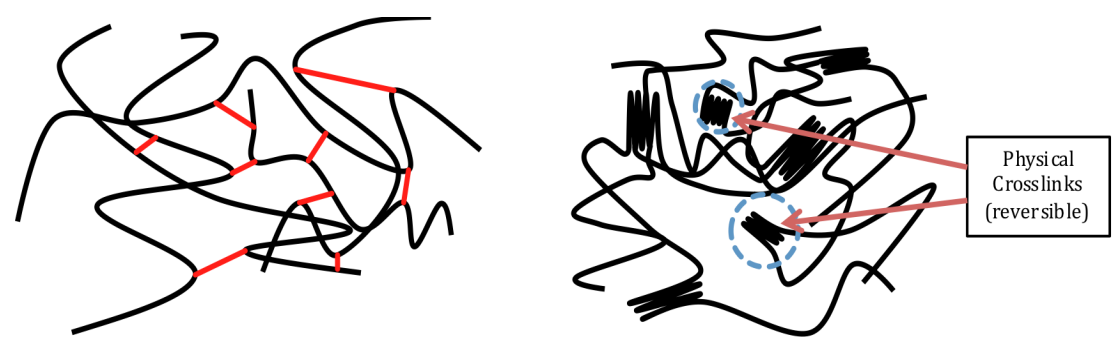

Figure 1.1.1. Thermoset polymer with crosslinks in orange (left) and a thermoplatic polymer with reversible crosslinks (right).

The discovery of new biologically compatible materials or "biomaterials" has lead to a host of new inventions and applications in polymer science and biomedical 
engineering. Dr. David Williams of the Wake Forest Institute of Regenerative Medicine once defined biomaterials as, "A non-viable material used in a medical device, intended to interact with biological systems." ${ }^{, 4}$ Well-established polymer based devices such as breast implants, pacemakers, catheters and contact lenses have been developed from the late 1950 s to the $1990 \mathrm{~s} .{ }^{5}$ More or less, the entire device is a polymer such as poly(vinyl chloride) that is processed (shaped) to fit the desired material specification and design (see Figure 1.1.2).

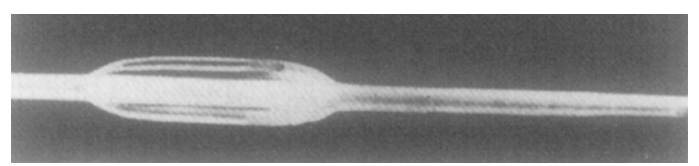

Figure 1.1.2. Original polyvinylchloride balloon stent tested in a dog in $1976 .{ }^{6}$ Recent advances in polymer science in conjugation with materials science have lead to advances in a wide variety of biomaterials. The combination of disciplines has accelerated the advancement of biomaterials, as a fundamental understanding of biology, chemistry, material properties, and engineering are all required. The primary problem with biomaterials is the host response. As depicted in Figure 1.1.3, the body is efficient at isolating and removing foreign bodies. 


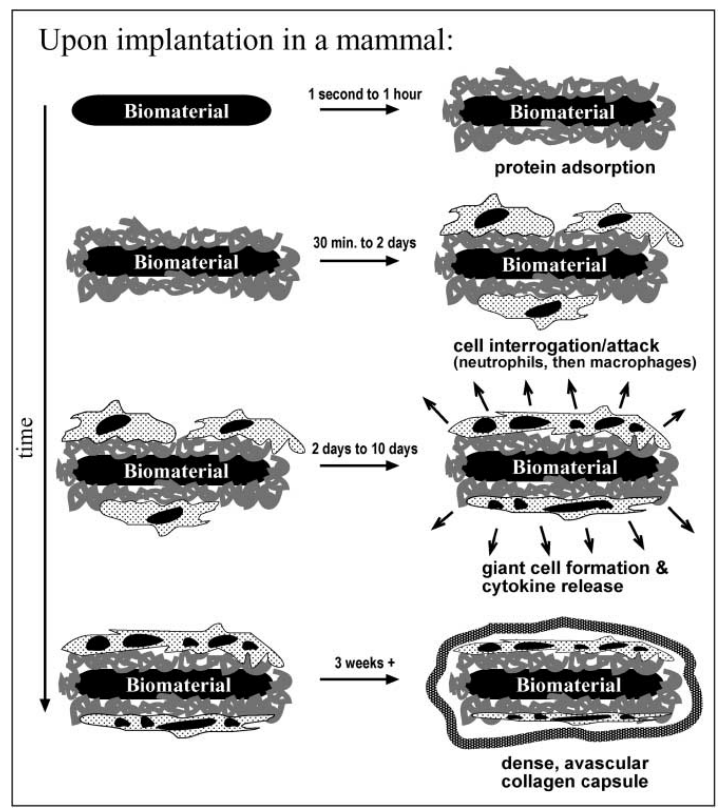

Figure 1.1.3. Host reaction to a foreign body. ${ }^{7}$

A few biomaterials that have garnered an interest over the past two decades include: biosensors, ${ }^{8}$ bio-fouling resistant materials, ${ }^{9}$ biomimetics (mimic biology), ${ }^{10}$ nanofabrication, ${ }^{11}$ and smart drug delivery. ${ }^{12}$ A strong proponent for the increase of new biomaterials has been the development of simple and efficient chemical reactions that are facile enough for a wide range of scientists and engineers.

\subsection{Synthesis of Polymers}

Synthetically, polymers can be made in a variety of ways. Chain growth and step growth are the two important methods of making polymers industrially. Step growth polymerization occurs when two reactive functional groups, A and B, react to form a chain or network of $(\mathrm{AB})_{\mathrm{n}}$. Some common products produced via step growth polymerization are nylons, polyesters, and polycarbonates. A key difference between step and chain growth is that high-molecular-weight polymer is formed almost immediately in 
a chain polymerization. Chain growth is responsible for the creation of polyethylene, polypropylene, polystyrene, rubber, polyvinyl chloride (PVC) and many other common materials.

Free radical, anionic and cationic polymerizations are all examples of chain growth polymerization. Chain growth uses active sites as the source of propagation to make long chains similar to pearls on a necklace. A radical, anionic, or cationic reactive center, once produced, adds many monomer units in a chain reaction and grows rapidly to a large size. ${ }^{13}$ Anionic and cationic are different from free radical in that they require either the use of a metal catalyst such as $\mathrm{AlCl}_{3}$ (cationic) or strong base such as n-butyl lithium bromide (anionic) to activate the reactive site.

\subsection{Free Radical Polymerization}

In free radical polymerization (FRP), the mechanism for the generation of radicals and the transfer of radicals to the monomer is well known. Benzoyl peroxide (BPO) and azobisisobutyronitrile (AIBN) are common initiators that require heat to simultaneously form radicals and breakdown and release $\mathrm{CO}_{2}$ or $\mathrm{N}_{2}$ (see Figure 1.3.1). After the radicals have been generated from the initiator they are then transferred to the monomer. In free radical polymerization, the process of generating a radical via an initiator and transferring the radical to a monomer is called initiation.

(1)

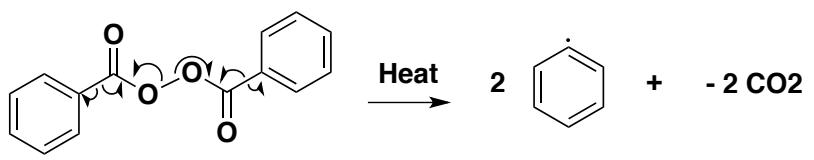

(2)

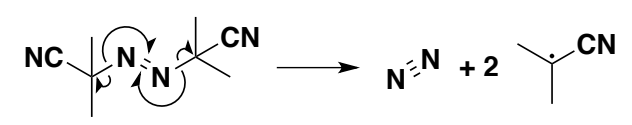

Figure 1.3.1. Mechanism for radical generation for benzoyl peroxide (1) and azobisisobutyronitrile (2). 
After initiation, the radical has been transferred to the monomer and can proceed to propagate. Propagation is when the radical on the monomer reacts with another monomer forming a chain similar to making beads on a string (see Figure 1.3.2). In free radical polymerization the average lifetime of the propagating radical is approximately three seconds (styrene, $50{ }^{\circ} \mathrm{C}$, at $0 \%$ conversion). ${ }^{14}$ Different monomers have different propagating rates in that some monomers would prefer to not attach to the same monomer but would rather attach to a different monomer. Other monomers prefer to polymerize with themselves and can therefore homopolymerize easily.

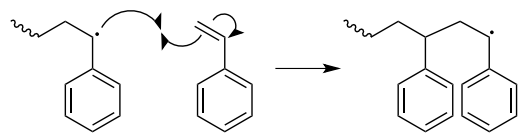

Figure 1.3.2. Propagation, the second step in polymerization.

Transfer and termination are the last two steps that follow propagation. Transfer is not the end of polymerization, but rather the transfer of the radical from one species to another. Termination is the end of the polymerization and results in non-propagating polymer chains. The full mechanism for chain growth from initiation to termination is shown below in Figure 1.3.3.
1. Initiation
$\mathrm{I}+\mathrm{M} \rightarrow \mathrm{IM}^{*}$
2. Propagation
$\mathrm{IM}^{*}+\mathrm{nM} \rightarrow \mathrm{I}(\mathrm{M})_{\mathrm{n}} \mathrm{M}^{*}$
3. Transfer
$\mathrm{I}(\mathrm{M})_{\mathrm{n}} \mathrm{M}^{*}+\mathrm{X} \rightarrow \mathrm{P}+\mathrm{X}^{*}$
4. Termination
$\mathrm{I}(\mathrm{M})_{\mathrm{n}} \mathrm{M}^{*}+\mathrm{X} \rightarrow \mathrm{P}+\mathrm{Y}$

Figure 1.3.3. Mechanism of chain growth polymerization.

An inherent problem with free radical polymerization is the inability to control the molecular weight. At the beginning of polymerization a propagating polymer can reach its maximum length due to concentration of monomer $([\mathrm{M}])$ being the highest. After time has passed and other polymers have propagated the $[\mathrm{M}]$ has decreased. Now the propagating polymers have less available monomer and therefore are unable to reach the 
same DP. This creates a mixture of both longer and shorter polymers (see Figure 1.3.4).

The degree to which there are polymers of varying length are calculated by the polydispersity index (PDI). A PDI of one corresponds to the polymers all being the exact same length (e.g. same DP) and is therefore the smallest value for a PDI. A PDI > 1 corresponds to a mixture of polymers of varying molecular weight. The greater the PDI, the greater the variability in molecular weight.

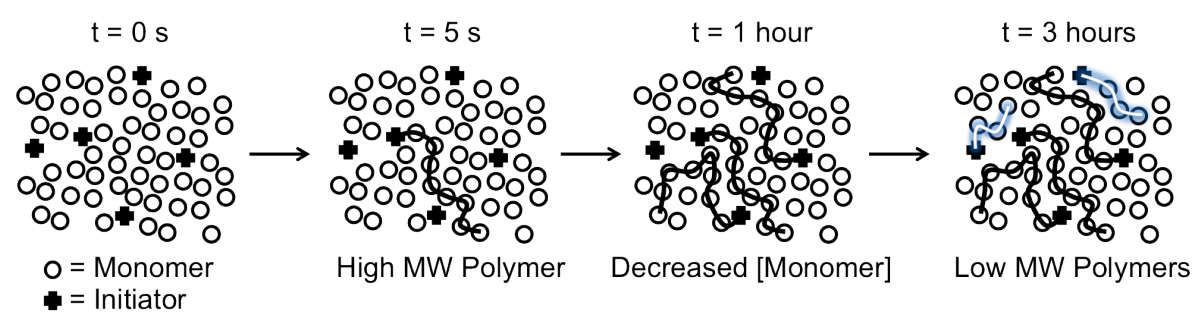

Figure 1.3.4. The effect of decreasing monomer concentration on the molecular weight of polymers.

\subsection{Controlled Radical Polymerization}

Two main branches of radical polymerization are free radical polymerization (FRP) and controlled radical polymerization (CRP). CRP is different from free radical polymerization in that there is an equilibrium between growing radicals and various types of dormant species. Due to the ease in which a transfer agent can be placed onto a small molecule, control of the topology, composition, and end functionality of the polymer can be controlled. A summary of the different types of polymers that have been synthesized by CRP are highlighted in Figure 1.4.1. 


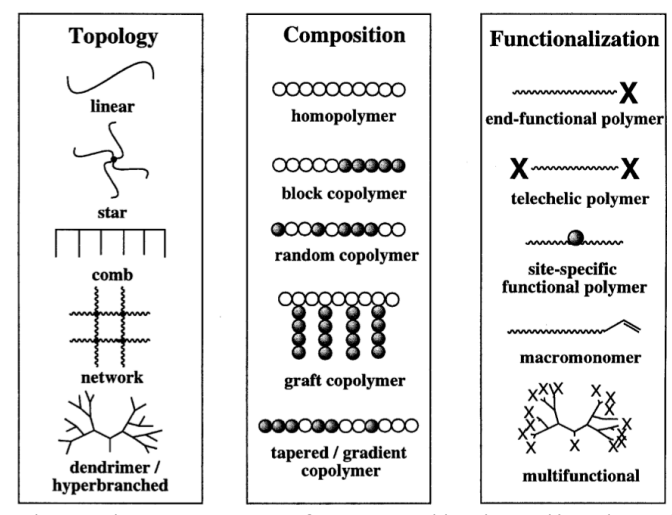

Figure 1.4.1. The advantages of controlled radical polymerization. ${ }^{15}$

The three most common forms of CRP are nitroxide mediated polymerization (NMP), atom transfer radical polymerization (ATRP) and degenerative transfer processes/reversible addition-fragmentation chain transfer (RAFT). NMP is good for polymerizing common monomers such as styrene and various acrlyates, but is unable to polymerize more complex monomers. ATRP is one of the most commonly used techniques due to its higher tolerance of polymerizable monomers as well as the ease of functionalization after the polymerization has completed. A downside to ATRP is the use of metal ligands that need to be stripped from the polymer post-processing. RAFT is one of the most versatile methods of CRP as it can polymerize most monomers while only requiring a radical source and an air free environment. Downsides to RAFT however is the difficulty in synthesizing the transfer agent, color conferred into the polymer by the transfer agent, as well as the strong smell of the transfer agents.

There are multiple ways of propagation within CRP and several are shown below in Table 1.4.1. In ATRP, the initiator agent could be an alkyl halide that coordinates with a metal ligand complex to activate and deactivate the propagating polymer through a series of oxidation and reduction reactions such as copper bromide with $N, N, N$ ', $N$ ' , $N$ ', pentamethyldiethylenetriamine. ${ }^{16}$ Other transfer agents include dithioesters or 
trithiocarbonates as used in RAFT or capping agents such as 2,2,6,6-

tetramethylpiperidine 1-oxyl (TEMPO) as used in NMP.

Table 1.4.1. Modes of propagation for NMP, ATRP, and RAFT.

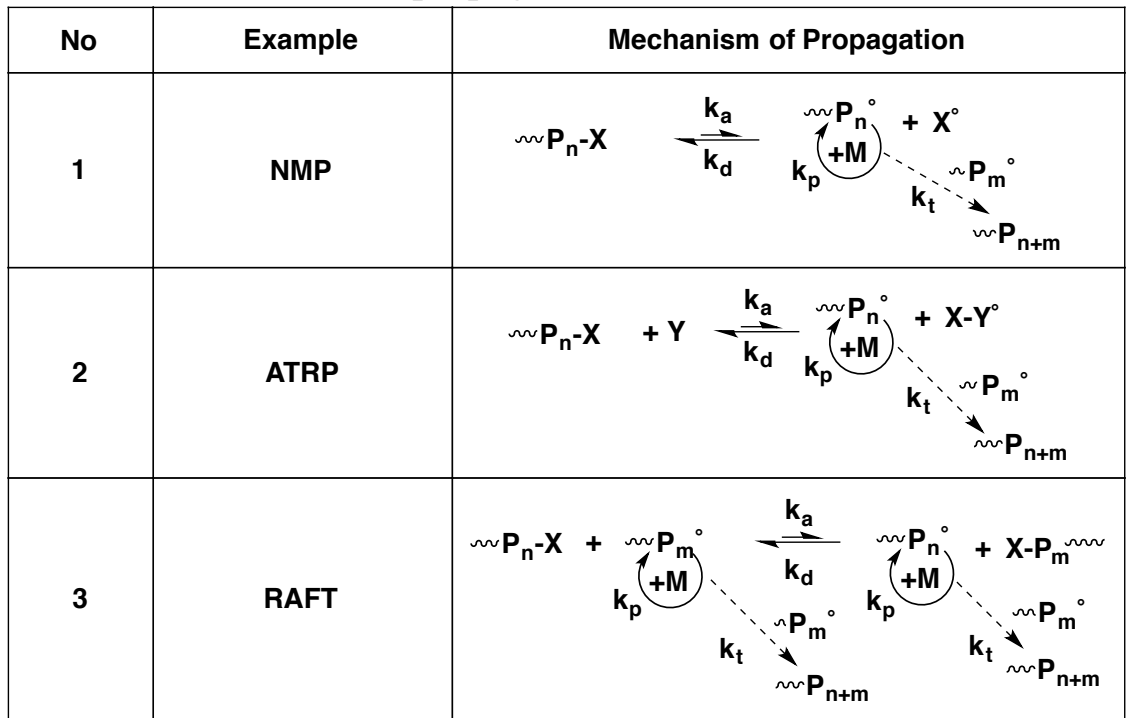

Controlled radical polymerization circumvents the problems that FRP has by decreasing the time that the polymer is active and alternating it from propagating to nonpropagating. By alternating the polymer between on (propagating) and off (dormant), the chains are able to grow more uniformly. Additionally, by decreasing the amount of time that the polymer is allowed to propagate (typically $0.1-10 \mathrm{~ms}$ ) the polymers grow in a controlled fashion. ${ }^{17}$ This creates a more uniform molecular weight among the polymers and a linear growth in molecular weight over time (Figure 1.4.2).

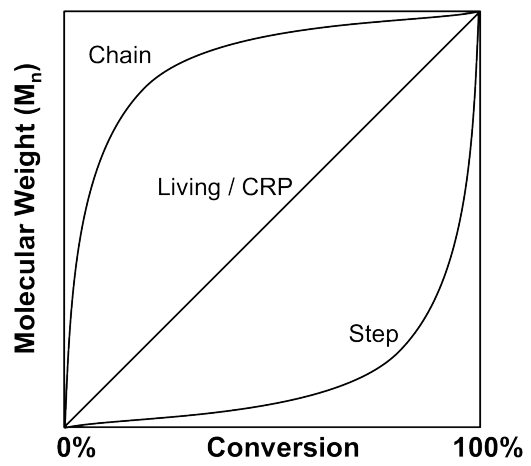

Figure 1.4.2. The change in molecular weight for different mechanisms of polymerization. 
The key feature in CRP is a transfer agent that controls whether or not the polymer is active (can propagate) or dormant (cannot propagate). In Figure 1.4.3, represents a propagating polymer that has become dormant. The $\bigcirc$ represents a dormant polymer that has become active. The new polymer $\bigcirc$ is able to propagate for a short while before it becomes deactivated and then another polymer is activated. The passing of the radical source from dormant to active allows for small bursts of propagation and allows all the chains to consume the same amount of monomer.

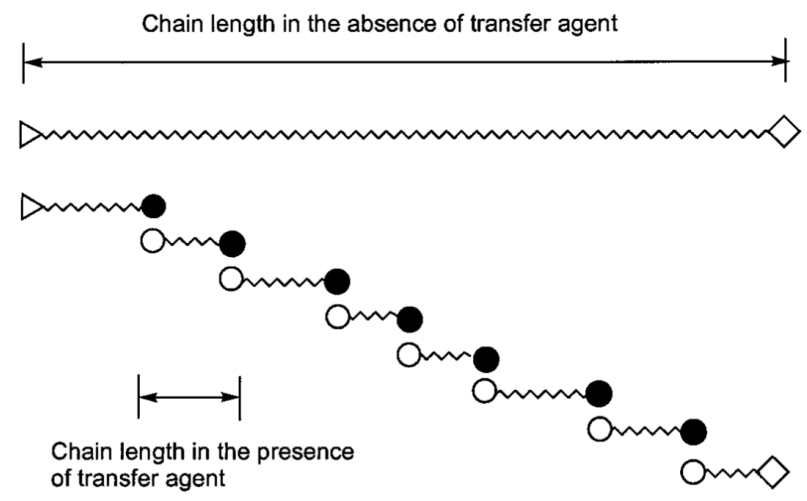

Figure 1.4.3. The difference in MW of polymers formed via FRP ( $\triangleright \diamond$ top) and CRP $\left(\bigcirc \bigcirc\right.$ bottom). ${ }^{18}$

Since the transfer agent is the site of propagation for polymerization to occur, various small molecules with one or more transfer agents are made to make a variety of polymeric architectures (See Figure 1.4.4). Additionally because the end group of the polymer is consistent, facile organic reactions can be used to attach a variety of molecules to polymers or even combine existing polymers together. It used to be very difficult to synthesize block copolymers, but now with the advent of CRP, triblock copolymers can be easily synthesized. 

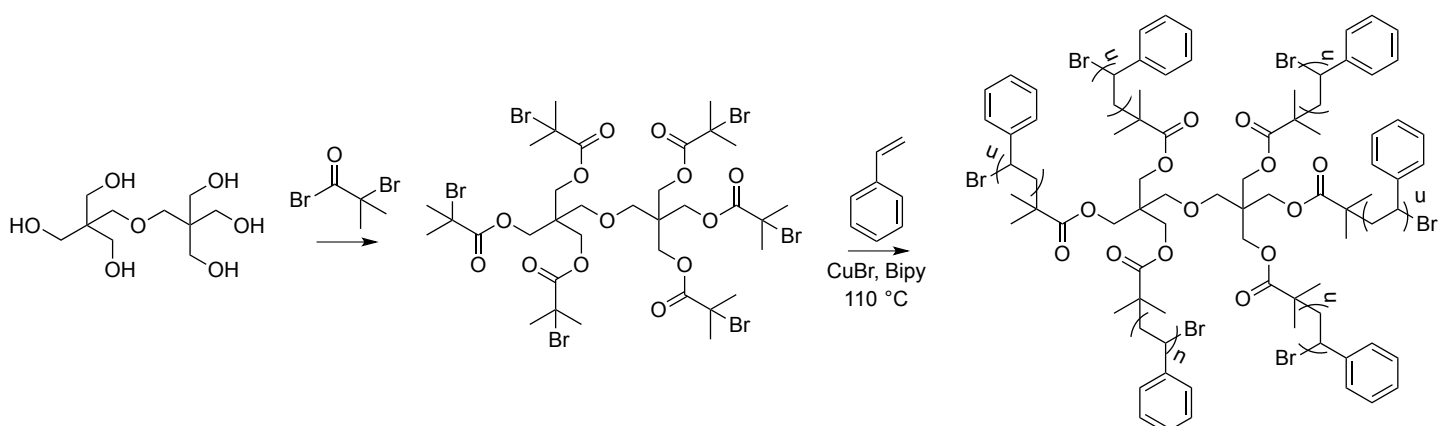

Figure 1.4.4. Synthesis of a star polymer via ATRP. ${ }^{19}$

\subsection{RAFT Polymerization}

What distinguishes RAFT polymerization from all other methods of controlled radical polymerization is that it can be used with a wide range of monomers and reaction conditions and in each case it provides controlled molecular weight polymers with very narrow polydispersities. ${ }^{20}$ The RAFT process involves free radical polymerization in the presence of dithioesters, triothiocarbonates, xanthates, etc. The difference between RAFT agents is the variable $\mathrm{Z}$ and $\mathrm{R}$ group (Figure 1.5.1). A trithiocarbonate has sulfur at the $\mathrm{Z}$ position bonded to an $\mathrm{R}$ group.<smiles>[R]SC([Z])=S</smiles>

Figure 1.5.1. Base structure of a RAFT agent. $Z$ represents an $O-R, S-R, N-R_{2}$, or other molecule. $R$ can be a variety of structures but primarily has a secondary, tertiary, or quaternary $\alpha$-carbon with an $\mathrm{R}$ group attached to it.

A key difference between RAFT polymerizations and non-controlled polymerizations is the mechanism at which polymerization occurs. In RAFT polymerization, the $\mathrm{R}$ group detaches from the RAFT agent forming a radical on itself and the trithiocarbonate. The trithiocarbonate can stabilize the radical via resonance. The radical formed on the $\mathrm{R}$ group can now react with a monomer and then propagate. The radical formed from propagation is in constant equilibrium with the radical on the 
trithiocarbonate and reattaches frequently (Figure 1.5.2). Due to this mechanism the polymerization is well controlled.

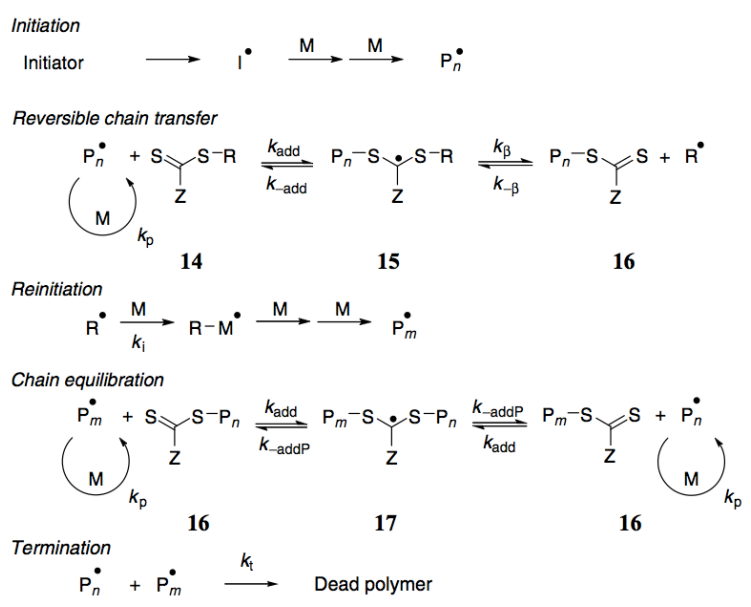

Figure 1.5.2. Mechanism of RAFT polymerization showing the steps of initiation, propagation, reversible chain transfer (also known as preequilibrium, initialization), reinitiation, chain equilibration (also known as main equilibrium) and termination. ${ }^{21}$

A major advantage of the RAFT polymerization process over other processes for controlled radical polymerization is that it is compatible with a very wide range of monomers including functional monomers containing, for example, acid (e.g. acrylic acid), acid salt (e.g. styrenesulfonic acid sodium salt), hydroxy (e.g. hydryoxyethyl methacrylate) or tertiary amino (e.g. dimethylaminoethyl methacrylate) groups. ${ }^{20}$

\subsection{Post polymerization modification.}

The concept of post-polymerization modification is important, as it has allowed for the synthesis of a wide range of useful polymers. In short, post polymerization modification can be defined as a physical or chemical modification to the polymer after polymerization has occurred. There has been a preponderance of various chemicals that have been covalently attached to polymers to the change the physical properties of the polymer, one example is shown below in Figure 1.6.1. 


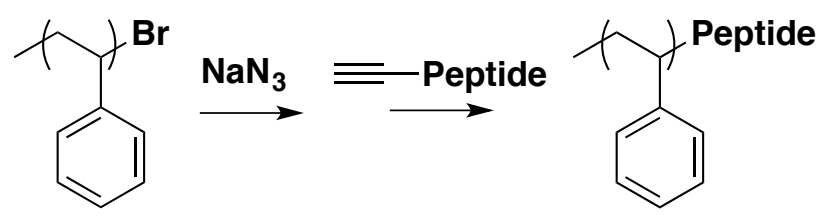

Figure 1.6.1. Facile synthesis of a biologically labeled polymer. ${ }^{22}$

Post-polymerization modification began with the advent of vulcanizing natural rubber in the $1840 \mathrm{~s} .{ }^{23}$ However the theory behind vulcanization was not developed, as the technology to understand polymers was not yet developed. Eventually it was found that sulfur crosslinked the double bonds present in the natural rubber. Later, researchers began to experiment with different varieties of sulfur containing molecules. In 1932, Holmberg used a high quality natural rubber with thioglycolic acid and demonstrated that the percentage of double bonds in the rubber went down after being incubated with the mercaptan. ${ }^{24}$ In 1948 Serniuk showed that aliphatic mercaptans are able to react with natural rubber, polyisoprene, polybutadiene, and copolymers of butadiene and acrylonitrile butadiene and styrene (ABS). ${ }^{25}$

\subsection{Click Chemistry}

As new synthetic techniques have been developed and communication of these techniques has improved, a wide range of recent chemical reactions have been applied to polymers. Figure 1.7.1 shows the number of papers published on post-polymerization modification along with when certain synthetic techniques began to be applied to polymers. Click is a term that has been recently coined for a class of reactions that are simple and provide high yield transformations of molecules. The term postpolymerization modification cannot be used without addressing the usefulness of click chemistry. 


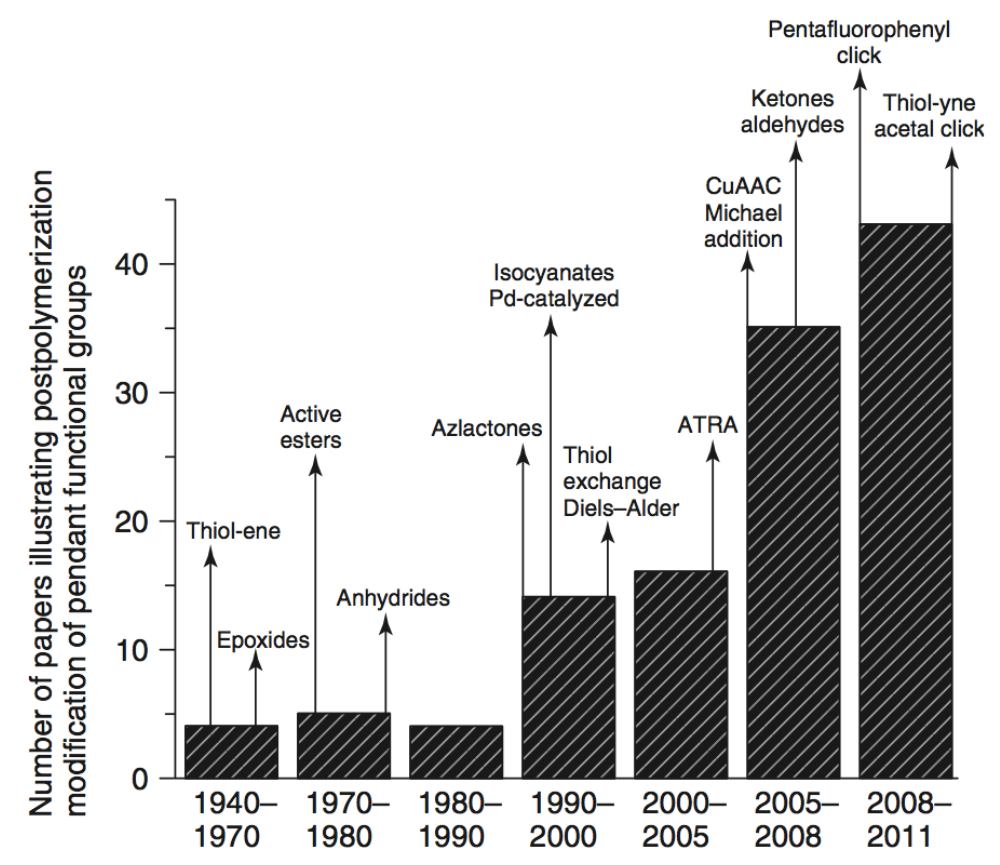

Figure 1.7.1. Historical overview of the development of post-polymerization modification. $^{26}$

Dr. Barry Sharpless defined click chemistry as, "A set of powerful, highly reliable, and selective reactions for the rapid synthesis of useful new compounds"27 It is not a specific type of reaction, but rather a synthetic concept that is built on a common goal, rather than a common reaction mechanism. In order to be classified as a click reaction the following criteria must be met: ${ }^{22}$

1. Produce quantitative yields

2. Be tolerant to other functional groups

3. Be insensitive to solvents (polar or non-polar)

4. React at various types of interfaces

Some classic click reactions include diels alder, the opening of an epoxide, the reaction of a thiol with an isocyanate, copper catalyzed Huisgen 1,3-dipolar cycloaddition (azide-alkyne, Figure 1.7.2), oxime, and thiolene/yne. ${ }^{28}$ With such high selectivity and 
yield, click chemistry is now used as a way to combine two molecules easily in ways that wasn't previously possible.

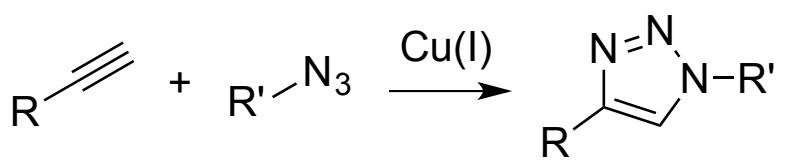

Figure 1.7.2. Azide-alkyne click.

The azide-alkyne click is the most commonly used form of click chemistry due to the large favorability of product formation and its compatibility with other functional groups and solvents. The driving force for product formation is quite large, specifically it is both thermodynamically and kinetically favorable (50 and $26 \mathrm{kcal} / \mathrm{mol}$, respectively). The reaction proceeds in any solvent including water, and only requires a small amount of copper catalyst. The reagent sodium azide $\left(\mathrm{NaN}_{3}\right)$ allows for facile addition of the azide functional group onto a variety of molecules (Figure 1.7.3). Probably the most commonly used method to attach an azide onto a molecule involves the replacement of a halogen with the azide. The azide acts as a nucleophile and attacks the carbon attached to the halogen, causing the halogen be displaced. Attaching a halogen onto a molecule is more difficult and will tend to have lower yields, however there are simple ways to do so if necessary.

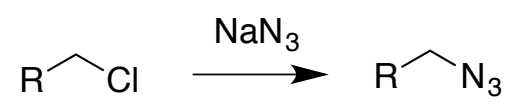

Figure 1.7.3. Attachment of an azide onto a molecule.

The combination of macromolecules of both natural and synthetic origin is an appealing strategy to prepare hybrid materials that combine the advantages of standard synthetic polymers with advanced biological functions (e.g. molecular recognition, programmed self-organization, biological targeting, enzymatic activity). ${ }^{29}$ Although click chemistry was initially postulated as a general concept for organic synthesis, this strategy 
also has enormous potential in materials science. In the 1990s, controlled radical polymerizations evolved to allow for very specific end groups on polymers. ${ }^{22}$ These welldetermined end groups can be functionalized and then "clicked" onto other molecules. This basic idea has led to dendrimers, block copolymers, fluorescently tagged polymers, polymer-drug conjugates, grafts, enzyme-polymer conjugates, and the attachment of polymers onto surfaces. Although enzyme-polymer conjugates and others mentioned were previously hard to synthesize, the advent of click chemistry has allowed anyone with very basic lab equipment and the proper chemicals to be able to make them.

George S. Hammond, in 1968 said that, "The most fundamental and lasting objective of synthesis is not production of new compounds, but production of properties. ${ }^{.27}$ Click chemistry in combination with polymer science has allowed for the facile change of polymeric properties from solubility to mechanical strength. By the extreme ease of being able to "click" any molecule onto another, the properties of polymers can be changed rapidly, assuming that they have the necessary functionality.

Additionally some polymers can use their built in functionality to provide either a halogen or another molecule to allow for the attachment of an azide. For example in atom transfer radical polymerization (ATRP) a halogen is left on the terminus of the polymer after polymerization. ${ }^{30-32}$ The residing halogen can react in a solvent with sodium azide to allow for the azide/alkyne click (Figure 1.7.4).

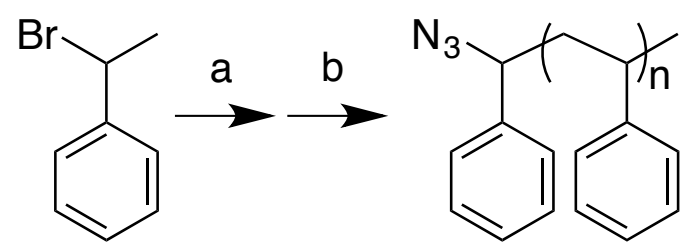

Figure 1.7.4. Synthesis of azide functionalized styrene via combination of ATRP and post-polymerization modification a) Styrene, $\mathrm{CuBr}_{2}, \mathrm{PMDETA}$. b) $\mathrm{NaN}_{3}$ 
Aside from the many benefits of performing a controlled radical polymerization, the ability to control the attachment of the azide to the polymer can lead to very high control of architecture In order to control the architecture, molecules with at least two terminal alkynes are used (Figure 1.7.5). Other variants of this have been tried in which a molecule with $3,4,5$, etc. terminal alkynes have been used to make star polymers with different numbers of branched arms. ${ }^{33,34}$<smiles>C#CCOC(=O)C1(C)CC(Br)(Br)C(=O)C(C)(C(C)(C)C(=O)OCC)C1</smiles>

Figure 1.7.5. Click of two different polymers to make a longer polymer. ${ }^{35}$

The basic principles and simplicity of the click chemistry has led polymer chemists to attach a variety of different molecules onto polymers. Some examples include fluorescent molecules that can be clicked onto a polymer. ${ }^{36}$ Other potential uses include attachment of drugs, ${ }^{37}$ hydrophilic polymers, and hydrophobic polymers. ${ }^{38,39}$

Clicking a superhydrophobic molecule onto a substrate can completely change the surface properties of the material. In Figure 1.7.6, capillary tube A is coated with a hydrophilic molecule. Tubes B-E are clicked with different hydrophobic molecules. The difference in capillary action between A (hydrophilic) and B-E exemplifies how click chemistry can be used to alter surface properties.

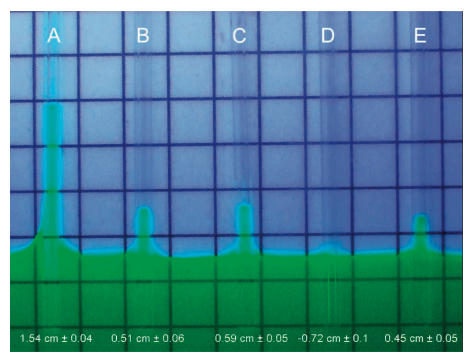

Figure 1.7.6. Optical micrograph of capillaries at various stages of functionalization filled with $\mathrm{H}_{2} \mathrm{O}$ containing fluorescein taken under $\mathrm{UV}$ conditions. ${ }^{40}$ 
While it may seem that click chemistry is used just in research labs, the underlying premise is that the reactions can be conducted in any laboratory with minimal equipment. The simplicity of the reactions has allowed other fields of science to study the properties of new materials. Polymeric molecules that were once envisioned as difficult to synthesis (dendrimers) can now be readily made by anyone who has the chemicals and in great yields. The efficiency of the reactions has allowed new found opportunities in the application of click chemistry to polymer science.

\subsection{Thiazolidine}

One lesser-used click reaction is thiazolidine chemistry. Thiazolidine chemistry is a commonly used reaction used in biological systems because the reaction requires the presence of both cysteine (a common amino acid) and an aldehyde or ketone. The reaction (shown below in Figure 1.8.1), begins with an imide formation from a condensation between the aldehyde (blue) and the amine of the cysteine (red). Then a cyclization reaction occurs as the free thiol attacks the imine and forms a five membered ring. The ring is biocompatible and is not thermally reversible.

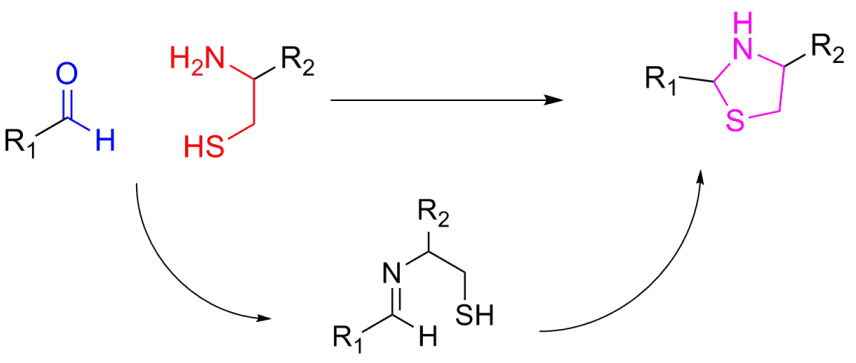

Figure 1.8.1. Thiazolidine formation from an aldehyde (blue) and a cysteine residue (red).

In the early 1900 s to the 1930 s, cysteine was shown to react with various aldehydes and ketones. It was found that cysteine was able to react with formaldehyde, 
butyric aldehyde, chloral, benzaldehyde and furfural. ${ }^{41}$ Additionally, it was found that the thiazolidine is acid sensitive and will reform its cysteine and aldehyde counterpart at a low $\mathrm{pH}$. Later, after the discovery of penicillin, a wide variety of thiazolidine containing derivatives were synthesized. It was found that the precursor to the drug 6aminopenicillic acid contains a thiazolidine ring (see Figure 1.8.2). In the mid-1950s there was an increased interest in peptide synthesis. Cysteine is a difficult amino acid to work with because it readily forms disulfide bonds. The thiazolidine protecting group was implemented in a variety of papers as a way to prevent the cysteine from reacting with itself as it was attached to the peptide. ${ }^{42,43}$

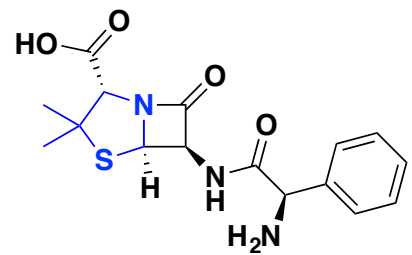

Figure 1.8.2. Structure of ampicillin (thiazolidine shown in blue).

Later work has been shown the effects of solvent on the mechanism by which the thiazolidine ring forms and breaks. ${ }^{44}$ Additionally an in situ polymerizing hydrogen made entirely by thiazolidine linkages formed between cysteine residues and poly(ethylene glycol) macromers has been made as a sealant in cataract surgeries. ${ }^{45,46}$ Also the detection of cysteine in food has led to a variety of fluorescent aldehydes and ketones that can react with the cysteine. ${ }^{47,48}$

If cysteine residues could be incorporated into a polymer then a variety of applications could be developed. Polymers containing free thiols (aka thiomers) have developed in the last decade to become great mucoadhesives. ${ }^{49}$ If there was a facile route to control the amount of free thiols along the polymer then more fine-tuned and potentially stronger adhesives could be made. Additionally the ability to trap acetones 
and aldehyde containing molecules via thiazolidine ring formation could lead to advances in detection and sequestration of certain molecules. A facile route to incorporating cysteine residues could lead to a wide variety of research in the conjugation of proteins to polymers in a reversible fashion. For these reasons the attachment of cysteine residues in a facile way via RAFT polymerization or small molecule synthesis was researched. 
References

(1) Baekeland, L. H. The Synthesis, Constitution, and Uses of Bakelite. Industrial \& Engineering Chemistry 1909, 1, 149-161.

(2) Michaeli, W.; Greif, H.; Kretzschmar, G. Training in Injection Molding: A Text and Workbook. Hanser Publishers 2001, 1-148.

(3) Pascault, J.-P.; Williams, R. J. J. Epoxy Polymers; Wiley-VCH, 2009.

(4) Williams, D. F. Tissue-biomaterial interactions. J Mater Sci 1987, 22, 34213445 .

(5) Greatbatch, W.; Holmes, C. F. History of implantable devices. Engineering in Medicine and Biology Magazine, IEEE 1991, 10, 38-41.

(6) Mueller, R. L.; Sanborn, T. A. The history of interventional cardiology: Cardiac catheterization, angioplasty, and related interventions. American Heart Journal 1995, 129, 146-172.

(7) Ratner, B. D.; Hoffman, A. S.; Schoen, F. J.; Lemons, J. E. Biomaterials Science; Academic Press, 2004.

(8) Heeger, P. S.; Heeger, A. J. Making sense of polymer-based biosensors. Proc. Natl. Acad. Sci. U.S.A. 1999, 96, 12219-12221.

(9) Youngblood, J. P.; Andruzzi, L.; Ober, C. K.; Hexemer, A.; Kramer, E. J.; Callow, J. A.; Finlay, J. A.; Callow, M. E. Coatings based on side-chain etherlinked poly(ethylene glycol) and fluorocarbon polymers for the control of marine biofouling. Biofouling 2003, 19 Suppl, 91-98.

(10) Sparks, B. J.; Hoff, E. F.; Hayes, L. P.; Patton, D. L. Mussel-Inspired Thiol-Ene Polymer Networks: Influencing Network Properties and Adhesion with Catechol Functionality. Chemistry of Materials 2012, 24, 3633-3642.

(11) Quake, S. R.; Scherer, A. From micro-to nanofabrication with soft materials. Science 2000, 290, 1536-1540.

(12) Duncan, R. The dawning era of polymer therapeutics. Nature reviews Drug discovery 2003, 2, 347-360.

(13) Odian, G. G. Principles of polymerization; John Wiley and Sons, 2004.

(14) Matheson, M. S.; Auer, E. E.; Bevilacqua, E. B.; Hart, E. J. Rate Constants in Free Radical Polymerization. III. Styrene1. J. Am. Chem. Soc. 1951, 73, 17001706.

(15) Patten, T. E.; Matyjaszewski, K. Atom transfer radical polymerization and the synthesis of polymeric materials. Adv. Mater. Weinheim 1998, 10, 901-915.

(16) Matyjaszewski, K.; Xia, J. Atom Transfer Radical Polymerization. Chem. Rev. 2001, 101, 2921-2990.

(17) Goto, A.; Fukuda, T. Kinetics of living radical polymerization. Progress in Polymer Science 2004, 29, 329-385.

(18) Matyjaszewski, K.; Davis, T. P. Handbook of Radical Polymerization; 1 st ed. Wiley-Interscience, 2002.

(19) Jankova, K.; Bednarek, M.; Hvilsted, S. Star polymers by ATRP of styrene and acrylates employing multifunctional initiators. J. Polym. Sci. A Polym. Chem. 2005, 43, 3748-3759.

(20) Chiefari, J.; YK Bill Chong; Ercole, F.; Krstina, J.; Jeffery, J.; Le, T. P. T.; Mayadunne, R. T. A.; Meijs, G. F.; Moad, C. L.; Moad, G. Living free-radical 
polymerization by reversible addition-fragmentation chain transfer: the RAFT process. Macromolecules 1998, 31, 5559-5562.

(21) Handbook of RAFT Polymerization; Barner-Kowollik, C., Ed. Wiley-VCH, 2008.

(22) Lutz, J. F.; Börner, H. G.; Weichenhan, K. Combining ATRP and "click" chemistry: a promising platform toward functional biocompatible polymers and polymer bioconjugates. Macromolecules 2006, 39, 6376-6383.

(23) Morton, M. History of Synthetic Rubber. Journal of Macromolecular ScienceChemistry 1981, 15, 1289-1302.

(24) Holmberg, B. Aufspaltungen von Mercaptal-und Mercaptolessigsäuren. Journal für Praktische Chemie 1932, 135, 57-100.

(25) Serniuk, G. E.; Banes, F. W.; Swaney, M. W. Study of the Reaction of Buna Rubbers with Aliphatic Mercaptans. J. Am. Chem. Soc. 1948, 70, 1804-1808.

(26) Günay, K. A.; Theato, P.; Klok, H. A. History of Post-Polymerization Modification. In Functional Polymers by Post-Polymerization Modification: Concepts, Guidelines, and Applications; Theato, P.; Klok, H. A., Eds. WileyVCH Verlag GmbH \& Co. KGaA, 2013; pp. 1-44.

(27) Kolb, H. C.; Finn, M.; Sharpless, K. B. Click chemistry: diverse chemical function from a few good reactions. Angew. Chem. Int. Ed. Engl. 2001, 40, 2004-2021.

(28) Flores, J. D.; Treat, N. J.; York, A. W.; McCormick, C. L. Facile, modular transformations of RAFT block copolymers via sequential isocyanate and thiolene reactions. Polym Chem 2011.

(29) Lahann, J. Click Chemistry for Biotechnology and Materials Science; John Wiley \& Sons Inc, 2009.

(30) Coessens, V. M. C.; Matyjaszewski, K. Fundamentals of Atom Transfer Radical Polymerization. Journal of chemical education 2010.

(31) Mecerreyes, D.; Atthoff, B.; Boduch, K.; Trollsaas, M.; Hedrick, J. Unimolecular combination of an atom transfer radical polymerization initiator and a lactone monomer as a route to new graft copolymers. Macromolecules 1999, 32, 51755182.

(32) Peng, C. H.; Kong, J.; Seeliger, F.; Matyjaszewski, K. Mechanism of Halogen Exchange in ATRP. Macromolecules 2011.

(33) Wu, P.; Feldman, A. K.; Nugent, A. K.; Hawker, C. J.; Scheel, A.; Voit, B.; Pyun, J.; Frechet, J. M. J.; Sharpless, K. B.; Fokin, V. V. Cover Picture: Efficiency and Fidelity in a Click-Chemistry Route to Triazole Dendrimers by the Copper (I)-Catalyzed Ligation of Azides and Alkynes (Angew. Chem. Int. Ed. 30/2004). Angew. Chem. Int. Ed. Engl. 2004, 43, 3863-3863.

(34) Binder, W. H.; Sachsenhofer, R. "Click"chemistry in polymer and materials science. Macromol Rapid Commun 2007, 28, 15-54.

(35) Opsteen, J. A.; van Hest, J. Modular synthesis of ABC type block copolymers by "click" chemistry. J. Polym. Sci. A Polym. Chem. 2007, 45, 2913-2924.

(36) Seo, T. S.; Li, Z.; Ruparel, H.; Ju, J. Click chemistry to construct fluorescent oligonucleotides for DNA sequencing. J. Org. Chem. 2003, 68, 609-612.

Medina, S. H.; El-Sayed, M. E. H. Dendrimers as carriers for delivery of 
chemotherapeutic agents. Chem. Rev. 2009, 109, 3141-3157.

(38) Li, H.; Cheng, F.; Duft, A. M.; Adronov, A. Functionalization of single-walled carbon nanotubes with well-defined polystyrene by "click" coupling. J. Am. Chem. Soc. 2005, 127, 14518-14524.

(39) Alvaro, M.; Atienzar, P.; la Cruz, de, P.; Delgado, J. L.; Garcia, H.; Langa, F. Sidewall functionalization of single-walled carbon nanotubes with nitrile imines. Electron transfer from the substituent to the carbon nanotube. The Journal of Physical Chemistry B 2004, 108, 12691-12697.

(40) Dirlam, P. T.; Strange, G. A.; Orlicki, J. A.; Wetzel, E. D.; Costanzo, P. J. Controlling Surface Energy and Wetability with Diels-Alder Chemistry.

Langmuir 2010, 26, 3942-3948.

(41) Schubert, M. P. Compounds of thiol acids with aldehydes. J. Biol. Chem. 1936, 114, 341-350.

(42) King, F. E.; Clark-Lewis, J. W.; Wade, R. 167. Syntheses from phthalimidoacids. Part VIII. Synthesis of glutathione by a new route to cysteinyl-peptides. Journal of the Chemical Society (Resumed) 1957, 880-885.

(43) Sheehan, J. C.; Yang, D.-D. H. A New Synthesis of Cysteinyl Peptides. J. Am. Chem. Soc. 1958, 80, 1158-1164.

(44) Huang, T.; Huang, L.; Ho, C. Mechanistic Studies on Thiazolidine Formation in Aldehyde/Cysteamine Model Systems. J. Agric. Food Chem. 1998, 46, 224-227.

(45) Wathier, M.; Jung, P. J.; Carnahan, M. A.; Kim, T.; Grinstaff, M. W. Dendritic macromers as in situ polymerizing biomaterials for securing cataract incisions. $J$. Am. Chem. Soc. 2004, 126, 12744-12745.

(46) Wathier, M.; Johnson, C. S.; Kim, T.; Grinstaff, M. W. Hydrogels formed by multiple peptide ligation reactions to fasten corneal transplants. Bioconjug. Chem. 2006, 17, 873-876.

(47) Wang, W.; Rusin, O.; Xu, X.; Kim, K. K.; Escobedo, J. O.; Fakayode, S. O.; Fletcher, K. A.; Lowry, M.; Schowalter, C. M.; Lawrence, C. M. Detection of homocysteine and cysteine. J. Am. Chem. Soc. 2005, 127, 15949-15958.

(48) Lim, S.; Escobedo, J. O.; Lowry, M.; Xu, X.; Strongin, R. Selective fluorescence detection of cysteine and N-terminal cysteine peptide residues. Chem. Commun. (Camb.) 2010, 46, 5707-5709.

(49) Wagh, M. P.; Joshi, O. U.; Patel, J. S.; Jain, V. R. Thiomers: a new generation of mucoadhesive polymers. Research J Pharm and Tech 2009, 2, 250-255. 


\section{LATENT CYSTEINE RESIDUES FORMED VIA RAFT POLYMERIZATION}

\subsection{Introduction}

Simple and efficient crosslinking techniques are sought after for many applications across a wide range of fields. Click reactions have gained favor due to near quantitative yields and fast reaction rates. The classical click reaction is the copper catalyzed 1,3-dipolar cycloaddition between an azide and an alkyne. However the presence of copper renders the material non-biocompatible as it is toxic to cells in certain concentrations. ${ }^{1}$ Ways to circumvent this problem has led to the development of expensive compounds that can undergo the same 1,3-dipolar cylcoaddition between an azide and an alkyne without copper. ${ }^{2,3}$ The fact that these useful compounds are not commercially available and involve multiple steps to synthesize, limit their use in biological systems.

Thiazolidine chemistry could prove to be a useful alternative to copper free azidealkyne reactions. The chemistry of thiazolidine ring formation is already known to occur in biological systems. ${ }^{4}$ Synthetically, the chemistry for thiazolidine ring formation has been worked out and a wide range of compounds ranging from treatments for melanoma to plant growth inhibitors have been synthesized using thiazolidine ring formation. ${ }^{5,6}$ Thiazolidine ring formation requires a 1,2-amino-mercapto terminated molecule to react with an aldehyde or ketone (see Figure 2.1.1). The amino forms an imine with the aldehyde and the mercapto cyclizes the ring.

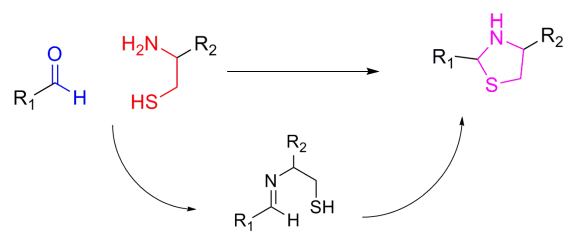

Figure 2.1.1. Thiazolidine ring formation with an aldehyde (left) and a 1,2-aminomercapto terminated molecule. 
Polymers researchers however have not fully incorporated the usefulness of thiazolidine rings. As mentioned previously, Grinstaff's group has synthesized a crosslinking hydrogel based entirely on thiazolidine ring formation. ${ }^{7,8}$ Another group has created a peptide dendrimer that was assembled via thiazolidine linkages of terminal cysteine residues. ${ }^{9}$ Aside from peptide ligation, thiazolidines have not been fully incorporated into polymer chemistry as compared to the other click reactions. One reason is the difficulty in synthesizing a 1,2-amino-mercapto terminated polymer.

A plausible route to placing a 1,2-amino-mercapto functional group on the terminus of the polymer is through the use of reversible addition-fragmentation chain transfer (RAFT) polymerization. The chain transfer agent (or CTA) is easily synthesized and can be manipulated through common organic reactions. ${ }^{10}$ A benefit to RAFT is that RAFT transfer agents (i.e. dithioesters or trithiocarbonates) already contain sulfur. The sulfur can be converted into a free mercaptan through the aminolysis of the transfer agent. $^{11-18}$ The free mercaptan can then be used for thiazolidine formation. The amino functionality can be obtained via polymerization of a nitrogen containing monomer.

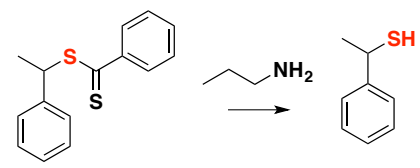

Figure 2.1.2. Aminolysis of a dithioester (left) resulting in a free thiol (right).

There are many reasons to choose RAFT as a controlled radical polymerization technique. The first being that it does not require a toxic metal/ligand to initiate polymerization as does atom-transfer radical polymerization (ATRP). A variety of monomers can be polymerized with minimal reaction conditions (air free and a radical source). A further benefit to RAFT polymerization is the ability to control molecular 
architecture while targeting an exact molecular weight. The RAFT transfer agent can also be the source of many post polymerization modifications. ${ }^{19}$

\subsection{Previous Work}

A paper published by Costanzo et al., showed how the use of reversible additionfragmentation chain transfer (RAFT) polymerization to incorporate thiazolidine linkages at the terminus of a polymer through the use of post-polymerization modification could be achieved. ${ }^{20}$ This idea was to use a RAFT transfer agent (containing two sulfur molecules) and acrylonitrile (containing a nitrogen) as the source for the 1,2-aminomercapto functionality (or cysteine like residue). The process entailed a RAFT mediated polymerization of styrene and then a block extension of acrylonitrile to place the nitrogen in a 1,2-amino-mercapto position (see Scheme 2.2.1.).

Scheme 2.2.1. Synthesis of poly(styrene)-block-poly(acrylonitrile) via RAFT.

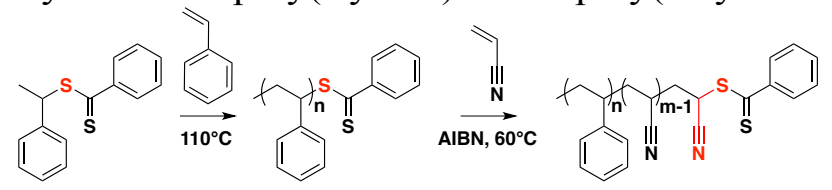

Complications arose when trying to directly reduce poly(sty)-blockpoly(acrylonitrile) (PS-PAN) with lithium aluminum hydride (LAH) to produce the free amino-mercaptan functionality. The two proposed complications were disulfide bond formation and trans-amidation (Figure 2.2.1). When the dithioester was reduced, the free thiol that is made could form disulfide bonds with other thiols. The coupling of the thiols ruins thiazolidine ring formation since the thiol functionality is necessary to cyclize the ring. Additionally, if the nitrile is reduced prior to the dithioester, the resulting amine can do a trans-amidation of the ester which ruins the amine functionality for thiazolidine ring formation. 


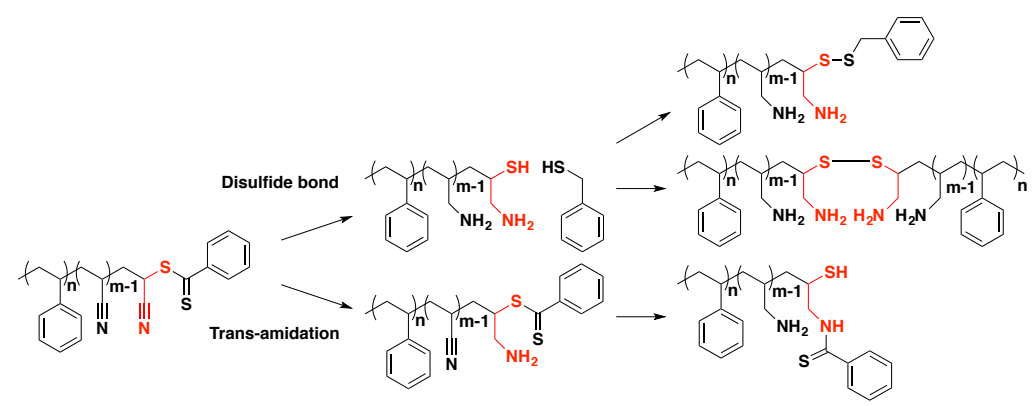

Figure 2.2.1. Potential side reactions from the direct reduction of PS-PAN with LAH.

To combat the issue of disulfide formation and trans-amidation, it was realized that direct reduction of the dithioester and the nitrile could not be done simultaneously. Instead, aminolysis of the dithioester with propylamine and a large excess of a thiol protecting group, S-methylthiosulfanate (MTS) propylamine was used (Scheme 2.2.2). This synthetic route eliminated both potential side reactions. With the thiol-protecting group, the polymer is unable to form disulfide bonds between other polymers. After the protection of the thiol, the nitrile can subsequently be reduced with LAH to the corresponding primary amine.

Scheme 2.2.2. Aminolysis and protection of the produced thiol with MTS and the subsequent reduction of the nitrile with LAH.

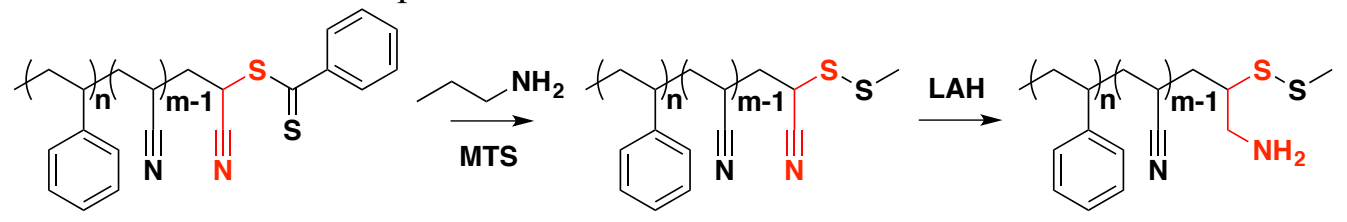

A benefit of using MTS is that it is cleavable in the presence of dithiothreitol (DTT). After cleavage of MTS, a cysteine residue is exposed that can undergo thiazolidine ring formation. Because the synthesized polymer contains only a single cysteine residue, if a molecule containing two aldehydes is added to the polymer then two thiazolidine rings can form (scheme2.2.3). If the two polymers are covalently linked, then the molecular weight of the coupled polymer is now doubled. 
Scheme 2.2.3. Coupling of the polymer via cleavage of MTS and subsequent thiazolidine formation with isophthalaldehyde.
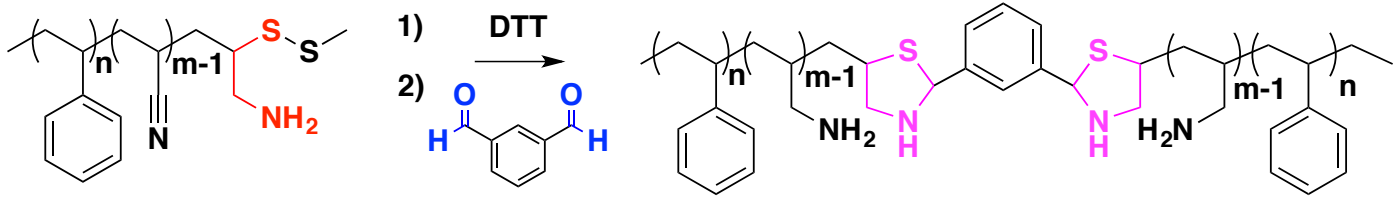

The doubling of molecular weight is easily seen in gel permeation chromatography (GPC). GPC separates molecules based upon size with small molecules taking longer to go through the column than larger molecules. Standards of known molecular weight polymers are used to calibrate the instrument so that at a given time, polymers of a certain molecular weight will elute. Shown below in Figure 2.2.2, are two coupling experiments with the protected thiol (PS-PAN-SSCH3) shown in black. The first coupling experiment involved a non-stoichiometric amount of isophthalaldehyde and the second used a stoichiometric amount ( 0.5 equivalents). It is shown that at 0.5 equivalents, complete coupling efficiency is observed. This proves that the chain extendion with acrylonitrile using RAFT can be modified through post-polymerization modifications to expose cysteine like residues.

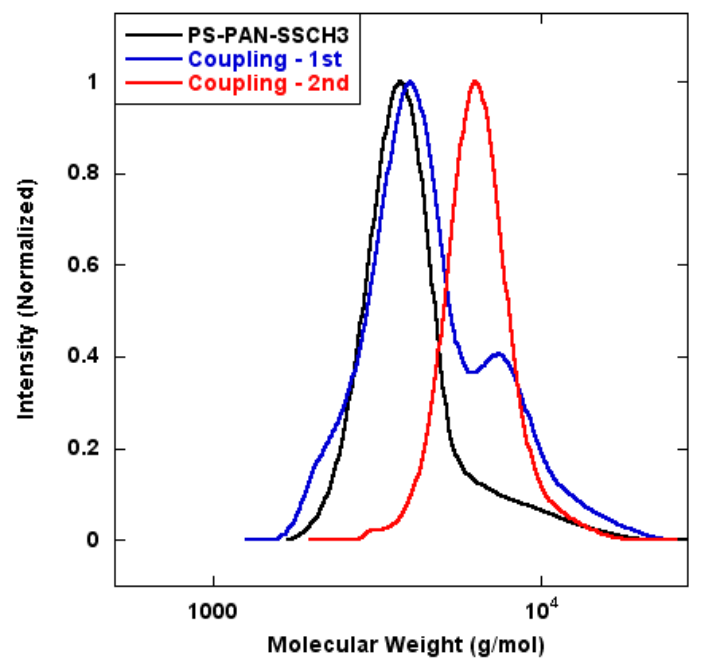

Figure 2.2.2. Precursor to coupling experiments (black) with the subsequent experiments using a non-stoichiometric amount of isophthalaldehyde (blue) and a stoichiometric amount (red). 


\subsection{Project Overview}

The previous research was limited based upon the harsh reaction conditions that were employed. LAH, while effective is not compatible with other functional groups that exist such as the esters in acrylates. While polystyrene is a good proof-of-principle, more "functional" prepolymers should be employed to illustrate the versatility of exposing the latent cysteine residue of the polymer. And lastly, the previous transfer agent (dithioester) required expensive reagents and advanced apparatuses to ensure purity (e.g. column and Kugelrohr).

\subsection{Experimental}

$\underline{\text { Methods and Materials }}$

All materials were purchased from commercially available sources. Styrene and acrylonitrile were dried over $\mathrm{CaH}_{2}$ and distilled to remove inhibitor. ${ }^{1} \mathrm{H}$ NMR spectra were recorded on a $300 \mathrm{MHz}$ varian instrument in $\mathrm{CDCl}_{3}$. Chemical shifts, $\delta(\mathrm{ppm})$, were referenced to the residual solvent signal. GPC analysis was conducted in THF at $25^{\circ} \mathrm{C}$

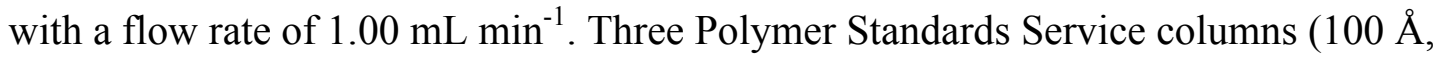
$1000 \AA$ and linear) were connected in series to a Thermo Separation Products P-100 isocratic pump, autosampler, column oven, and Knauer refractive index detector. Samples were calibrated against linear polystyrene.

Synthesis of 3-((((1-carboxyethyl)thio) carbonothioyl)thio)propanoic acid (TA-1)

To $250 \mathrm{~mL}$ round bottom flask, $100 \mathrm{~mL}$ deionized water, $\mathrm{NaOH}(16 \mathrm{~g}, 400$ mmol), and 3-mercaptopropionic acid (10.6 g, $99.9 \mathrm{mmol})$ was added along with stir bar. The solution was stirred for 30 minutes prior to drop wise addition of carbon disulfide 
(7.56 g,98.5 mmol). The yellow solution was then stirred overnight. The drop wise addition 2-bromopropionic acid (15.3 g, $100 \mathrm{mmol})$ was added to the mixture.

Concentrated hydrochloric acid then added to the mixture resulting in a precipitate. The precipitate was then collected using a Buchner funnel, washed with deionized water and dried overnight. Yield (44.5 g, 90\%). ${ }^{1} \mathrm{H}$ NMR ( $d_{6}$-DMSO) $\delta(\mathrm{ppm}): 1.55\left(\mathrm{~d}, \mathrm{CH}_{3}-\mathrm{CH}\right)$ $2.74\left(\mathrm{t},-\mathrm{CH}_{2}-\mathrm{COOH}\right), 3.59\left(\mathrm{t},-\mathrm{S}-\mathrm{CH}_{2}-\right), 4.77\left(\mathrm{q},-\mathrm{S}-\mathrm{CH}-\mathrm{CH}_{3}(\mathrm{COOH})\right.$.

Homopolyerization of Styrene under Bulk Conditions (TA-1 PS).

TA-1 (6.24 g, $24.6 \mathrm{mmol})$, styrene (128.2 g, $1.23 \mathrm{~mol})$ was added to $200 \mathrm{~mL}$ round bottom flask along with the stir bar. The mixture was purged with $\mathrm{N}_{2}$ for 30 minutes, and then heated at $110^{\circ} \mathrm{C}$ for 48 hours. Yield $(78.8 \mathrm{~g}, 58 \%)$ as a yellow powder. GPC: $M_{\mathrm{n}}-3700 \mathrm{~g} \mathrm{~mol}^{-1}(\mathrm{PDI}-1.07)$.

Synthesis of Polystyrene-b-polyacrylonitrile (TA-1 PS-PAN)

TA-1 PS (5 g, $1.35 \mathrm{mmol})$, acrylonitrile (12.21 g, $230 \mathrm{mmol}$ ), azobisbutyronitrile $(\mathrm{AIBN})(0.4 \mathrm{~g}, 2.42 \mathrm{mmol})$ and tetrahydrofuran $(\mathrm{THF}, 18 \mathrm{~mL})$ was added to $50 \mathrm{~mL}$ round bottom flask along with the stir bar. The reaction mixture was purged with $\mathrm{N}_{2}$ for 45 minutes, and then heated at $60{ }^{\circ} \mathrm{C}$ oil bath for 7.5 minutes. The reaction was exposed to air and cooled to room temperature. The mixture then precipitated in methanol and collected using vacuum filtration. Yield $(4.81 \mathrm{~g}, 96.2 \%)$ as a yellow powder. GPC: $M_{\mathrm{n}}$ $3987 \mathrm{~g} \mathrm{~mol}^{-1}(\mathrm{PDI}-1.09)$. 
Preparation of polystyrene-b-polyacrylonitrile-S-SCH$\left(\mathrm{TA}-1 \mathrm{PS}-\mathrm{PAN}-\mathrm{S}-\mathrm{S}-\mathrm{CH}_{3}\right)$

TA-1 PS-PAN (4.676 g, $1.17 \mathrm{mmol})$, THF (15 mL) and stir bar was added to 50 $\mathrm{mL}$ round bottom flask. Methyl methanethiosulfonate (MTS) (2.97 g, $23.5 \mathrm{mmol})$, and propylamine $(0.7 \mathrm{~g}, 11.8 \mathrm{mmol})$ were added to the mixture and stirred for 60 minutes at room temperature. The resulting polymer was precipitated in methanol and collected using vacuum filtration and dried overnight. Yield (4.2 g, 90\%) as a white powder. GPC: $M_{\mathrm{n}}-3930 \mathrm{~g} \mathrm{~mol}^{-1}(\mathrm{PDI}-1.10)$.

Preparation of polystyrene-b-polyallylamine-S-S-CH$\left(\mathrm{TA}-1 \mathrm{PS}-\mathrm{PNH} \mathrm{H}_{2}-\mathrm{S}-\mathrm{S}-\mathrm{CH}_{3}\right)$

TA-1 PS-PAN-S-S-CH $3(2.91 \mathrm{~g}, 0.74 \mathrm{mmol})$ and THF $(10 \mathrm{~mL})$ was added to 50 $\mathrm{mL}$ round bottom flask along with the stir bar. Next, ethanol $(2.5 \mathrm{~mL})$ and tetrabutyl ammonium borohydride (TBAB) (0.96 g, $3.73 \mathrm{mmol}$ ) was added to the mixture, the reaction turned brown. The reaction was stirred overnight and precipitated into methanol. The resulting polymer was collected using vacuum filtration and dried overnight. Yield $(0.75 \mathrm{~g}, 26 \%)$ as a white powder.

Preparation of polymeric dimers (TA-1 Coupling)

TA-1 PS-PNH $2-S-S-C_{3}(0.54 \mathrm{~g}, 0.14 \mathrm{mmol})$ and dithiothreitol (DTT) (0.0318 g, $0.2 \mathrm{mmol}$ ) was added to a $50 \mathrm{~mL}$ Schlenk flask along with a sir bar. The flask was vacuum backfilled with $\mathrm{N}_{2}$ three times. A purged solution of THF (12 mL) and methanol $(8 \mathrm{~mL})$ was added to the Schlenk flask and the reaction was allowed to stir for 24 hours. Next, isophthalaldehyde $(9.3 \mathrm{mg}, 0.07 \mathrm{mmol})$ was dissolved in THF (4 mL) and purged with $\mathrm{N}_{2}$ for 20 minutes and then added to the reaction mixture. The reaction went another 
24 hours. Afterwards, solvent was gently removed under reduced pressure and then precipitated in methanol and vacuum filtered to collect the polymer. Yield $(0.2 \mathrm{~g}, 37 \%)$ as a white powder. GPC: $M_{\mathrm{n}}-5149 \mathrm{~g} \mathrm{~mol}^{-1}(\mathrm{PDI}-1.20)$.

Synthesis of 2-(((dodecylthio)carbonothioyl)thio)-2-methylpropanoic acid (TA-2)

1-dodecanethiol (10 g, $49.4 \mathrm{mmol})$, acetone $(30 \mathrm{~mL})$, and tetrabutylammonium bromide $(0.65 \mathrm{~g}, 2 \mathrm{~mol}))$ were mixed in a jacketed reactor cooled to $10{ }^{\circ} \mathrm{C}$ under a nitrogen atmosphere. 50\% sodium hydroxide solution ( $4.8 \mathrm{~g})$ was added over 20 minutes. The mixture was stirred for 15 minutes before adding carbon disulfide $(3.78 \mathrm{~g}, 50 \mathrm{mmol})$ in acetone $(6 \mathrm{ml})$ was added over 20 minutes, the reaction turned red. Ten minutes later, chloroform (5 g, $41 \mathrm{mmol})$ was added to the mixture, followed by dropwise addition of $50 \%$ sodium hydroxide solution $(20 \mathrm{~g}$ ) over 30 minutes period. The reaction was stirred overnight. Deionized water $(75 \mathrm{~mL})$ was added, followed by concentrated $\mathrm{HCl}(12 \mathrm{~mL})$ to acidify the aqueous solution. Nitrogen was purged through the reactor with vigorous stirring to help evaporate off acetone. The solid then collected with a Buchner funnel and then stirred in 2-propanol $(250 \mathrm{~mL})$. The undissolved solid was filtered off. The solution was concentrated to dryness and the resulting solid was recrystallized from hexanes.

Yield $(8.27 \mathrm{~g}, 46 \%)$ as a yellow solid. ${ }^{1} \mathrm{H}$ NMR $\left(\mathrm{CDCl}_{3}\right) \delta(\mathrm{ppm}): 0.87\left(\mathrm{t}, 3 \mathrm{H}, \mathrm{CH}_{3}\right), 1.25$ (m, 16H, $\left.\left(\mathrm{CH}_{2}\right)_{8}\right), 1.38\left(\mathrm{~m}, 2 \mathrm{H}, \mathrm{CH}_{2}\right), 1.67\left(\mathrm{~m}, 2 \mathrm{H}, \mathrm{CH}_{2}\right), 1.73\left(\mathrm{~s}, 6 \mathrm{H}, \mathrm{C}\left(\mathrm{CH}_{3}\right)_{2}\right), 3.28(\mathrm{t}$, $\left.2 \mathrm{H}, \mathrm{CH}_{2} \mathrm{~S}\right)$. 
Homopolyerization of Styrene under Bulk Conditions (TA-2 PS).

TA-2 (0.1 g, $0.27 \mathrm{mmol})$, styrene $(1.709 \mathrm{~g}, 16.4 \mathrm{mmol})$ was added to $25 \mathrm{~mL}$ round bottom flask along with the stir bar. The mixture was purged with $\mathrm{N}_{2}$ for 30 minutes, and then heated at $140^{\circ} \mathrm{C}$ for 3 hours. Yield $(.78 \mathrm{~g}, 43 \%)$ as a yellow powder. GPC: $M_{\mathrm{n}}-3845 \mathrm{~g} \mathrm{~mol}^{-1}(\mathrm{PDI}-1.07)$.

Preparation of polystyrene-b-polyacrylonitrile (TA-2 PS-PAN)

TA-2 PS (0.5 g, $0.13 \mathrm{mmol})$ acrylonitrile (1.158 g, $21.8 \mathrm{mmol})$, azobisbutyronitrile (AIBN) $(0.04 \mathrm{~g}, 0.24 \mathrm{mmol})$ and tetrahydrofuran $(1.8 \mathrm{~mL})$ was added to $25 \mathrm{~mL}$ round bottom flask along with the stir bar. The reaction mixture was purged with $\mathrm{N}_{2}$ for 45 minutes, and then heated at $60^{\circ} \mathrm{C}$ oil bath for 5 minutes. The reaction was exposed to air and cooled to room temperature. The mixture then precipitated in methanol and collected using vacuum filtration. Yield $(0.318 \mathrm{~g}, 64 \%)$ as a yellow powder. GPC: $M_{n^{-}} 3982 \mathrm{~g} \mathrm{~mol}^{-1}(\mathrm{PDI}-1.08)$.

Preparation of polystyrene-b-polyacrylonitrile-S-SCH$\left(\mathrm{TA}-2 \mathrm{PS}-\mathrm{PAN}-\mathrm{S}-\mathrm{S}-\mathrm{CH}_{3}\right)$

TA-2 PS-PAN (0.2513 g, $0.063 \mathrm{mmol})$, THF (15 mL) and stir bar was added to $50 \mathrm{~mL}$ round bottom flask. S-Methyl methanethiosulfonate (MTS) $(0.16 \mathrm{~g}, 1.27 \mathrm{mmol})$, and propylamine $(0.04 \mathrm{~g}, 0.67 \mathrm{mmol})$ were added to the mixture and stirred for 60 minutes at room temperature. The resulting polymer was precipitated in methanol and collected using vacuum filtration and dried overnight. Yield $(0.21 \mathrm{~g}, 84 \%)$ as a white powder. GPC: $M_{\mathrm{n}}-3659 \mathrm{~g} \mathrm{~mol}^{-1}(\mathrm{PDI}-1.07)$. 
Preparation of polystyrene-b-polyallylamine-S-S-CH$\left(\mathrm{TA}-2 \mathrm{PS}-\mathrm{PNH}_{2}-\mathrm{S}-\mathrm{S}-\mathrm{CH}_{3}\right)$

TA-2 PS-PAN-S-S-CH $(0.201 \mathrm{~g}, 0.05 \mathrm{mmol})$ and THF $(2 \mathrm{~mL})$ was added to 25 $\mathrm{mL}$ round bottom flask along with the stir bar. Next, ethanol $(1 \mathrm{~mL})$ and tetrabutyl ammonium borohydride (TBAB) $(0.0435 \mathrm{~g}, 0.17 \mathrm{mmol})$ was added to the mixture. The reaction was stirred overnight and precipitated in methanol. The resulting polymer was collected using vacuum filtration and dried overnight. Yield $(0.15 \mathrm{~g}, 75 \%)$ as a white powder.

Preparation of polymeric dimers (TA-2 Coupling)

TA-2 PS-PNH $2-S-S-C_{3}(0.08$ g, $0.02 \mathrm{mmol})$, potassium carbonate $(0.03 \mathrm{~g}, 0.21$ mmol) and dithiothreitol (DTT) $(0.347 \mathrm{~g}, 2.25 \mathrm{mmol})$ was added to a $50 \mathrm{~mL}$ Schlenk flask along with the sir bar. The mixture was vacuum backfilled with $\mathrm{N}_{2}$ three times. The solution of THF and methanol (12 mL THF, $8 \mathrm{~mL}$ methanol) was purged with $\mathrm{N}_{2}$ for 20 minutes before added to the Schlenk flask mixture. Next, isophthalaldehyde (1.5 mg, $0.011 \mathrm{mmol}$ ) was dissolved in THF (4 mL) and purged with $\mathrm{N}_{2}$ for 20 minutes. THF solution then added to the reaction and stirred overnight. The mixture then precipitated in methanol and vacuum filter to collect the polymer. Yield $(0.028 \mathrm{~g}, 35 \%)$ as a white powder. GPC: $M_{\mathrm{n}}-4458 \mathrm{~g} \mathrm{~mol}^{-1}(\mathrm{PDI}-1.15)$.

Synthesis of benzyl 2-(((dodecylthio)carbonothioyl)thio)-2-methylpropanoate (TA-3)

TA-2 (1.0 g, $2.7 \mathrm{mmol})$, dimethylformaldehyde (DMF) (8 mL) and a stir bar were added to a $25 \mathrm{~mL}$ round bottom flask. To the mixture, 1,8-diazabycloundec-7-ene $(0.487$ $\mathrm{g}, 3.2 \mathrm{mmol}$ ) was then added, which turned the reaction orange. Five minutes later, 
bromoethylbenzyl (BEB) $(0.475 \mathrm{~g}, 2.78 \mathrm{mmol})$ was added to the mixture and stirred at room temperature overnight. Dichloromethane $(30 \mathrm{~mL})$ was added to the mixture and was washed three times with water, $5 \% \mathrm{HCl}$ and brine. The organic layer was then dried with anhydrous magnesium sulfate and filtered. Excess solvent was removed via rotary evaporation. Additional solvent was removed under reduced pressure yielding a viscous liquid (0.41 g, 33.4\%). ${ }^{1} \mathrm{H}$ NMR $\left(\mathrm{CDCl}_{3}\right) \delta(\mathrm{ppm}): 0.87$ (t, 3H, $\left.\mathrm{CH}_{3}\right), 1.25(\mathrm{~m}, 16 \mathrm{H}$, $\left.\left(\mathrm{CH}_{2}\right) 8\right), 1.38\left(\mathrm{~m}, 2 \mathrm{H}, \mathrm{CH}_{2}\right), 1.67\left(\mathrm{~m}, 2 \mathrm{H}, \mathrm{CH}_{2}\right), 1.73\left(\mathrm{~s}, 6 \mathrm{H}, \mathrm{C}\left(\mathrm{CH}_{3}\right)_{2}\right), 3.28\left(\mathrm{t}, 2 \mathrm{H}, \mathrm{CH}_{2}-\right.$ S) $4.78\left(\mathrm{~s}, 2 \mathrm{H},-\mathrm{S}-\mathrm{CH}_{2}-\mathrm{Bz}\right), 7.30-7.48(\mathrm{~m}, 5 \mathrm{H}, \mathrm{Bz})$.

\section{Homopolyerization of Styrene under Bulk Conditions (TA-3 PS).}

TA-3 (0.4 g, $0.88 \mathrm{mmol})$, styrene $(5.45 \mathrm{~g}, 52.4 \mathrm{mmol})$ was added to $25 \mathrm{~mL}$ round bottom flask along with the stir bar. The mixture was purged with $\mathrm{N}_{2}$ for 30 minutes, and then heated at $140^{\circ} \mathrm{C}$ for 4 hours. Yield $(3.36 \mathrm{~g}, 62 \%)$ as a yellow powder. GPC: $M_{\mathrm{n}}-$ $9450 \mathrm{~g} \mathrm{~mol}^{-1}(\mathrm{PDI}-1.15)$.

Preparation of polystyrene-b-polyacrylonitrile (TA-3 PS-PAN)

TA-3 PS (1.0 g, $0.105 \mathrm{mmol})$ acrylonitrile $(0.9875 \mathrm{~g}, 18.6 \mathrm{mmol})$, azobisbutyronitrile (AIBN) $(0.032 \mathrm{~g}, 0.19 \mathrm{mmol})$ and toluene $(8 \mathrm{~mL})$ was added to $25 \mathrm{~mL}$ round bottom flask along with the stir bar. The reaction mixture was purged with $\mathrm{N}_{2}$ for 45 minutes, and then heated at $60^{\circ} \mathrm{C}$ oil bath for 5 minutes. The reaction was exposed to air and cooled to room temperature. The mixture then precipitated in methanol and collected using vacuum filtration. Yield $(0.72 \mathrm{~g}, 72 \%)$ as a yellow powder. GPC: $M_{\mathrm{n}}$ $10010 \mathrm{~g} \mathrm{~mol}^{-1}(\mathrm{PDI}-1.13)$. 
Preparation of polystyrene-b-polyacrylonitrile-S-SCH $3(T A-3$ PS-PAN-S-S-CH$)$

TA-3 PS-PAN (0.72 g, $0.072 \mathrm{mmol})$, THF (15 mL) and stir bar was added to 50 $\mathrm{mL}$ round bottom flask. Methyl methane thiosulfane (MTS) $(0.178 \mathrm{~g}, 1.41 \mathrm{mmol})$, and propylamine $(0.045 \mathrm{~g}, 0.76 \mathrm{mmol})$ were added to the mixture and stirred for 60 minutes at room temperature. The resulting polymer was precipitated in methanol and collected using vacuum filtration and dried overnight. Yield $(0.51 \mathrm{~g}, 71 \%)$ as a white powder. GPC: $M_{\mathrm{n}}-9602 \mathrm{~g} \mathrm{~mol}^{-1}($ PDI- 1.16).

Preparation of polystyrene-b-polyallylamine-S-S-CH$\left(\mathrm{CH}_{3}-3 \mathrm{PS}-\mathrm{PNH}_{2}-\mathrm{S}-\mathrm{S}-\mathrm{CH}_{3}\right)$

TA-3 PS-PAN-S-S-CH $3(0.475 \mathrm{~g}, 0.05 \mathrm{mmol})$ and THF $(5 \mathrm{~mL})$ was added to 25 $\mathrm{mL}$ round bottom flask along with the stir bar. Next, ethanol $(2 \mathrm{~mL})$ and tetrabutyl ammonium borohydride (TBAB) $(0.0513 \mathrm{~g}, 0.20 \mathrm{mmol})$ was added to the mixture. The reaction was stirred overnight and precipitated into methanol. The resulting polymer was collected using vacuum filtration and dried overnight. Yield $(0.21 \mathrm{~g}, 44 \%)$ as a white powder.

Preparation of polymeric dimers (TA-3 Coupling)

TA-3 PS-PNH 2 -S-S-CH 3 (0.187 g, $0.019 \mathrm{mmol})$, potassium carbonate $(0.03 \mathrm{~g}$, $0.21 \mathrm{mmol})$ and dithiothreitol (DTT) $(0.325 \mathrm{~g}, 2.1 \mathrm{mmol})$ was added to $50 \mathrm{~mL}$ sclenk flask along with the sir bar. The mixture was vacuum backfilled with $\mathrm{N}_{2}$ three times. The solution of THF and methanol (12 mL THF, $8 \mathrm{~mL}$ methanol) was purged with $\mathrm{N}_{2}$ for 20 minutes before added to the schlenk flask mixture. Next, isophthalaldehyde (1.3 $\mathrm{mg}$, $0.010 \mathrm{mmol}$ ) was dissolved in THF $(4 \mathrm{~mL})$ and purged with $\mathrm{N}_{2}$ for 20 minutes. THF 
solution then added to the sclenk mixture and stirred overnight. The mixture then precipitated in methanol and vacuum filter to collect the polymer. Yield $(0.039 \mathrm{~g}, 21 \%)$ as a white powder. GPC: $M_{\mathrm{n}}-11330 \mathrm{~g} \mathrm{~mol}^{-1}$ (PDI-1.20).

\subsection{Results \& Discussion}

Synthesis of RAFT transfer agents

Scheme 2.5.1. Synthesis of RAFT transfer agents.

a)

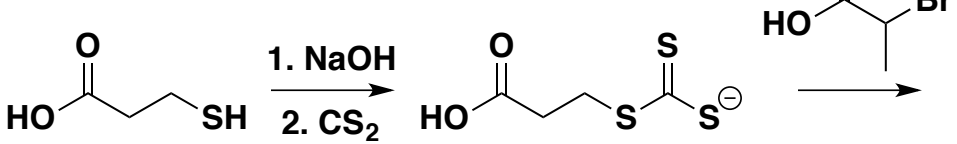<smiles>CC(SC(=S)SCCC(=O)O)C(=O)O</smiles>

1. TBAB

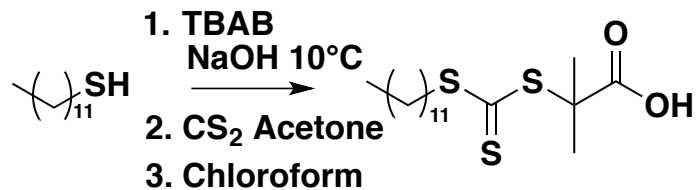

TA-2

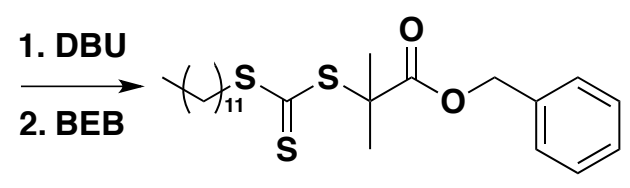

TA-3

The synthesis of new transfer agents was carried out to find a simple and efficient synthesis that did not require much purification and afforded high yields. The synthesis of TA-1 (Scheme 2.5.1a) was chosen as it was synthesized previously by Dr. McCormick's group. ${ }^{21}$ The synthesis of this compound is so efficient ( $90 \%$ yield) because takes advantage of the solubility of the carboxylic acids. At a high $\mathrm{pH}$, the molecule is water soluble due to the carboxylic acids being deprotonated. When acidified by the addition of concentrated hydrochloric acid, the molecule precipitates out of water as a solid. The synthesis of TA-2 has been previously reported as well and additionally uses the carboxylic acid group to control solubility. ${ }^{22}$ TA-3 was made through a simple esterification of TA-2. A benefit to the esterification of TA-2 was that it lacks ${ }^{1} \mathrm{H}$ NMR peaks in the range of 4-10 ppm. Therefore it was easy to confirm the esterification with 
the appearance of the benzylic protons $\left(4.78 \mathrm{ppm}\right.$ for the $\mathrm{CH}_{2}$ and 7.30-7.48 ppm for the benzylic peaks).

Homopolymerization of styrene for all the transfer agents was straightforward and proceeded with a decent conversion $(>60 \%)$. Styrene is able to create radicals at an elevated temperature due to the formation of radicals generated through a Diels-Alder reaction which is why no additional initiator was added to the reaction. ${ }^{23,24}$ In the presence of the RAFT transfer agent, the polymerization of styrene was able to proceed in a controlled fashion as all transfer agents had a polydispersity index (PDI) of less than 1.15 (Figure 2.5.1). The molecular weight difference for TA-3 PS compared to TA-1 PS and TA-2 PS was not expected. TA-3 has a very similar structure to TA-2 and should therefore react at a similar rate, however the reaction time for the homopolymerization was longer for TA-3 PS than TA-2 PS and should therefore have reached a higher molecular weight.

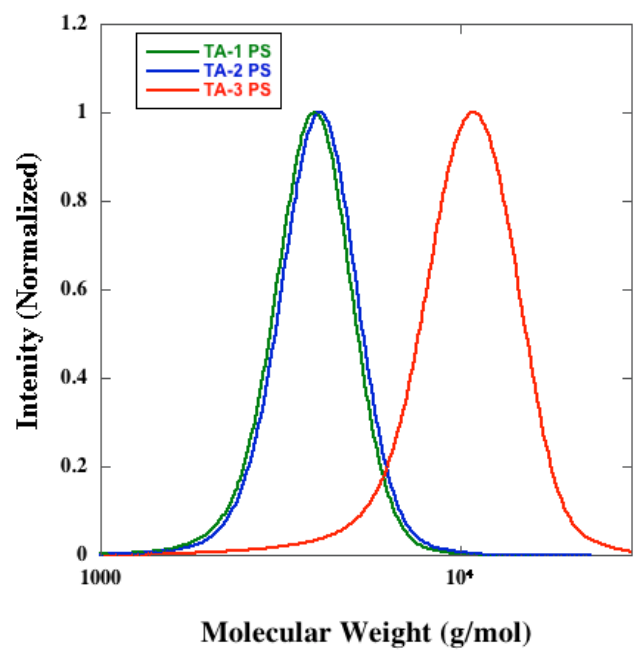

Figure 2.5.1. GPC trace of the homopolymerization of styrene with three transfer agents.

A small block of acrylonitrile (AN) of approximately 2 to 6 repeat units was added to the polymer. As previous experiments had shown, larger acrylonitrile blocks proved problematic. After reduction, the polymer became too hydrophilic and proved to 
be difficult to isolate. Additionally, the presence of extra amines compromises the efficiency of the thiazolidine coupling. As done previously, a high concentration of acrylonitrile and a relatively high concentration of AIBN (TA:AIBN 1.0:1.9) was used.

TA-1 PS-PAN and TA-2 PS-PAN showed an ideal chain extension as there is a shift in molecular weight in both the low molecular weight and high molecular regions (Figure 2.5.1 a,b). TA-3 PS-PAN did not show as clean of a shift in molecular weight in the higher molecular weight region, which indicates that there may be dead chains present that were unable to incorporate the acrylonitrile. It is possible that the excess amount of AIBN could have reacted with the transfer agent causing transfer of the chains to terminate. ${ }^{25}$ However a more likely explanation is that not enough time was given for all of the chains to become active evenly and so some polymers began to grow, while others did not.
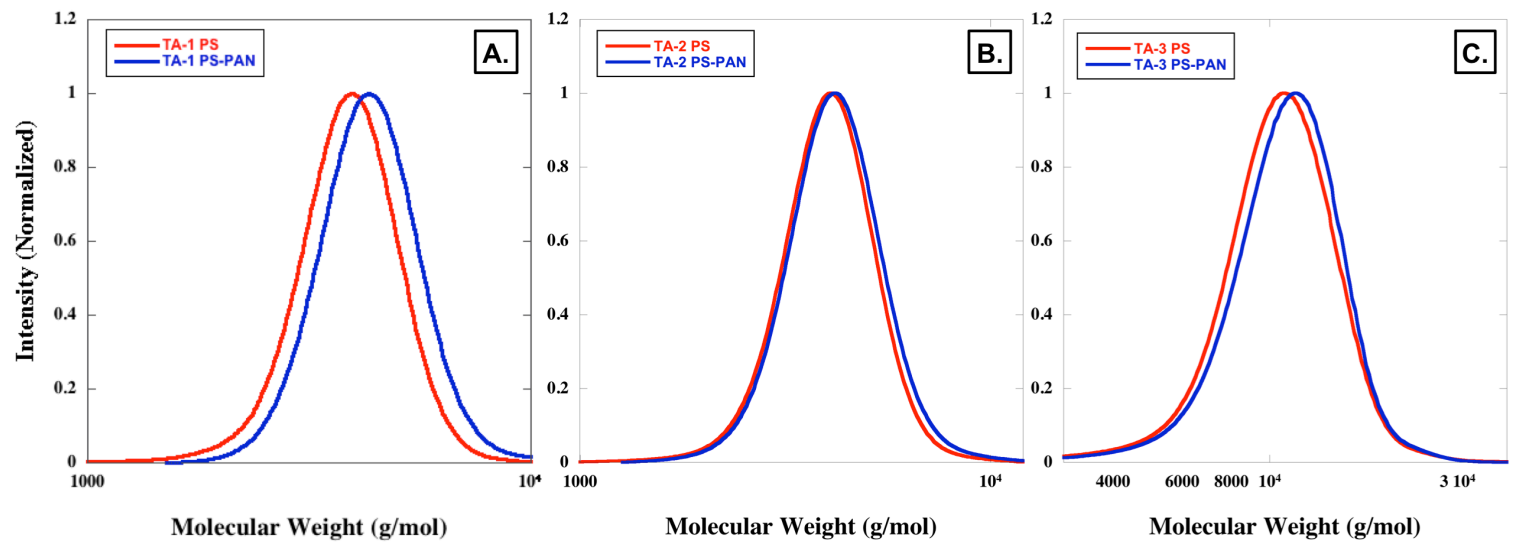

Figure 2.5.2. Chain extension of polystyrene with acrylonitrile for three different transfer agents.

Following the chain extension of AN, MTS and propylamine were added to cleave the trithiocarbonates and protect the exposed thiol simultaneously. The propylamine reacts with the trithiocarbonate end group and cleaves thiocarbonylthio producing a free thiol. Because the reaction is done in the presence of oxygen, the thiols 
are readily oxidized and can form disulfide bonds with the excess MTS in the reaction. ${ }^{26}$ The GPC is an important tool in this reaction because if disulfide bonds are formed between polymers, then a doubling of molecular weight would be apparent. If the reaction is successful, the molecular weight should decrease as there is cleavage of $\sim 100 \mathrm{~g} \mathrm{~mol}^{-1}$ of transfer agent. As shown in Figure 2.5.3, TA-1 PS-PAN-S-S-CH3 and TA-2 PS-PAN-S-S-CH3 show a clean shift as the molecular weight of the polymer has decreased uniformly. Additional evidence of the cleavage of the thiocarbonylthio is the absence of color in the polymer that precipitates (white). The GPC of TA-3 PS-PAN-SS-CH3 shows that some chains have a partial decrease in molecular weight, yet many chains did not decrease in molecular weight. This can mean that not all polymers had transfer agents on them which can explain why some chains in the chain extension step with AN did not increase in MW. Within radical polymerization a percentage of chains can terminate via coupling so it is possible that a portion of chains in TA-3 PS-PAN lacked transfer agents.

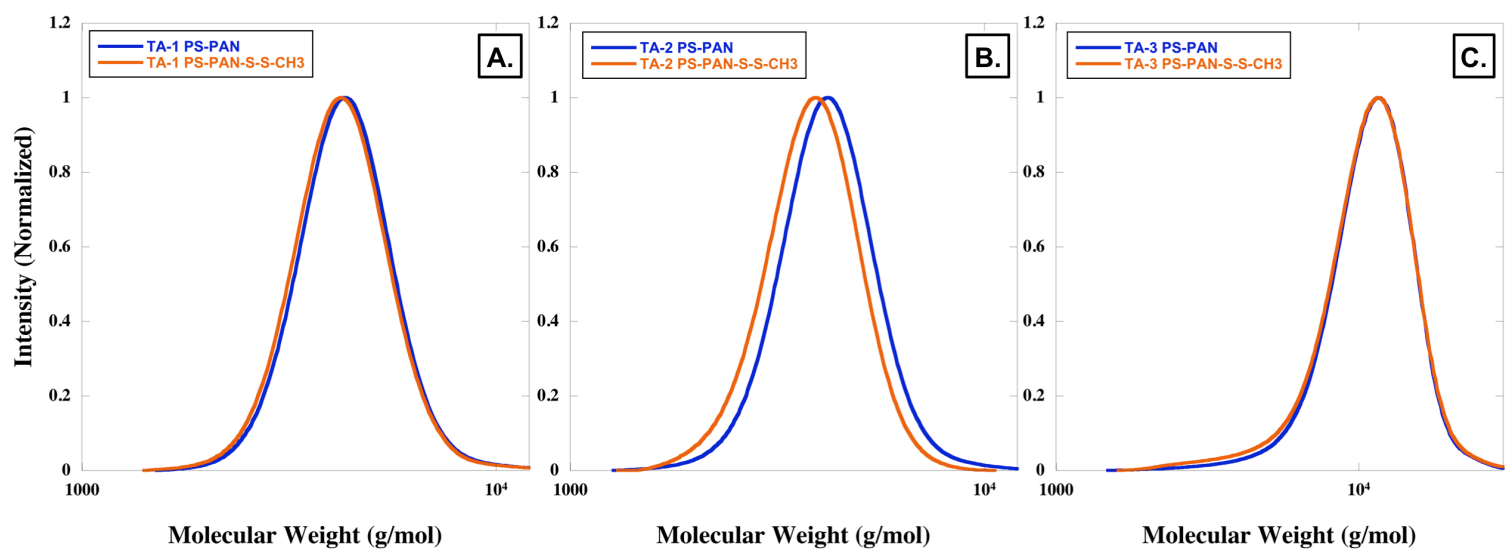

Figure 2.5.3. Cleavage of the transfer agent for three different chain extended polymers. After the cleavage of the transfer agent and the subsequent protection with MTS, the polyacrylonitrile block was reduced to a polyallylamine block. This was done through the addition of tetrabutyl ammonium borohydride (TBAB) in an ethanol:THF mixture. 
The mixture effervesced initially and changed from a white solution to a deep brown over time. There was no analysis to ensure complete conversion of the nitrile to the amine.

Lastly, coupling experiments of all three polymers prepared from their respective transfer agent was performed. For each reaction, dithiothreitol (DTT) was added to cleave the disulfide bond that was made with between MTS and the polymer. After the reaction had stirred for 24 hours, a 0.5 molar equivalent of isophthalaldehyde was added to the reaction and allowed to stir for an additional 24 hours. The results of the coupling experiments for the three transfer agents are shown in Figure 2.5.4. All three transfer agents did not show complete coupling which was unfortunate. It was surprising to see that TA-3 Coupling showed the highest degree of coupling compared to the other two. TA-3 PS-PAN did not show the best chain extension and TA-3 PS-PAN-S-S-CH3 certainly did not have a clean reduction in molecular weight so it is interesting that it out performed the other two in coupling.

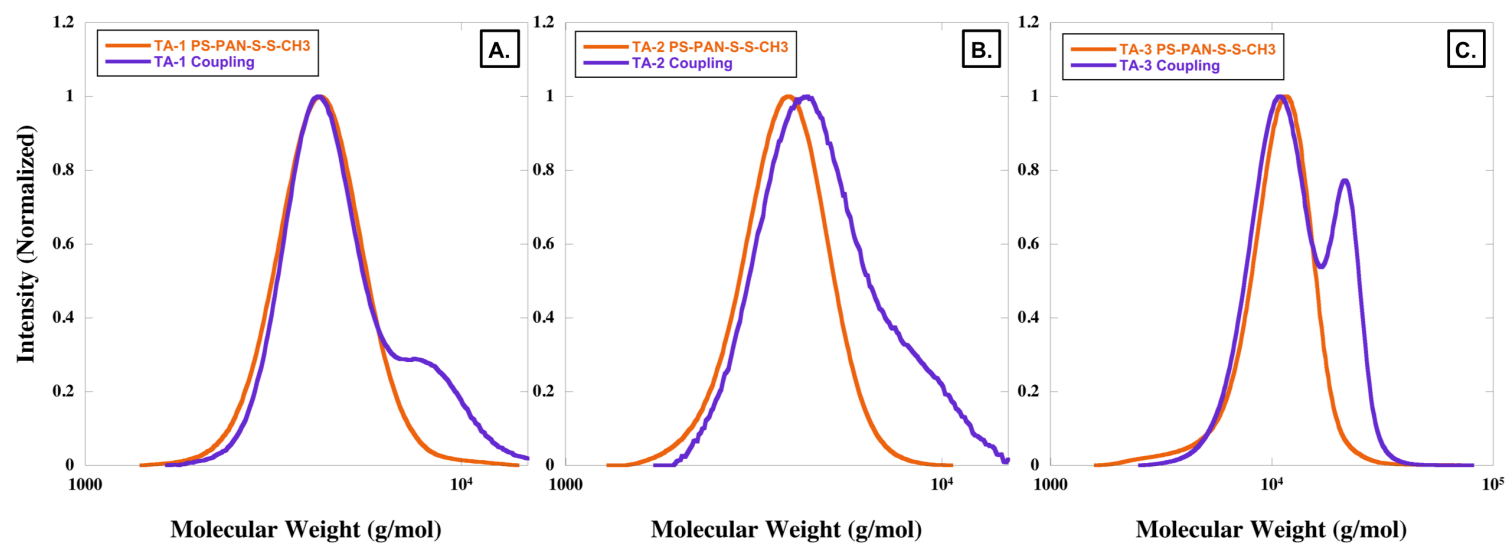

Figure 2.5.4. GPC analysis of polymeric dimers via thiazolidine coupling. The goal of this project was to start with an easy to synthesize RAFT transfer agent, so due to the higher degree of synthetic complexity of TA-3, future coupling experiments were performed with TA-1. It was thought that the conditions of the 
coupling were not optimized, so a wide range of variables including the presence of base (potassium carbonate), the amount dithiothreitol, time, and solvent selection were analyzed to see if a maximum efficiency could be obtained.

The first variable analyzed was the effect of solvent. Initial couplings of the transfer agents were performed at a ratio of 1:10 methanol:tetrahydrofuran (MeOH:THF). A previous study found that when the concentration of ethanol was around $60 \%$ (in a phosphate buffer) there was an apparent increase in thiazolidine formation. ${ }^{27}$ As shown in Figure 2.5.5a, an increase in the polarity has an effect on thiazolidine ring formation. The difference between 1:5 and 3:2 MeOH:THF while small still illustrates the effect solvent can have on coupling. In future experiments the 3:2 MeOH:THF ratio was employed. Reaction time was then analyzed to see if the thiazolidine ring formation needs additional time to reach a higher degree of coupling. As shown in Figure 2.5.5b there is little effect of coupling if given additional time. It was determined that the additional 24 hours did not merit a significant boost in coupling so 24 hours was allotted for future coupling experiments.

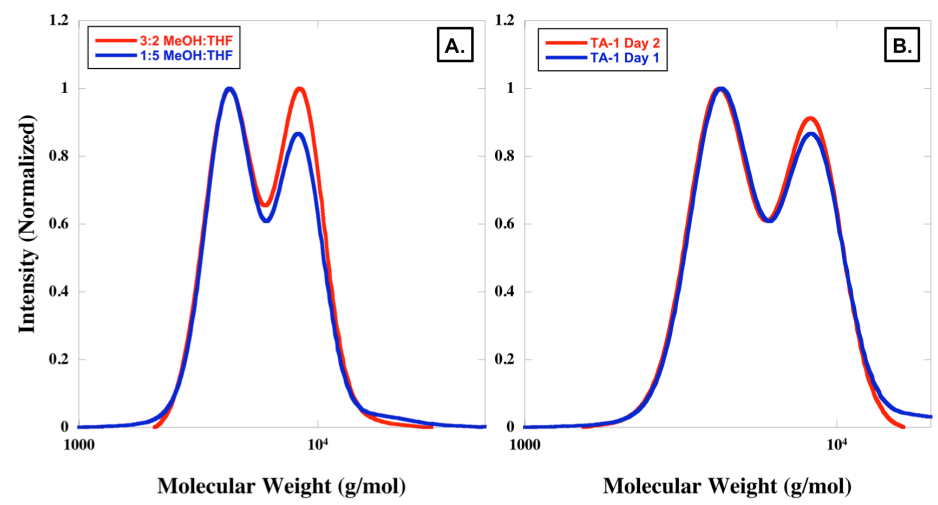

Figure 2.5.5. A) The effect of solvent on the ratio of methanol:THF and B) the effect of time on coupling efficiency.

The amount of DTT in the system was then analyzed to see if there was an effect on coupling efficiency. The ratios of DTT attempted were 1:1.5 (as done in previous 
experiments) and a new ratio of 1:3. As the amount of DTT was increased there was a significant increase in coupling efficiency. One possible reason that an increase in DTT could improve efficiency is that if a disulfide bond were to reform, the excess DTT could again cleave the disulfide bond and allow for thiazolidine ring formation.

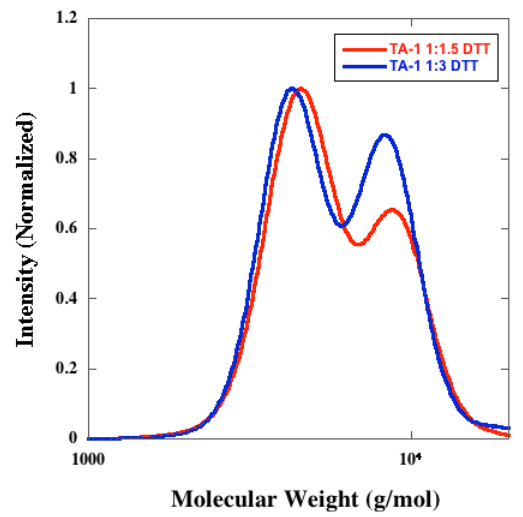

Figure 2.5.6. The effect of the amount of DTT on the coupling efficiency.

Lastly the $\mathrm{pH}$ of the reaction was adjusted to see if there was an effect on coupling efficiency. While the $\mathrm{pH}$ of an organic solution cannot be directly determined with a $\mathrm{pH}$ meter (because it is non-aqueous) the addition of base in the form of potassium carbonate can effectively raise the $\mathrm{pH}$ of the mixture. As shown in Figure 2.5.7, an increase in potassium carbonate directly correlates to an increase in coupling efficiency. It has been shown previously that thiazolidine coupling is dependent on $\mathrm{pH} \cdot{ }^{27}$

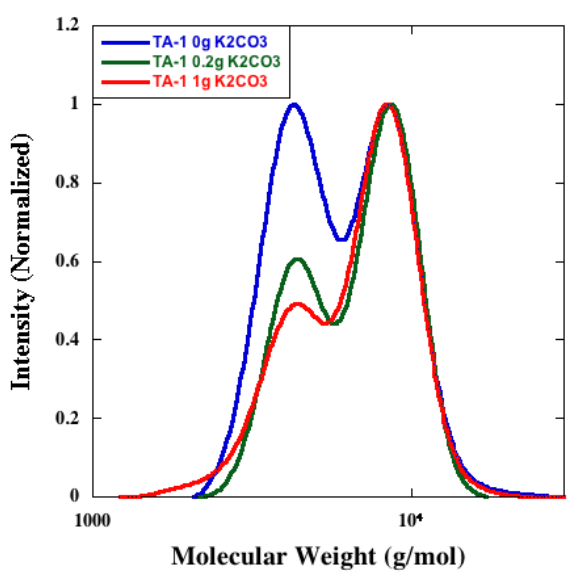

Figure 2.5.7. Effect of potassium carbonate on coupling efficiency. 


\subsection{Conclusion}

The use of three different transfer agents to achieve latent cysteine residues through polymerization and post-polymerization modification was attempted. While initial results showed that all transfer agents did not achieve 100\% coupling, a reexamination of the conditions showed that coupling efficiency could be manipulated. It was learned that increasing the polarity of the solvent, increasing the amount of DTT, and the addition of $\mathrm{K}_{2} \mathrm{CO}_{3}$ all help to increase the efficiency of thiazolidine ring formation. Allowing the ring to form at longer periods of time did not correlate to any significant increase in ring formation. It is unfortunate that further studies could not have been done to further optimize the reaction conditions. However, after so many attempts showed incomplete coupling, an alternative scheme was proposed.

A limitation to this method is that only the chain ends of the polymer can provide the latent cysteine residues necessary to achieve coupling. Additionally, multiple postpolymerization modifications were necessary and eventually effected recovery of the polymer. Future work should include the development of a single molecule that contains cysteine-like residues. This molecule should require high yielding synthetic steps and should be able to be easily attached to a polymer. A benefit to this method is that the cysteine residues do not need to exist entirely on chain ends of the polymer but can be added to the polymer as desired. 
References

(1) Seth, R.; Yang, S.; Choi, S.; Sabean, M.; Roberts, E. A. In vitro assessment of copper-induced toxicity in the human hepatoma line, Hep G2. Toxicol In Vitro 2004, 18, 501-509.

(2) Jewett, J. C.; Bertozzi, C. R. Cu-free click cycloaddition reactions in chemical biology. Chem Soc Rev 2010, 39, 1272-1279.

(3) Chang, P. V.; Prescher, J. A.; Sletten, E. M.; Baskin, J. M.; Miller, I. A.; Agard, N. J.; Lo, A.; Bertozzi, C. R. Copper-free click chemistry in living animals. Proc. Natl. Acad. Sci. U.S.A. 2010, 107, 1821-1826.

(4) Ino, A.; Murabayashi, A. Synthetic studies of thiazoline and thiazolidinecontaining natural products. Part 3: Total synthesis and absolute configuration of the siderophore yersiniabactin. Tetrahedron 2001, 57, 1897-1902.

(5) Li, W.; Lu, Y.; Wang, Z.; Dalton, J. T.; Miller, D. D. Synthesis and antiproliferative activity of thiazolidine analogs for melanoma. Bioorganic \& Medicinal Chemistry Letters 2007, 17, 4113-4117.

(6) Inamori, Y.; Muro, C.; Tanaka, R.; Adachi, A.; Miyamoto, K.; Tsujibo, H. Phytogrowth-inhibitory activity of sulphur-containing compounds. I: Inhibitory activities of thiazolidine derivatives on plant growth. Chemical and pharmaceutical bulletin 1992, 40, 2854-2856.

(7) Wathier, M.; Johnson, C. S.; Kim, T.; Grinstaff, M. W. Hydrogels formed by multiple peptide ligation reactions to fasten corneal transplants. Bioconjug. Chem. 2006, 17, 873-876.

(8) Wathier, M.; Jung, P. J.; Carnahan, M. A.; Kim, T.; Grinstaff, M. W. Dendritic macromers as in situ polymerizing biomaterials for securing cataract incisions. $J$. Am. Chem. Soc. 2004, 126, 12744-12745.

(9) Chaves, F.; Calvo, J. C.; Carvajal, C.; Rivera, Z.; Ramírez, L.; Pinto, M.; Trujillo, M.; Guzmán, F.; Patarroyo, M. E. Synthesis, isolation and characterization of Plasmodium falciparum antigenic tetrabranched peptide dendrimers obtained by thiazolidine linkages. J. Pept. Res. 2001, 58, 307-316.

(10) Thang, S. H.; Mayadunne, R. T.; Moad, G.; Rizzardo, E. A novel synthesis of functional dithioesters, dithiocarbamates, xanthates and trithiocarbonates. Tetrahedron letters 1999, 40, 2435-2438.

(11) Xu, J.; He, J.; Fan, D.; Wang, X.; Yang, Y. Aminolysis of Polymers with Thiocarbonylthio Termini Prepared by RAFT Polymerization: The Difference between Polystyrene and Polymethacrylates. Macromolecules 2006, 39, 86168624.

(12) Lima, V.; Jiang, X.; Brokken-Zijp, J.; Schoenmakers, P. J.; Klumperman, B.; Van Der Linde, R. Synthesis and characterization of telechelic polymethacrylates via RAFT polymerization. J. Polym. Sci. A Polym. Chem. 2005, 43, 959-973.

(13) Li, H.; Yu, B.; Matsushima, H.; Hoyle, C. E.; Lowe, A. B. The ThiolIsocyanate Click Reaction: Facile and Quantitative Access to $\omega$-End-Functional Poly (N, N-diethylacrylamide) Synthesized by RAFT Radical Polymerization. Macromolecules 2009, 42, 6537-6542.

(14) Yu, B.; Chan, J. W.; Hoyle, C. E.; Lowe, A. B. Sequential thiol-ene/thiol-yne and thiol-ene/thiol-yne reactions as a route to well-defined mono and bis end- 
functionalized poly (N-isopropylacrylamide). J. Polym. Sci. A Polym. Chem. 2009, 47, 3544-3557.

(15) Boyer, C.; Granville, A.; Davis, T. P.; Bulmus, V. Modification of RAFT-

polymers via thiol-ene reactions: A general route to functional polymers and new architectures. J. Polym. Sci. A Polym. Chem. 2009, 47, 3773-3794.

(16) Huang, X.; Boyer, C.; Davis, T. P.; Bulmus, V. Synthesis of heterotelechelic polymers with affinity to glutathione-S-transferase and biotin-tagged proteins by RAFT polymerization and thiol-ene reactions. Polym Chem 2011.

(17) Rikkou, M. D.; Patrickios, C. S. Polymers prepared using cleavable initiators: Synthesis, characterization and degradation. Progress in Polymer Science 2011, 36, 1079-1097.

(18) Flores, J. D.; Treat, N. J.; York, A. W.; McCormick, C. L. Facile, modular transformations of RAFT block copolymers via sequential isocyanate and thiolene reactions. Polym Chem 2011.

(19) Inglis, A. J.; Sinnwell, S.; Davis, T. P.; Barner-Kowollik, C.; Stenzel, M. H. Reversible Addition Fragmentation Chain Transfer (RAFT) and Hetero-DielsAlder Chemistry as a Convenient Conjugation Tool for Access to Complex Macromolecular Designs. Macromolecules 2008, 41, 4120-4126.

(20) Carlson, J. S.; Hill, M. R.; Young, T.; Costanzo, P. J. Novel polymer coupling chemistry based upon latent cysteine-like residues and thiazolidine chemistry. Polymer Chemistry 2010, 1, 1423-1426.

(21) Wang, R.; McCormick, C. L.; Lowe, A. B. Synthesis and evaluation of new dicarboxylic acid functional trithiocarbonates: RAFT synthesis of telechelic poly (n-butyl acrylate) s. Macromolecules 2005, 38, 9518-9525.

(22) Zhang, T.; Wu, Y.; Pan, X.; Zheng, Z.; Ding, X.; Peng, Y. An approach for the surface functionalized gold nanoparticles with $\mathrm{pH}$-responsive polymer by combination of RAFT and click chemistry. European Polymer Journal 2009, 45, 1625-1633.

(23) Mayo, F. R. The dimerization of styrene. J. Am. Chem. Soc. 1968, 90, 12891295.

(24) Khuong, K. S.; Jones, W. H.; Pryor, W. A.; Houk, K. N. The mechanism of the self-initiated thermal polymerization of styrene. Theoretical solution of a classic problem. J. Am. Chem. Soc. 2005, 127, 1265-1277.

(25) Perrier, S.; Takolpuckdee, P.; Mars, C. A. Reversible addition-fragmentation chain transfer polymerization: End group modification for functionalized polymers and chain transfer agent recovery. Macromolecules 2005, 38 .

(26) Willcock, H.; O'Reilly, R. K. End group removal and modification of RAFT polymers. Polym Chem 2010, 1, 149-157.

(27) Huang, T.; Huang, L.; Ho, C. Mechanistic Studies on Thiazolidine Formation in Aldehyde/Cysteamine Model Systems. J. Agric. Food Chem. 1998, 46, 224-227. 


\section{INCORPORATION OF A PROTECTED CYSTEINE INTO A POLYMER}

\subsection{Introduction}

The ability to attach a cysteine residue to a polymer or onto a polymerizable monomer is potentially useful for a wide range of biomedical and biochemical applications. In the past decade, polymers containing thiols (thiomers) has been lauded as a new type of bioadhesive for mucosa tissue. Muscosa tissue, specifically the glycolproteins, have cysteine rich domains that can be oxidized to form new disulfides with thiomers. ${ }^{1}$ Cysteine residues have also led to thiazolidine prodrugs for use in the development anti-cancer medicines. ${ }^{2}$ The usefulness of the thiazolidine chemistry is starting to increase as a multitude of papers have shown high yielding reactions within the past couple years.

In the past decade there has been a recent drive for facile ways to incorporate useful chemicals into materials to change material properties. The motivation for this work is to design a single molecule that can be attached to polymers either through modification of the monomer or attachment of the molecule as a post-polymerization modification.

\subsection{Experimental Approach}

In order to incorporate a molecule with a cysteine like residue onto a polymer, the cysteine residue needs to be synthesized. As a proof of concept, a molecule containing a cysteine residue that could form a thiazolidine ring needed to be developed. The following scheme was developed as a way to achieve the proof of concept (scheme 3.2.1). 
Scheme 3.2.1. Synthesis of a cysteine residue from styrene.

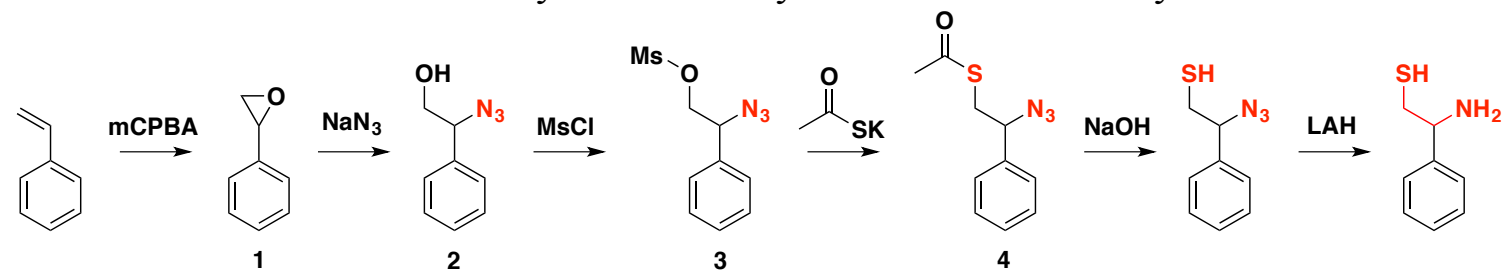

The first step of the reaction (styrene to styrene oxide) proved to be difficult to achieve in high yields. Two reaction conditions were attempted in the synthesis of $\mathbf{1}$, one in dichloromethane (1b) and the other in tetrahydrofuran (THF, 1a). Both reactions went overnight and after isolation it was found via ${ }^{1} \mathrm{H}$ NMR that a portion of styrene was unreacted. A distillation of styrene oxide is typical for the purification of impure styrene oxide, however this was not attempted. ${ }^{3}$ The reaction of styrene oxide (purchased from Sigma Aldrich) with sodium azide was attempted in a variety of solvent conditions and different temperatures. It appeared that heating the mixture in dimethylformamide (DMF) for 24 hours resulted in degradation as purification yielded unclean NMR spectrum (2a). A paper published by Amantini et al. showed that his group was able to synthesize $\mathbf{2}$ in a heterogenous mixture using only water as a solvent. They also found that under acidic or basic conditions a $97 \%$ attack of the azide at the $\alpha$ position (Figure 3.2.1). ${ }^{4}$ The discreet attack of sodium azide at the $\alpha$ position is beneficial as it means that there will not be a racemic mixture of products. The reaction conditions were unfortunately not provided within the paper directly so experimentally it was determined that excess sodium azide in water with sodium hydroxide at room temperature $(\mathbf{2 b})$ and at $50{ }^{\circ} \mathrm{C}(\mathbf{2 c})$ allowed for high yields and near complete conversion (>97 \%) of the epoxide. 


\begin{tabular}{cccccc}
\hline Entry & Epoxide & $\mathrm{pH}$ & $\mathrm{t}(\mathrm{h})$ & $\mathrm{C}-\beta / \mathrm{C}-\alpha$ & Yield $^{\mathrm{a}}(\%)$ \\
\hline \multirow{2}{*}{7} & $\overbrace{\alpha}^{\mathrm{O}} \mathrm{Ph}$ & 9.5 & 13 & $3 / 97$ & 90 \\
& & 4.2 & 0.3 & $3 / 97$ & 92 \\
\hline
\end{tabular}

Figure 3.2.1. Azidolysis in water of 1,2 -epoxides by sodium azide at $30{ }^{\circ} \mathrm{C} .{ }^{4}$

Following the successful incorporation of the azide in the proper location for subsequent steps, the alcohol of $\mathbf{2}$ was converted into a leaving group by reacting $\mathbf{2} \mathbf{b}$ with methanesulfonyl chloride $(\mathrm{MsCl})$ in acetonitrile $(\mathrm{ACN})$. The reaction was successful as seen by the disappearance of the alcohol peak at $3.56 \mathrm{ppm}$ and the appearance of the $\mathrm{CH}_{3}$ singlet from the mesylate (Figure 3.2.2). A column separated byproducts and some residual starting material from the reaction. The NMR spectrum of the impurities were not taken but a significant amount of material showed in the form of two distinct TLC spots that were separated in dichloromethane:hexanes (90:10). A significant amount of material was lost in the column leading to a yield of only $58 \%$.

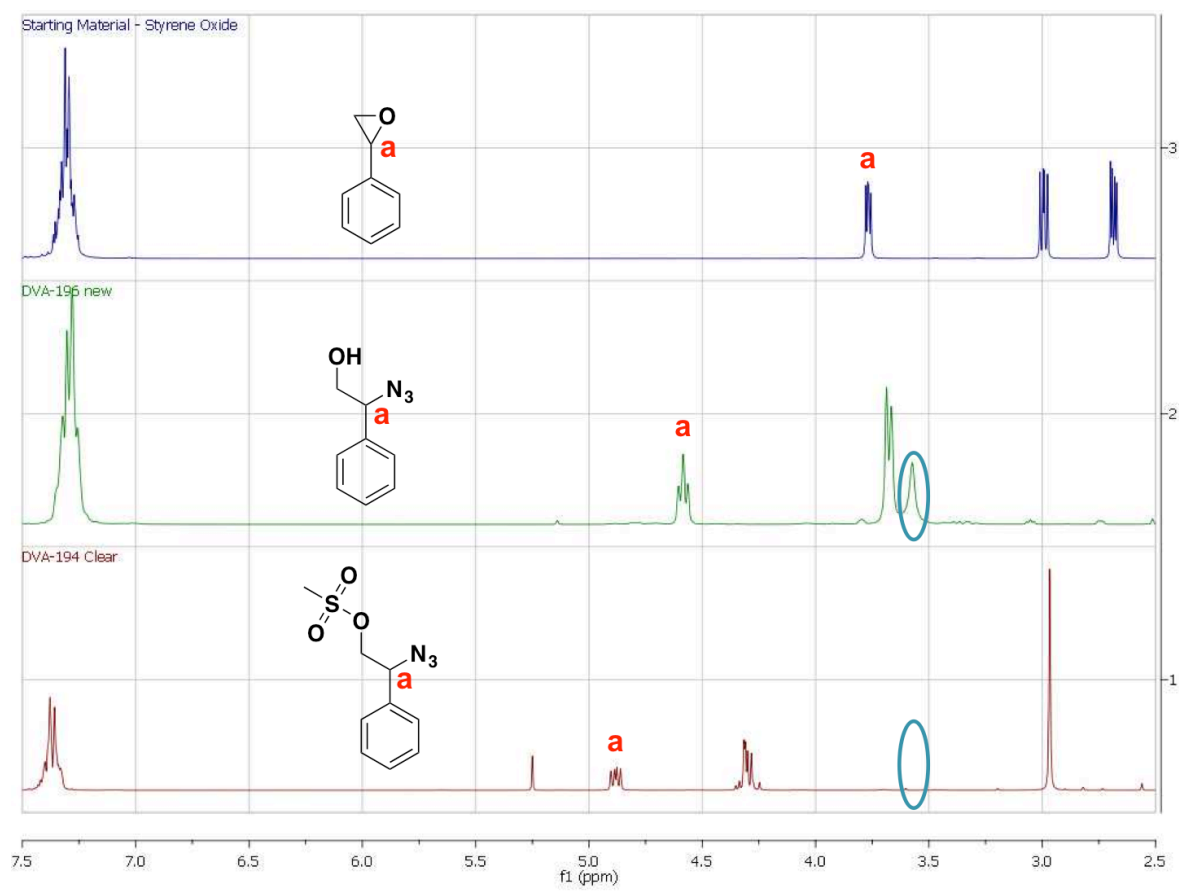

Figure 3.2.2. ${ }^{1} \mathrm{H}$ NMR spectra of the conversion of styrene azide (top) to the alcoholazide (middle) to the mesylated product. 
After a clean synthesis of compound $\mathbf{3}$ was achieved, potassium thioacetate was added to react with the mesylated alcohol. To do this, $\mathbf{2} \mathbf{b}$ was added to thioacetate in DMF. There was an instantaneous color change, however a TLC spot analysis after eight hours revealed four independent spots. The starting material and a variety of side products were found. It appeared that $80{ }^{\circ} \mathrm{C}$ was too high of a reaction temperature and led to a variety of products. It was clear that this synthesis would require a distillation, at least two columns and a substantial loss in yield and so an alternative route was investigated.

Grinstaff, et al. had already published an alternative synthetic method that used cysteine directly. This route was attempted since it would require fewer steps and the synthesis appeared to be high yielding. ${ }^{5}$ In their synthesis, L-cysteine $\mathrm{HCl}$ was reacted with acetone to yield a thiazolidine that protected the thiol as well as created a secondary amine. Then the secondary amine was protected with di-tert-butyl dicarbonate $\left(\mathrm{Boc}_{2} \mathrm{O}\right)$ (Scheme 3.2.2).

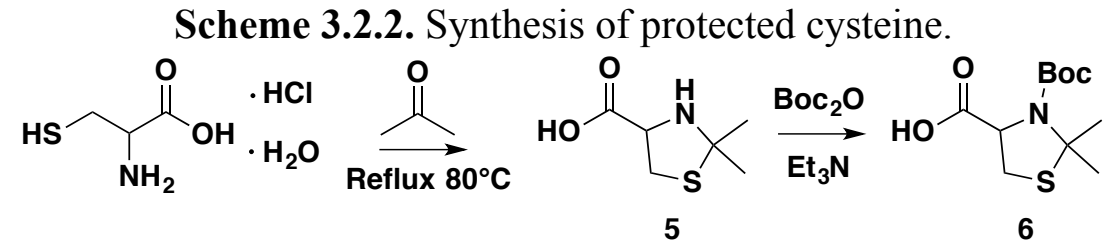

The synthesis of $\mathbf{5}$ was simple and efficient. L-cysteine $\mathrm{HCl}$ does not appear to be soluble in acetone, but when refluxed at $80^{\circ} \mathrm{C}$, the solution eventually becomes homogeneous and $\mathbf{5}$ precipitates out. It was found that residual L-cysteine $\mathrm{HCl}$ could be avoided by filling the reaction vessel to about three fourths full as it prevents the salt from plating out of the solvent. The synthesis of $\mathbf{6}$ proved to be exceedingly difficult. A variety of reaction conditions (6a-6e) were attempted. Two different non-nucleophilic 
bases triethylamine $\left(\mathrm{Et}_{3} \mathrm{~N}\right)$ and $\mathrm{N}, \mathrm{N}$-diisopropylethylamine (DIPEA) were used as well a variety of solvents (THF, $\mathrm{ACN}$, and $\mathrm{DMF}$ ) and temperatures (r.t., $40^{\circ} \mathrm{C}$ and $70{ }^{\circ} \mathrm{C}$ ). The Boc protecting group is very sensitive to acid so it is possible that when $\mathrm{HCl}$ was added it hydrolyzed the Boc group and reformed $\mathbf{5}$ which is readily soluble in water.

Alternative routes were attempted, the first being the reduction of the carboxylic acid in 5 to a primary alcohol 7 (scheme 3.2.3a). A primary issue when trying to reduce a salt is the homogeneity of the reaction mixture. It was apparent that the reducing agents were in solution while L-cysteine $\mathrm{HCl}$ cannot participate in the reaction which is likely why the reduction was unsuccessful. This was again realized as the reduction of Lcysteine with iodine and $\mathrm{NaBH}_{4}$ was unsuccessful in THF (8) as well as DMF (9).

Scheme 3.2.3. Reduction of carboxylic acid with protected and unprotected cysteine to create a primary alcohol.

a)

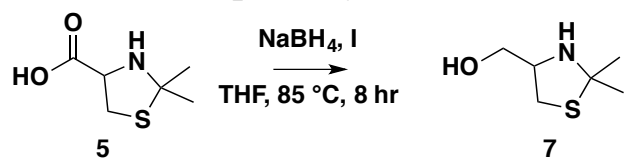

b)

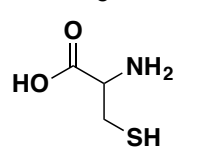

c)

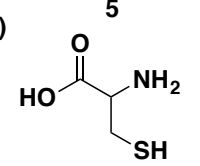

5

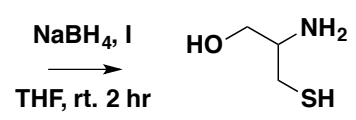

$8 a$

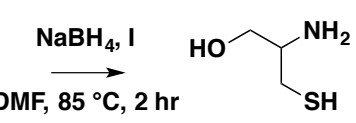

8b

From this lack of solubility it was desired to make the salt more hydrophobic so instead of reacting the L-cysteine $\mathrm{HCl}$ in acetone, acetophenone (9) and 2-heptanone (10) were used instead (Scheme 3.2.4). In both attempts in the synthesis of $\mathbf{9}$ and 10, it was assumed that simply placing the L-cysteine $\mathrm{HCl}$ salt in the reaction vessel and refluxing would lead to conversion to our desired product. This technique proved implausible, as the L-cysteine $\mathrm{HCl}$ was isolated from the reaction. Unfortunately it was later found that 
thiazolidine ring formation with acetophenone and a variety of hydrophobic moieties is possible, but requires the addition of a co-solvent mixture such as ethanol/water. ${ }^{6}$

Scheme 3.2.4. Synthesis of hydrophobic thiazolidine cysteine residues.

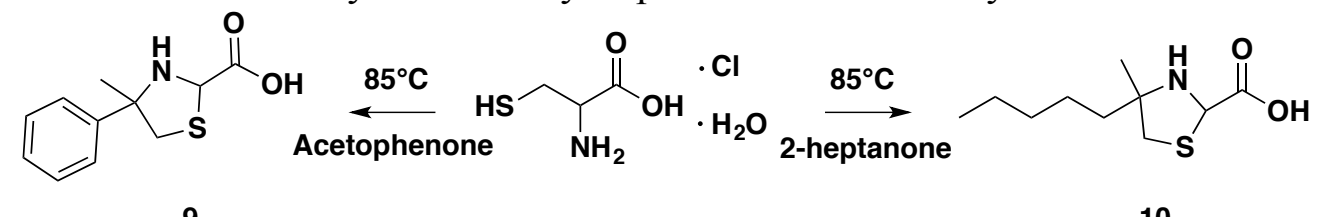

An inherent problem with the reactions with $\mathbf{5}$ was solubility. Due to the reaction with di-tert-butyl dicarbonate being unsuccessful, a new protecting group was necessary to improve the solubility of the protected cysteine in organic solvents. A paper published by Sheenan and Yang showed that it was possible to generate a mixed anhydride in situ that could formylate the amine. ${ }^{7}$ They described that sodium formate can react with acetic anhydride to create a mixed anhydride. This mixed anhydride formylates the amine leading to the synthesis of $\mathbf{1 1}$ (scheme 3.2.5).

Scheme 3.2.5. Formylation of protected cysteine.

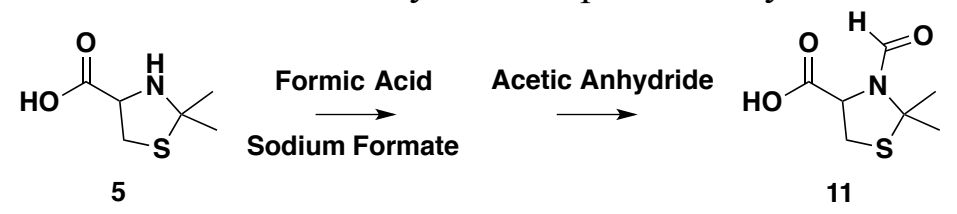

The synthesis of $\mathbf{1 1}$ was confirmed directly via ${ }^{1} \mathrm{H}$ NMR after it was recrystallized from methanol and water (Figure 3.2.3). The appearance of the aldehyde peak at $8.3 \mathrm{ppm}$ and the change in the splitting pattern of the $\mathrm{CH}$ and $\mathrm{CH}_{2}$ peaks observed provide strong evidence for attachment of the formyl group. 


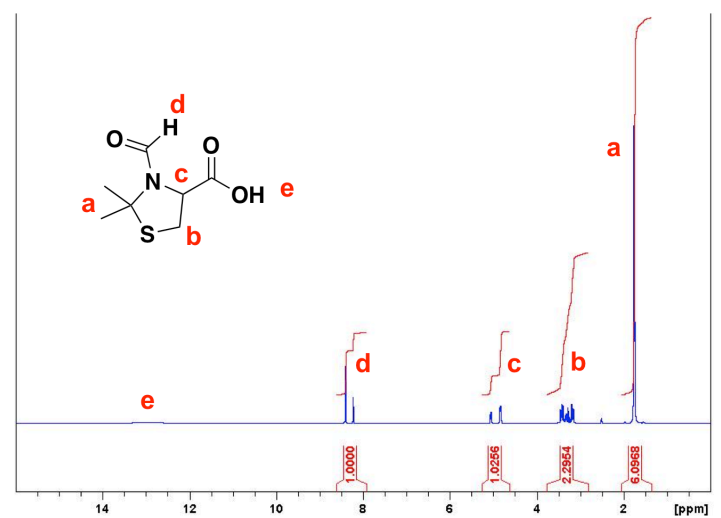

Figure 3.2.3. ${ }^{1} \mathrm{H}$ NMR of $\mathbf{1 1}$ in $d_{6} \mathrm{DMSO}$.

After the successful attachment of the formyl group a way to attach the fully protected cysteine to both a polymerizable monomer and a clickable molecule was attempted. The first esterification was the reaction between 11 and 4-vinylchlorobenzyl chloride (scheme 3.2.6). The additional esterification with propargyl chloride (13) was attempted as a facile way to attach the protected cysteine residue to a variety of molecules via an azide alkyne click reaction. As expected, when a base such as $\mathrm{Et}_{3} \mathrm{~N}$ or DIPEA was added to $\mathbf{1 1}$, it became soluble in a wide range of organic solvents. The synthesis of both $\mathbf{1 2}$ and $\mathbf{1 3}$ was successful, however it was found experimentally that the ester bond that was formed was acid labile and would unfortunately release the protected cysteine prior to the deprotection of the cysteine.

Scheme 3.2.6. Esterification of 11 with vinyl-chlorobenzyl chloride (a) and propargyl chloride (b).

a)

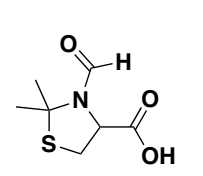

11
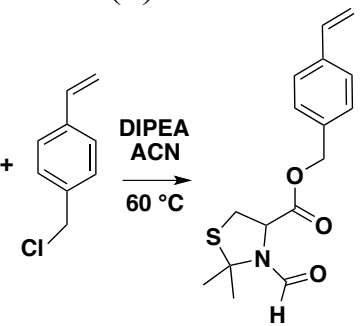

b)

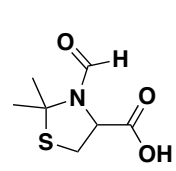

11
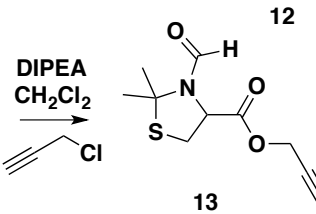
In order to ensure complete deprotection of the cysteine, an acidic solution is necessary. This was found to be an issue for the esters $\mathbf{1 2}$ and $\mathbf{1 3}$. To circumvent this issue an amide was chosen to replace the ester. A very common ligation strategy in peptide synthesis is the use of carbodiimide coupling. ${ }^{8}$ Dicyclohexylcarbodiimide (DCC) and 5-aminopentan-1-ol were reported although other carbodiimides and amines were attempted with similar results (scheme 3.2.7). A problem with the synthesis of 14 was that molecule became amphiphilic and was hard to isolate. Grinstaff et al. found that the boc protected cysteine residue (6) was hard to obtain good yields with various carbodiimides, so it is not surprising that there were issues with DCC. ${ }^{5}$

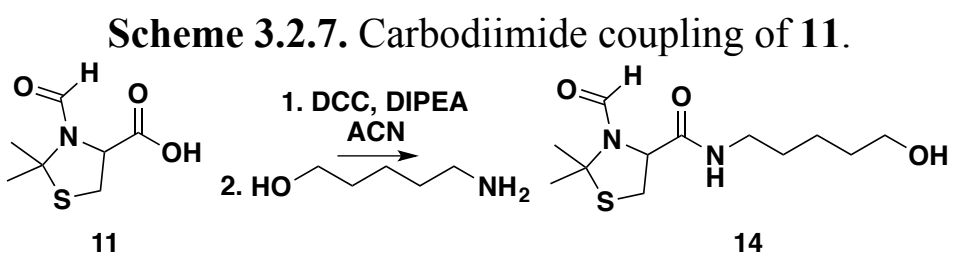

To avoid carbodiimides an alternative ligation strategy was necessary, so a modified synthesis from Sheenan and Yang was developed. The reaction was performed in a three-step process, the first being to add a non-nucleophilic base such as $\mathrm{Et}_{3} \mathrm{~N}$. Once an equivalent of base was added, $\mathbf{1 1}$ became soluble and then was subsequently cooled to $0{ }^{\circ} \mathrm{C}$. Methyl chloroformate was then added to create a mixed anhydride. The chloride from the chloroformate forms a salt once it has reacted with the carboxylic acid, which forces it again out of solution. Next a primary amine was added to form the amide (allowed to react 3-12 hours). Controlling the solubility of the intermediates of the reaction allowed for high yields $(>65 \%)$.

The first amines to be subjected to this process were benzylamine and furfuryl amine (scheme 3.2.8). In the synthesis of both amides 15 and 16, the purification was 
simple and reaction time did not seem to have an affect on the yield (benzylamine-24 hrs, $56 \%$ yield; furfuryl amine- $2.5 \mathrm{hrs}, 66 \%$ yield). ${ }^{1} \mathrm{H}$ NMR revealed a shift in the benzylic $\mathrm{CH}_{2}$ hydrogens, which indicates attachment. The benyl peaks overlap the amide peak, which is why furfuryl amine was chosen. Furfuryl amine showed a very clean amide at $7.22 \mathrm{ppm}$ along with a clean shift of the $\mathrm{CH}_{2}$ adjacent to the furan.

Scheme 3.2.8. Synthesis of an amide containing protected cysteines.

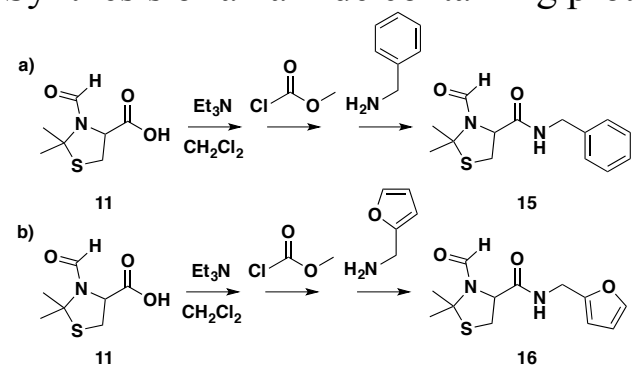

Once the procedure had been worked out, a polymerizable amine containing monomer was necessary to ligate to $\mathbf{1 1}$. In order to achieve this, 4-vinylbenzyl chloride was reacted with sodium azide and then treated with lithium aluminum hydride to convert the azide to an amine (scheme 3.2.9). The previously used synthesis of 4-vinylbenzyl azide was in a mixture of water and DMF which led to slight formation of 4-vinylbenzyl alcohol (17a). The presence of the alcohol is unwanted, as it would later create an ester as opposed to an amide with 11. A straight DMF reaction was attempted with a 1:1 stoichiometric ratio of azide to chloride which was successful but not high yielding (17b). An optimum reaction condition (17c) was found with an excess amount of sodium azide (1:6 ratio chloride:azide) that afforded a better yield and was highly reproducible.

Scheme 3.2.9. Synthesis of 4-vinylbenzyl amine.

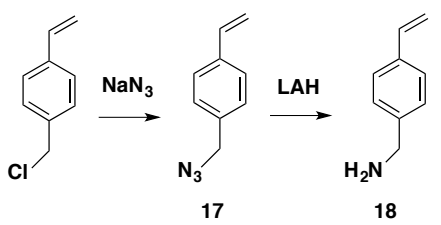


After the synthesis of the azide was worked out the reduction to the amine was attempted in two ways. The first was to use sodium borohydride with cobalt chloride in water as had been previously reported in literature, but this reaction (18a) did not yield an amine product. ${ }^{9}$ The use of LAH was successful in affording pure amine product (18b). The conversion of azide to the amine was confirmed by the appearance of the amine as well as a shift in the $\mathrm{CH}_{2}$ adjacent to the amine.

The vinylbenzyl amine (18b) was then ligated to the protected cysteine (11) using the mixed anhydride method with methyl chloroformate (scheme 3.2.10). The ligation was successful (56\% yield) and the product (19) was confirmed by the shift of the $\mathrm{CH}_{2}$ next to the newly formed amide as well as the presence of the amide bond at $7.2 \mathrm{ppm}$.

Scheme 3.2.10. Ligation of a polymerizable monomer with the protected cysteine.

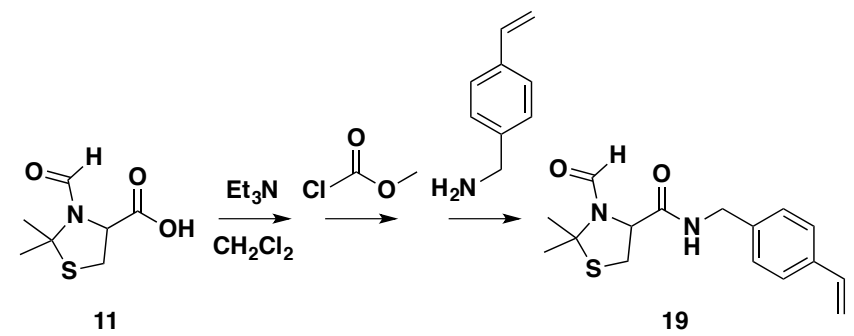

A copolymerization of $\mathbf{1 9}$ with styrene was then performed to incorporate the protected cysteine into a polymer (scheme 3.2.11). In the first attempt (20a) AIBN was used as the radical source, however it was found that the conversion of monomer to polymer was low (25\%) and the polymerization was ended too early. ${ }^{1} \mathrm{H}$ NMR showed slight incorporation of the thiazolidine with a subtle broadening of the aldehyde peak. In the second polymerization attempt (20b) BPO was used at $80{ }^{\circ} \mathrm{C}$ yielding a much higher conversion (56\%) within the same amount of time. ${ }^{1} \mathrm{H}$ NMR of the polymer showed a strong broadening of the peaks pertaining to the protected cysteine, indicating successful incorporation of the protected cysteine into the polymer. However, the calculated 
percentage of the potential cysteine groups incorporated into the backbone of the polymer relative to styrene was less than ten percent. The low percent incorporation presented an issue later with infrared spectroscopy being able to detect the deprotection of the cysteine.

Scheme 3.2.11. Copolymerization of the 19 with styrene.

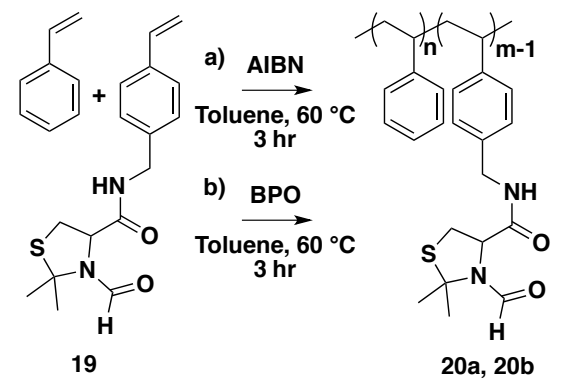

Subsequent attempts to create $\mathbf{1 8}$ utilizing LAH proved to be more difficult to separate the lithium salts from the product so a more repeatable synthesis was attempted. So instead of reducing the azide and ligating it to the protected cysteine (11), it was proposed to ligate propargyl amine to the protected cysteine and then click the azide (17) to the alkyne (21) (scheme 3.2.12). The synthesis of 21 was just as facile as the others with a similar yield (55\%). The click reaction between 21 and $\mathbf{1 7}$ in the presence of sodium ascorbate and copper (II) sulfate had a relatively low yield (33\%) however the ease in purification (precipitates upon addition of water) made the work up exceptionally easily. The ${ }^{1} \mathrm{H}$ NMR of 22 confirmed the click reaction with presence of the triazole hydrogen at $7.93 \mathrm{ppm}$, the change of the $\mathrm{CH}_{2}$ benzylic hydrogens, and the new splitting of the $\mathrm{CH}_{2}$ adjacent to the amide. 
Scheme 3.2.12. Click ligation strategy.

a)

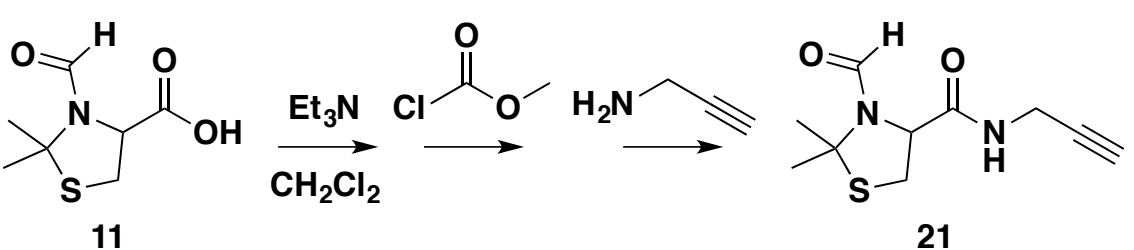

b)<smiles>C#CCNC(=O)C1CSC(C)(C)N1C=O</smiles>

21<smiles>C=Cc1ccc(CN)cc1</smiles>

17
1. $t-B u O H: \mathrm{H}_{2} \mathrm{O}(1: 1)$

2. Sodium Ascorbate 3. $\mathrm{CuSO}_{4} \cdot\left(\mathrm{H}_{2} \mathrm{O}\right)_{5}$<smiles>C=Cc1ccc(Cn2cc(CNC(=O)C3CSC(C)(C)N3C=O)nn2)cc1</smiles>

22

A kinetic study on the hydrolysis of the thiazolidine ring of 22 was performed using $5 \% \mathrm{HCl}$ acid in $d_{6} \mathrm{DMSO}$ (see Figure 3.2.4). Within one week the appearance of acetone at $2.05 \mathrm{ppm}$ and the disappearance of the thiazolidine di-methyls at $1.65 \mathrm{ppm}$ indicate that the thiazolidine ring is reversible and can be hydrolyzed.

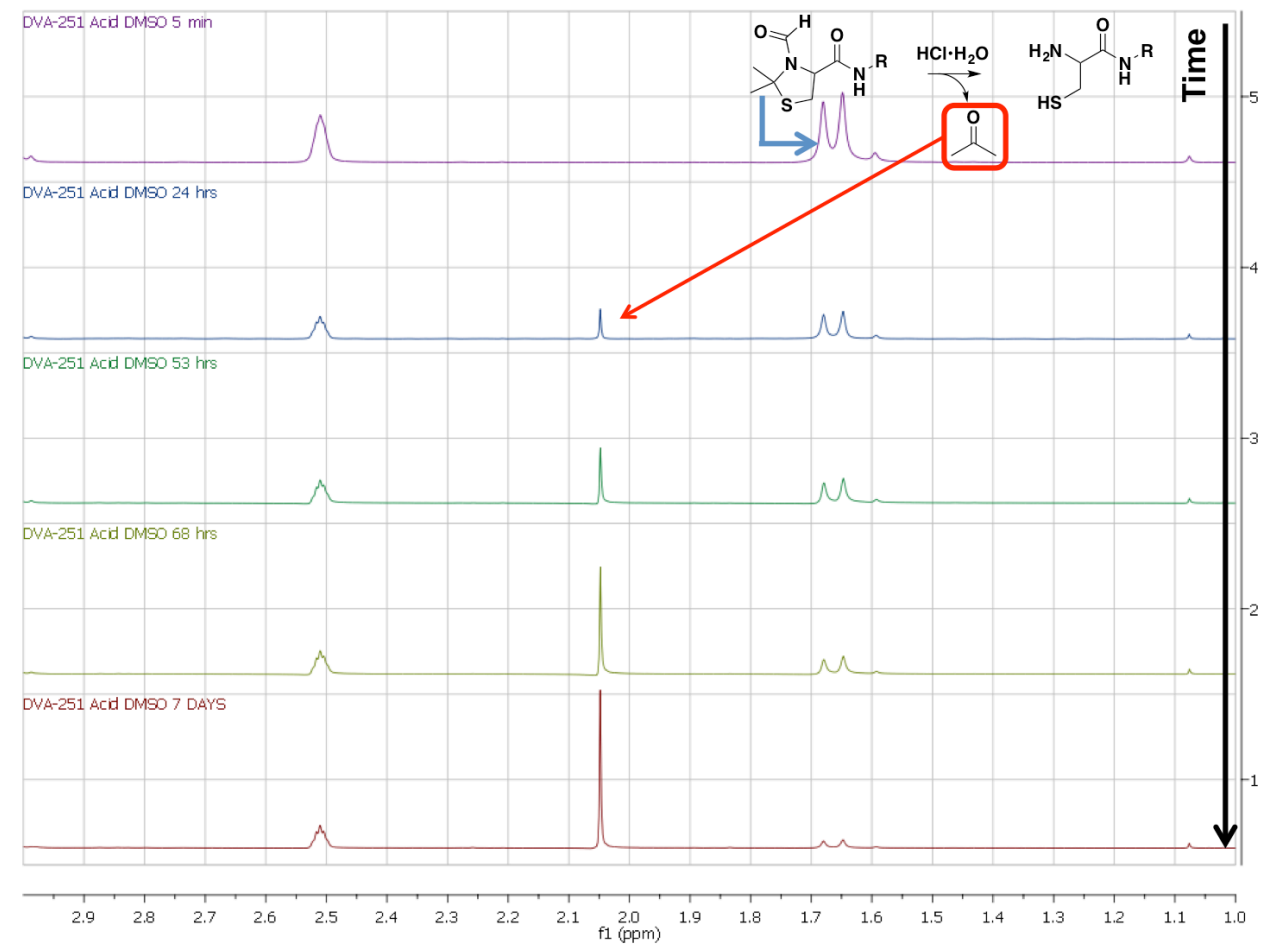

Figure 3.2.4. Kinetics of the reversibility of thiazolidine linkages in acid $d_{6}$ DMSO. 


\subsection{Experimental}

Synthesis of styrene oxide (1a)

Styrene $(3 \mathrm{~mL})$, THF $(15 \mathrm{~mL})$ and stir bar was added to $25 \mathrm{~mL}$ round bottom flask. The mixture cooled to $0-5{ }^{\circ} \mathrm{C}$. Solution of meta-chloroperoxybenzoic acid $(0.05 \mathrm{~g}$, $0.29 \mathrm{mmol})$ and THF $(10 \mathrm{~mL})$ was added dropwise to the mixture. The reaction stirred for 48 hours. ${ }^{1} \mathrm{H}$ NMR showed the residual of starting material.

\section{Synthesis of styrene oxide $\mathbf{( 1 \mathbf { b } )}$}

Styrene $(1 \mathrm{~mL})$, dichloromethane $(10 \mathrm{~mL})$ and stir bar was added to $25 \mathrm{~mL}$ round bottom flask, and the mixture cooled to $0-5{ }^{\circ} \mathrm{C}$. Meta-chloroperoxybenzoic acid $(0.05 \mathrm{~g}$, $0.29 \mathrm{mmol})$ and dichloromethane $(10 \mathrm{~mL})$ was added to the mixture. The reaction stirred for 48 hours. ${ }^{1} \mathrm{H}$ NMR showed the residual styrene peaks.

Synthesis of 2-azido-2-phenylethan-1-ol (2a)

Styrene oxide (3.81 g, $31.7 \mathrm{mmol}$ ), sodium azide (2.66 g, $40.9 \mathrm{mmol})$, DMF (30 $\mathrm{mL}$ ) and stir bar was added to $50 \mathrm{~mL}$ round bottom flask. The mixture heated at $60{ }^{\circ} \mathrm{C}$ for 24 hours. Dichloromethane was added to the mixture. Then the mixture washed with brine (x3), dried with anhydrous magnesium sulfate and filtered. Excess solvent was removed via rotary evaporation and further solvent removed under reduced pressure. ${ }^{1} \mathrm{H}$ NMR of crude mixture revealed starting material as well as addition products. 
Synthesis of 2-azido-2-phenylethan-1-ol (2b)

Styrene oxide (5 g, $41.6 \mathrm{mmol})$, sodium azide ( $6.0 \mathrm{~g}, 92.3 \mathrm{mmol})$, DI water (30 $\mathrm{mL}$ ) and stir bar was added to $50 \mathrm{~mL}$ round bottom flask. Sodium hydroxide solution $(1 \mathrm{M}, 30 \mathrm{~mL})$ was added to mixture. The mixture was stirred for 24 hours at room temperature. Dichloromethane was added to the mixture. Then the mixture washed with brine (x3), dried with anhydrous magnesium sulfate and filtered. Excess solvent was removed via rotary evaporation and further solvent removed under reduced pressure. Yield $(6.1 \mathrm{~g}, 89 \%)$ as a white liquid. ${ }^{1} \mathrm{H} \mathrm{NMR}\left(\mathrm{CDCl}_{3}\right) \delta(\mathrm{ppm})$ 3.57-3.69 $\left(2 \mathrm{~s}, \mathrm{CH}_{2}\right)$, $4.58(\mathrm{t}, \mathrm{CH}), 7.26-7.32(\mathrm{~m}, \mathrm{CH})$.

Synthesis of 2-azido-2-phenylethan-1-ol (2c)

Sodium azide (11.45 g, $176.2 \mathrm{mmol})$, DI water $(20 \mathrm{~mL})$, sodium hydroxide $(1 \mathrm{M}, 3.7 \mathrm{~mL})$ and stir bar was added to $100 \mathrm{~mL}$ round bottom flask. Styrene oxide (7.45 g, $62 \mathrm{mmol}$ ) was added to the mixture. The reaction then stirred at $50{ }^{\circ} \mathrm{C}$ for 24 hours. Dichloromethane $(30 \mathrm{~mL})$ was added to the mixture. The organic layer was obtained, dried, and filtered. Excess solvent was removed via rotary evaporation. Further solvent was removed under reduced pressure. Yield ( $8.2 \mathrm{~g}, 84 \%)$ as clear liquid. ${ }^{1} \mathrm{H}$ $\operatorname{NMR}\left(\mathrm{CDCl}_{3}\right) \delta(\mathrm{ppm}) 3.57-3.69\left(2 \mathrm{~s}, \mathrm{CH}_{2}\right), 4.58(\mathrm{t}, \mathrm{CH}), 7.26-7.32(\mathrm{~m}, \mathrm{CH})$.

Synthesis of 2-azido-2-phenylethyl methanesulfonate (3)

To a $50 \mathrm{~mL}$ round bottom flask, $\mathbf{2 b}(3.25 \mathrm{~g}, 20 \mathrm{mmol})$, diisopropylethylamine (3.1 g, $24 \mathrm{mmol})$, dry acrylonitrile (14 $\mathrm{mL})$ and a stir bar were added. Methanesulfonyl chloride (2.62 g, $22.9 \mathrm{mmol}$ ) was added dropwise to the mixture over 30 minutes period. 
The mixture then heated at $50{ }^{\circ} \mathrm{C}$ for 24 hours. A column was loaded with a silica slurry in dichloromethane:hexanes (90:10), glass wool and sand. The reaction mixture was separated with a 90:10 ratio, a clear liquid was isolated. Excess solvent was removed via rotary evaporation and residual solvent was removed under reduced pressure yielding a viscous clear liquid (2.8 g, $58 \%) .{ }^{1} \mathrm{H}$ NMR $\left(\mathrm{CDCl}_{3}\right) \delta(\mathrm{ppm}) 2.95\left(\mathrm{~s}, \mathrm{CH}_{3}\right), 4.21-4.28$ (m, $\left.\mathrm{CH}_{2}\right), 4.85(\mathrm{~m}, \mathrm{CH}), 7.31-7.36(\mathrm{~m}, \mathrm{CH})$.

Synthesis of 2-azido-2-phenylethyl ethanethioate (4)

Potassium thioacetate (300mg, $2.6 \mathrm{mmol}, 3$ (330 mg, $1.01 \mathrm{mmol})$, and stir bar was added to $25 \mathrm{~mL}$ round bottom flask. DMF ( $3 \mathrm{~mL})$ was added to the mixture and allowed to stir at $80^{\circ} \mathrm{C}$ for 24 hours. Thin layer chromatography (TLC) revealed multiple products were formed.

Synthesis of L-4-Carboxy-2,2-dimethylthiazolidine hydrochloride (5)

A suspension of L-cysteine hydrochloride monohydrate $(7.0 \mathrm{~g}, 40 \mathrm{mmol})$ in acetone $(200 \mathrm{~mL})$ in a $250 \mathrm{~mL}$ flask was heated under reflux for 24 hours. The white powder formed was collected by vacuum filtration. Yield $(6.5 \mathrm{~g}, 82 \%)$ was obtained as white powder. ${ }^{1} \mathrm{H}$ NMR (DMSO) $\delta(\mathrm{ppm}) 1.7\left(\mathrm{~s}, \mathrm{CH}_{3}\right), 3.5\left(2 \mathrm{~s}, \mathrm{CH}_{2}\right), 4.9(\mathrm{~s}, \mathrm{NH}), 11.3$ (br, $\mathrm{COOH}) .{ }^{13} \mathrm{C}$ NMR (DMSO) $\delta(\mathrm{ppm}) 27.1-28.6\left(2 \mathrm{~S}, \mathrm{CH}_{3}\right), 31.3\left(\mathrm{CH}_{2}\right), 60.8(\mathrm{CH})$, $71.7(\mathrm{C})$, and $168.1(\mathrm{COOH})$. 
Synthesis of 3-(tert-butoxycarbonyl)-2,2-dimethylthiazolidine-4-carboxylic acid (6a)

To a suspension of 5 (2 g, $10.5 \mathrm{mmol})$ and $\mathrm{Boc}_{2} \mathrm{O}(3.62 \mathrm{~g}, 16.6 \mathrm{mmol})$ in a $50 \mathrm{~mL}$ round bottom flask, dry $\mathrm{ACN}(10 \mathrm{~mL})$ was added. The suspension was stirred at $70^{\circ} \mathrm{C}$ for 24 hours. The ACN was removed under reduced pressure, and the remaining oil was dissolved in ether and concentrated in vacuo to an oily solid. The oily solid was then dissolved in ether, and the amine salt was removed from the ether solution by filtration through celite. The filtrate was washed with $0.1 \mathrm{M} \mathrm{HCl}(15 \mathrm{~mL}, \mathrm{x} 2)$, water $(15 \mathrm{~mL}, \mathrm{x} 2)$, and brine $(15 \mathrm{~mL}, \mathrm{x} 1)$, dried, and concentrated to a clear oil that was dissolved in hexanes and concentrated in vacuo to a liquid. ${ }^{1} \mathrm{H}$ NMR determined the liquid to be $\mathrm{Boc}_{2} \mathrm{O}$.

Synthesis of 3-(tert-butoxycarbonyl)-2,2-dimethylthiazolidine-4-carboxylic acid (6b)

DIPEA (6.6 mL, $37.8 \mathrm{mmol})$ was added to a suspension of 5 (6.8 g, $34.7 \mathrm{mmol})$ and $\mathrm{Boc}_{2} \mathrm{O}(10 \mathrm{~g}, 46 \mathrm{mmol})$ in dry $\mathrm{ACN}(75 \mathrm{~mL})$. The suspension was stirred for 2 days. The ACN was placed on a rotary evaporator, and the remaining oil was dissolved in ether and concentrated in vacuo to an oily solid. The oily solid was then dissolved in ether, and the amine salt was removed from the ether solution by filtration through celite. The filtrate was washed with $0.1 \mathrm{M} \mathrm{HCl}(15 \mathrm{~mL}, \mathrm{x} 1)$, water $(15 \mathrm{~mL}, \mathrm{x} 2)$, and brine $(15 \mathrm{~mL}$, $\mathrm{x} 1)$, dried, and concentrated to a clear oil that was dissolved in hexanes and concentrated in vacuo to a liquid. ${ }^{1} \mathrm{H}$ NMR determined the liquid to be $\mathrm{Boc}_{2} \mathrm{O}$.

Synthesis of 3-(tert-butoxycarbonyl)-2,2-dimethylthiazolidine-4-carboxylic acid (6c) A stir bar, 5 (0.55 g, $2.8 \mathrm{mmol})$, and di-tert-butyl dicarbonate $\left(\mathrm{Boc}_{2} \mathrm{O}\right)(0.93 \mathrm{~g}$, $4.26 \mathrm{mmol})$ was added to $25 \mathrm{~mL}$ round bottom flask. THF (10 $\mathrm{mL})$ and triethyl amine 
( $0.45 \mathrm{~g}, 4.4 \mathrm{mmol})$ was added to the mixture. The reaction was stirred at room temperature overnight. The mixture was washed with $0.1 \mathrm{~N} \mathrm{HCl}(15 \mathrm{~mL}, \mathrm{x} 1)$, water $(15 \mathrm{~mL}, \mathrm{x} 2)$, and brine $(15 \mathrm{~mL}, \mathrm{x} 1)$, dried, and concentrated to a clear oil that was dissolved in hexane. Excess solvent was removed via rotary evaporation and solvent was further removed under reduced pressure yielding a viscous liquid. ${ }^{1} \mathrm{H}$ NMR determined the liquid to be $\mathrm{Boc}_{2} \mathrm{O}$.

Synthesis of 3-(tert-butoxycarbonyl)-2,2-dimethylthiazolidine-4-carboxylic acid (6d)

To a suspension of 5 (3.4 g, $17.5 \mathrm{mmol})$ and $\mathrm{Boc}_{2} \mathrm{O}(5 \mathrm{~g}, 23 \mathrm{mmol})$ in DMF $(20 \mathrm{~mL})$ was added DIPEA $(3.5 \mathrm{~mL}, 19 \mathrm{mmol})$. The suspension was stirred at $40^{\circ} \mathrm{C}$ for 24 hours. The DMF was removed under reduced pressure, and the remaining oil was dissolved in ether and concentrated in vacuo to an oily solid. The oily solid was then dissolved in ether, and the amine salt was removed from the ether solution by filtration through celite. The filtrate was washed with $0.1 \mathrm{~N} \mathrm{HCl}(15 \mathrm{~mL}, \mathrm{x} 1)$, water $(15 \mathrm{~mL}, \mathrm{x} 2)$, and brine $(15 \mathrm{~mL}, \mathrm{x} 1)$, dried, and concentrated to a clear oil that was dissolved in hexanes and concentrated in vacuo to a liquid. ${ }^{1} \mathrm{H}$ NMR determined the liquid to be $\mathrm{Boc}_{2} \mathrm{O}$.

Synthesis of 3-(tert-butoxycarbonyl)-2,2-dimethylthiazolidine-4-carboxylic acid (6e)

To a suspension of $5(3.4 \mathrm{~g}, 17.5 \mathrm{mmol})$ and $\mathrm{Boc}_{2} \mathrm{O}(5 \mathrm{~g}, 23 \mathrm{mmol})$ in DMF (20 mL), DIPEA $(3.5 \mathrm{~mL}, 19 \mathrm{mmol})$ was added. The suspension was stirred at $70^{\circ} \mathrm{C}$ for 24 hours. The DMF was removed under reduced pressure, and the remaining oil was dissolved in ether and concentrated in vacuo to an oily solid. The oily solid was then dissolved in ether, and the amine salt was removed from the ether solution by filtration 
through Celite. The filtrate was washed with $0.1 \mathrm{~N} \mathrm{HCl}(15 \mathrm{~mL}, \mathrm{x} 1)$, water $(15 \mathrm{~mL}, \mathrm{x} 2)$, and brine $(15 \mathrm{~mL}, \mathrm{x} 1)$, dried, filtered, and excess solvent was removed via rotary evaporation. The clear oil obtained was dissolved in hexanes and concentrated in vacuo to a liquid. ${ }^{1} \mathrm{H}$ NMR determined the liquid to be $\mathrm{Boc}_{2} \mathrm{O}$.

Synthesis of (2,2-dimethylthiazolidin-4-yl)methanol (7)

Sodium borohydride (0.238 g, $6.3 \mathrm{mmol}), 5$ (0.52 g, $2.65 \mathrm{mmol})$, THF (25 mL) and stir bar was added to $50 \mathrm{~mL}$ round bottom flask. Iodine $(0.347 \mathrm{~g}, 1.4 \mathrm{mmol})$ was added to the mixture and the mixture turned red. The reaction was refluxed at $85{ }^{\circ} \mathrm{C}$ overnight. Methanol was then added to the mixture to quench borohydride. Excess solvent was removed via rotary evaporation and solvent was further removed under reduced pressure. ${ }^{1} \mathrm{H}$ NMR was inconclusive.

Synthesis of 2-amino-3-mercaptopropan-1-ol (8a)

L-cysteine (0.5 g, $4.2 \mathrm{mmol})$, sodium borohydride (0.501 g, $13.2 \mathrm{mmol})$, THF $(20 \mathrm{~mL})$ and stir bar was added to $50 \mathrm{~mL}$ round bottom flask. Iodine $(0.48 \mathrm{~g}, 1.9 \mathrm{mmol})$ was added to the mixture and the mixture turned purple. The reaction was allowed to go at room temperature for two hours. Methanol was then added to the mixture to quench borohydride. Excess solvent was removed via rotary evaporation and solvent was further removed under reduced pressure. ${ }^{1} \mathrm{H}$ NMR was inconclusive. 
Synthesis of 2-amino-3-mercaptopropan-1-ol (8b)

L-cysteine ( $0.5 \mathrm{~g}, 4.2 \mathrm{mmol})$, sodium borohydride ( $0.251 \mathrm{~g}, 6.61 \mathrm{mmol})$, THF $(15 \mathrm{~mL})$ and stir bar was added to $50 \mathrm{~mL}$ round bottom flask. Iodine (0.28 g, $1.1 \mathrm{mmol})$ was added to the mixture and the mixture turned purple. The reaction was kept at $85{ }^{\circ} \mathrm{C}$ overnight. Methanol was then added to the mixture to quench borohydride. Excess solvent was removed via rotary evaporation and solvent was further removed under reduced pressure. ${ }^{1} \mathrm{H}$ NMR was inconclusive.

Synthesis of 4-methyl-4-phenylthiazolidine-2-carboxylic acid (9)

A suspension of L-cysteine hydrochloride monohydrate $(0.5 \mathrm{~g}, 2.9 \mathrm{mmol})$ in acetophenone $(10 \mathrm{~mL})$ was heated at $85^{\circ} \mathrm{C}$ for 24 hours. The solid obtained from the mixture via vacuum filtration was confirmed to be L-cysteine hydrochloride monohydrate by ${ }^{1} \mathrm{H}$ NMR.

Synthesis of 4-methyl-4-pentylthiazolidine-2-carboxylic acid (10)

A suspension of L-cysteine hydrochloride monohydrate $(0.5 \mathrm{~g}, 2.9 \mathrm{mmol})$ in 2heptanone $(15 \mathrm{~mL})$ was heated at $85^{\circ} \mathrm{C}$ for 24 hours. ${ }^{1} \mathrm{H}$ NMR confirmed that the solid obtained to be L-cysteine hydrochloride monohydrate.

\section{L-4-Carboxy-3-formyl-2,2-dimethylthiazolidine (11)}

Acetic anhydride (14 ml.) was added dropwise over a period of one hour to a stirring solution of formic acid ( $42 \mathrm{~mL}, 98 \%), 5(5 \mathrm{~g}, 25.3 \mathrm{mmol})$ and sodium formate $(2 \mathrm{~g}, 20 \mathrm{mmol})$ at a temperature between $0-5^{\circ} \mathrm{C}$. The mixture was then stirred at room 
temperature for six hours. Ice water $(56 \mathrm{~mL})$ was added to the mixture to obtained white crystalline precipitate. The resulting powder then collected via vacuum filtration and recrystallized with methanol:water (3:1). Yield (4.3, 90\%) was obtained as a white crystal. ${ }^{1} \mathrm{H}$ NMR (DMSO) $\delta(\mathrm{ppm}) 1.7\left(\mathrm{~s}, \mathrm{CH}_{3}\right), 3.1-3.4\left(\mathrm{~m}, \mathrm{CH}_{2}\right.$ ), 4.8-5 (2s, NH), 8.2-8.4 (2s, H-C-O), 11.3 (br, COOH). ${ }^{13} \mathrm{C}$ NMR (DMSO) $\delta$ (ppm) 27.1- 29.1 (2 S, $\mathrm{CH}_{3}$ ), 30.4$31.3\left(\mathrm{CH}_{2}\right), 61.8-64.9(\mathrm{CH}), 69.6-70.1(\mathrm{C}), 159-160(\mathrm{COOH})$, and 170.6-172 (H-C-O).

Synthesis of 4-vinylbenzyl 3-formyl-2,2-dimethylthiazolidine-4-carboxylate (12)

DIPEA (1.75 g, $13.6 \mathrm{mmol}), 11$ (2 g, $10.6 \mathrm{mmol})$, dry ACN (11 mL) and a stir bar was added to $125 \mathrm{~mL}$ round bottom flask and sonicated for 5 minutes. The mixture was stirred for 10 minutes prior to the addition of 4-vinyl benzyl chloride (1.9 g, $12.2 \mathrm{mmol}$ ). The reaction was stirred at $60{ }^{\circ} \mathrm{C}$ for 24 hours. The mixture then cooled and placed on a rotary evaporator. Then, dichloromethane was added to the mixture and a solid precipitated. The solid was collected via vacuum filtration and rinsed with DI water. Yield $(1.21 \mathrm{~g}, 37.3 \%)$ as a white solid. ${ }^{1} \mathrm{H}$ NMR $\left(\mathrm{CDCl}_{3}\right) \delta(\mathrm{ppm}) 1.8\left(2 \mathrm{~s}, \mathrm{CH}_{3}\right), 3.3-3.5$ (m, $\left.\mathrm{CH}_{2}\right), 3.8\left(\mathrm{~s}, \mathrm{CH}_{2}\right), 5.1(\mathrm{~m}, \mathrm{CH})$, 5.4-5.8 (d of d, $\left.\mathrm{CH}\right), 6.7(\mathrm{~d}$ of d, $\mathrm{CH}), 7.3-7.5$ (d of d, $\mathrm{CH}), 8.35$ (s, $\mathrm{H}-\mathrm{C}=\mathrm{O})$.

Synthesis of prop-2-yn-1-yl 3-formyl-2,2-dimethylthiazolidine-4-carboxylate (13)

A stir bar, 11 (1.02 g, $5.4 \mathrm{mmol})$, DIPEA (0.94 g, $7.3 \mathrm{mmol})$ and dichloromethane $(10 \mathrm{~mL})$ was added into $25 \mathrm{~mL}$ round bottom flask. The mixture then sonicated for 10 minutes until the solid dissolved. The mixture then cooled to $0-5{ }^{\circ} \mathrm{C}$ in an ice bath. Then propargyl chloride ( $3 \mathrm{ml}, 41.5 \mathrm{mmol})$ was added dropwise to the mixture, turning the 
mixture into brown. The reaction was stirred at room temperature overnight. The mixture diluted with dichloromethane $(30 \mathrm{~mL})$ and then washed with $5 \% \mathrm{HCl}(15 \mathrm{~mL})$, water $(15$ $\mathrm{mL})$, saturated sodium bicarbonate $(15 \mathrm{~mL})$ and brine $(15 \mathrm{~mL})$. The excess solvent in the organic layer obtained, was removed via rotary evaporation, and further solvent was removed under reduced pressure yielding a white solid $(0.5 \mathrm{~g}, 41 \%) .{ }^{1} \mathrm{H} \mathrm{NMR}\left(\mathrm{CDCl}_{3}\right) \delta$ (ppm) $1.7\left(\mathrm{~s}, \mathrm{CH}_{3}\right), 3.31(\mathrm{~s}, \mathrm{CH}), 3.5\left(2 \mathrm{~s}, \mathrm{CH}_{2}\right), 4.82\left(\mathrm{~s}, \mathrm{CH}_{2}\right), 4.9(\mathrm{~s}, \mathrm{NH}), 11.3$ (br, $\mathrm{COOH})$

Synthesis of 3-formyl-N-(5-hydroxypentyl)-2,2-dimethylthiazolidine-4-carboxamide

A stir bar, 11 (0.5 g, $2.64 \mathrm{mmol})$, DIPEA (0.4 g, $3.1 \mathrm{mmol})$ and dry ACN (6 mL) was added to $25 \mathrm{~mL}$ round bottom flask. The mixture was stirred for 10 minutes prior to the addition of N,N-dicyclohexylcarbodiimide (DCC) (0.608 g, $2.9 \mathrm{mmol})$. The solution 5-amino propanol $(0.273 \mathrm{~g}, 2.65 \mathrm{mmol})$ in $\mathrm{ACN}(2 \mathrm{~mL})$ was then added to the cloudy mixture and allowed to go overnight. The product became water soluble as there was no trace of it apparent in the organic layer.

Synthesis of N-benzyl-3-formyl-2,2-dimethylthiazolidine-4-carboxamide (15)

Triethylamine (0.124 g, $1.22 \mathrm{mmol}), 11$ (0.2 g, $1.06 \mathrm{mmol})$, dichloromethane $(10 \mathrm{~mL})$ and a stir bar was added to $200 \mathrm{~mL}$ round bottom flask and cooled to $0-5{ }^{\circ} \mathrm{C}$. The solution of methyl chloroformate $(0.1 \mathrm{~g}, 1.04 \mathrm{mmol})$ in dichloromethane $(2 \mathrm{~mL})$ was added to the mixture. Salt was formed so additional dichloromethane $(20 \mathrm{~mL})$ was added. The solution of benzyl amine $(0.118 \mathrm{~g}, 1.1 \mathrm{mmol})$ in dichloromethane $(6 \mathrm{~mL})$ was added to $25 \mathrm{~mL}$ vial and placed in the freezer for 10 minutes prior to the addition to the mixture. 
The reaction was stirred at room temperature for 2.5 hours. Next, dichloromethane $(20 \mathrm{~mL})$ was added to the mixture. The mixture then washed with $5 \% \mathrm{HCl}(20 \mathrm{~mL})$, saturated sodium bicarbonate $(10 \mathrm{~mL})$, and DI water $(15 \mathrm{~mL})$. The organic layer then obtained and dried with anhydrous sodium sulfate, filtered, and excess solvent was removed via rotary evaporation. The solvent was further removed under reduced pressure. Yield $(0.21 \mathrm{~g}, 71 \%)$ as white solid . ${ }^{1} \mathrm{H}$ NMR $\left(\mathrm{CDCl}_{3}\right) \delta(\mathrm{ppm}) 1.71-1.74(2 \mathrm{~s}$, $\left.\mathrm{CH}_{3}\right), 3.09-3.53\left(\mathrm{~m}, \mathrm{CH}_{2}\right), 4.30\left(\mathrm{~m}, \mathrm{CH}_{2}\right), 4.92(\mathrm{t}, \mathrm{CH}), 7.15-7.20(\mathrm{~m}, \mathrm{CH}), 8.21(\mathrm{~s}, \mathrm{H}-$ $\mathrm{C}=\mathrm{O})$.

Synthesis of 3-formyl-N-(furan-2-ylmethyl)-2,2-dimethylthiazolidine-4-carboxamide (16) Triethylamine (0.214 g, $2.12 \mathrm{mmol}), 11$ (0.4 g, $2.13 \mathrm{mmol})$, dichloromethane ( $7 \mathrm{~mL}$ ) and a stir bar was added to $200 \mathrm{~mL}$ round bottom flask and cooled to $0-5{ }^{\circ} \mathrm{C}$. The solution of methyl chloroformate $(0.208 \mathrm{~g}, 2.16 \mathrm{mmol})$ in dichloromethane $(2 \mathrm{~mL})$ was added to the mixture. Salt was formed so additional dichloromethane $(20 \mathrm{~mL})$ was added. The solution of furfuryl amine $(0.21 \mathrm{~g}, 2.1 \mathrm{mmol})$ in $6 \mathrm{~mL}$ of dichloromethane was added to $25 \mathrm{~mL}$ vial and placed in the freezer for 10 minutes prior to the addition to the mixture. The reaction was stirred at room temperature for 2.5 hours. Next, dichloromethane $(20 \mathrm{~mL})$ was added to the mixture. The mixture then washed with $5 \% \mathrm{HCl}(20 \mathrm{~mL})$, saturated sodium bicarbonate $(10 \mathrm{~mL})$, and DI water $(15 \mathrm{~mL})$. The organic layer then obtained and dried with anhydrous sodium sulfate, filtered, and excess solvent was removed via rotary evaporation. The solvent was further removed under reduced pressure. Yield $(0.38 \mathrm{~g}, 66 \%)$ as white solid. ${ }^{1} \mathrm{H}$ NMR $\left(\mathrm{CDCl}_{3}\right) \delta(\mathrm{ppm}) 1.75-1.83(2 \mathrm{~s}$, 
$\left.\mathrm{CH}_{3}\right), 3.19-3.67\left(\mathrm{~m}, \mathrm{CH}_{2}\right), 4.42\left(\mathrm{~s}, \mathrm{CH}_{2}\right), 5.01(\mathrm{~m}, \mathrm{CH}), 6.22-6.30(2 \mathrm{~s}, \mathrm{CH}), 7.22(\mathrm{~s}, \mathrm{NH})$, $7.33(\mathrm{~s}, \mathrm{CH}), 8.35(\mathrm{~s}, \mathrm{H}-\mathrm{C}=\mathrm{O})$.

Synthesis of 4-vinylbenzyl azide (17a)

To a $100 \mathrm{~mL}$ round bottom flask, 4-vinylbenzyl chloride (14.5 g, $95 \mathrm{mmol})$, DI water (10mL), DMF (30 mL) and stir bar was added. Sodium azide $(8.1 \mathrm{~g}, 124.6 \mathrm{mmol})$ and potassium carbonate $(0.5 \mathrm{~g}, 3.6 \mathrm{mmol})$ was then added to the mixture. The reaction stirred at room temperature 24 hours. Dichloromethane $(50 \mathrm{~mL})$ was added to the mixture. The mixture washed with brine $(x 3,15 \mathrm{~mL})$ and DMF was removed under reduced pressure. ${ }^{1} \mathrm{H}$ NMR showed a mixture of products.

\section{Synthesis of 4-vinylbenzyl azide (17b)}

Sodium azide (2.2 g, $33.8 \mathrm{mmol})$, 4-benzylchloride (4.64 g, $30.4 \mathrm{mmol})$ and stir bar was added to $50 \mathrm{~mL}$ round bottom flask. DMF $(20 \mathrm{~mL})$ was added to the mixture and stirred at room temperature for 24 hours. DI water $(100 \mathrm{~mL})$ then added to the mixture prior to washing with diethyl ether (x3) and ethyl acetate (x2). The organic layer collected and then washed with brine (x3), dried with anhydrous sodium sulfate, filtered and excess solvent was removed via rotary evaporation. Further solvent was removed under reduced pressure. Yield (2.05 g, 43\%) obtained an orange liquid. ${ }^{1} \mathrm{H}$ NMR $\left(\mathrm{CDCl}_{3}\right)$ $\delta(\mathrm{ppm}) 4.15\left(\mathrm{~s}, \mathrm{CH}_{2}\right), 5.18-5.21(\mathrm{~d}, \mathrm{CH}), 5.66-5.72(\mathrm{~d}, \mathrm{CH}), 6.58-6.68(\mathrm{~d}$ of d, CH), 7.13-7.32 ( $\mathrm{d}$ of $\mathrm{d}, \mathrm{CH})$. 
Synthesis of 4-vinylbenzyl azide (17c)

A stir bar, 4-vinylbenzyl chloride (5.01 g, $37.9 \mathrm{mmol})$, and $40 \mathrm{~mL}$ of DMF, and sodium azide $(6.40 \mathrm{~g}, 98.7 \mathrm{mmol})$ was added to a $100 \mathrm{~mL}$ round bottom flask. The reaction was stirred for 24 hours. DI water $(100 \mathrm{~mL})$ then added to the mixture prior to washing with diethyl ether $(x 3,50 \mathrm{~mL})$ and ethyl acetate $(x 2,50 \mathrm{~mL})$. The organic layers were collected and then washed with brine $(\mathrm{x} 3,50 \mathrm{~mL})$, dried with anhydrous magnesium sulfate and excess solvent was removed via rotary evaporation. Further solvent was removed under reduced pressure. Yield (3.1 g, 51\%) obtained an orange liquid. ${ }^{1} \mathrm{H}$ NMR $\left(\mathrm{CDCl}_{3}\right) \delta(\mathrm{ppm}) 4.15\left(\mathrm{~s}, \mathrm{CH}_{2}\right), 5.18-5.21(\mathrm{~d}, \mathrm{CH}), 5.66-5.72(\mathrm{~d}, \mathrm{CH}), 6.58-6.68(\mathrm{~d}$ of d, $\mathrm{CH}), 7.13-7.32(\mathrm{~d}$ of $\mathrm{d}, \mathrm{CH})$.

\section{Synthesis of 4-vinylbenzyl amine (18a)}

Cobalt chloride ( $48 \mathrm{mg}, 2 \mathrm{mmol}), \mathbf{1 7 c}(0.32 \mathrm{~g}, 2 \mathrm{mmol})$, and a stir bar were added to the $50 \mathrm{~mL}$ round bottom flask. Aliquat $336(0.08 \mathrm{~g}, 0.2 \mathrm{mmol})$ and sodium borohydride (15.2 mg, $4 \mathrm{mmol}$ ) in $4 \mathrm{~mL}$ of DI water was added dropwise to round bottom flask. The mixture then stirred for 30 minutes. The mixture was extracted with ether and the organic layer then dried with anhydrous sodium sulfate, filtered, and excess solvent was removed via rotary evaporation. Further solvent was removed under reduced pressure. ${ }^{1} \mathrm{H}$ NMR of the product did not show the presence of an amine.

\section{Synthesis of 4-vinylbenzyl amine (18b)}

A stir bar, $17 \mathbf{c}(3.2 \mathrm{~g}, 20.1 \mathrm{mmol})$, and dry ether $(40 \mathrm{~mL})$ were added to a $500 \mathrm{~mL}$ round bottom flask. The flask was cooled to $0{ }^{\circ} \mathrm{C}$ and LAH $(0.82 \mathrm{~g}, 21.1 \mathrm{mmol})$ was 
added slowly to the reaction mixture. The reaction mixture stirred overnight. Cold DI water $(3 \mathrm{~mL}), \mathrm{NaOH}(2.5 \mathrm{~mL}, 15 \% \mathrm{w} / \mathrm{v})$, and water $(5 \mathrm{~mL})$ was added to the reaction to quench the LAH and precipitate the LAH. The solution became yellow and the lithium precipitant was filtered off. Excess solvent was removed via rotary evaporation. Yielding $\left(1.3 \mathrm{~g}, 48 \%\right.$ \%). ${ }^{1} \mathrm{H}$ NMR $\left(\mathrm{CDCl}_{3}\right) \delta(\mathrm{ppm}): 1.84\left(\mathrm{~s}, \mathrm{br}, \mathrm{NH}_{2}\right), 3.80\left(\mathrm{~s}, \mathrm{CH}_{2}\right), 5.22(\mathrm{~d}, \mathrm{CH})$, $5.74(\mathrm{~d}, \mathrm{CH}), 6.64$ (d of d, CH), 7.21-7.37 (m, CH).

Synthesis of 3-formyl-2,2-dimethyl-N-(4-vinylbenzyl)thiazolidine-4-carboxamide (19) Triethylamine (0.543 g, $5.37 \mathrm{mmol}), 11$ (1.0 g, $5.3 \mathrm{mmol})$, dichloromethane $(10 \mathrm{~mL})$ and a stir bar was added to $200 \mathrm{~mL}$ round bottom flask and cooled to $0-5{ }^{\circ} \mathrm{C}$. The solution of methyl chloroformate $(0.528 \mathrm{~g}, 5.59 \mathrm{mmol})$ in $5 \mathrm{~mL}$ of dichloromethane was added to the mixture. Salt was formed so additional dichloromethane $(20 \mathrm{~mL})$ was added. The solution of $\mathbf{1 8 b}(0.669 \mathrm{~g}, 5.03 \mathrm{mmol})$ in dichloromethane $(6 \mathrm{~mL})$ was added to $25 \mathrm{~mL}$ vial and placed in the freezer for 10 minutes prior to the addition to the mixture. The reaction was stirred at room temperature over night. Next, dichloromethane $(20 \mathrm{~mL})$ was added to the mixture. The mixture then washed with $5 \% \mathrm{HCl}(20 \mathrm{~mL})$, saturated sodium bicarbonate $(10 \mathrm{~mL})$, and DI water $(15 \mathrm{~mL})$. The organic layer obtained was dried with anhydrous sodium sulfate, filtered, and excess solvent was removed via rotary evaporation. The solvent was further removed under reduced pressure. Yield $(0.9 \mathrm{~g}$, $56 \%)$ as an opaque liquid. ${ }^{1} \mathrm{H}$ NMR $\left(\mathrm{CDCl}_{3}\right) \delta(\mathrm{ppm})$ 1.62-1.68 $\left(2 \mathrm{~s}, \mathrm{CH}_{3}\right), 3.06-3.35(\mathrm{~m}$, $\left.\mathrm{CH}_{2}\right), 4.18-4.38\left(\mathrm{~m}, \mathrm{CH}_{2}\right), 4.82(\mathrm{~m}, \mathrm{CH}), 5.1(\mathrm{~d}, \mathrm{CH}), 5.63(\mathrm{~d}, \mathrm{CH}), 6.55(\mathrm{~d}$ of d, CH), 7.07-7.23(d of d, CH), $7.33(\mathrm{~s}, \mathrm{NH}), 8.12(\mathrm{~s}, \mathrm{H}-\mathrm{C}=\mathrm{O})$. 
Copolymerization of styrene with a protected thiazolidine (20a)

Styrene (2.3 g, $22.1 \mathrm{mmol}), \mathbf{1 9}(0.22 \mathrm{~g}, 0.72 \mathrm{mmol})$ and a stir bar were added to $25 \mathrm{~mL}$ round bottom flask. AIBN $(0.24 \mathrm{~g}, 1.46 \mathrm{mmol})$ and toluene $(3 \mathrm{~mL})$ was added to the mixture. The mixture purged with nitrogen for 20 minutes and then heated at $60{ }^{\circ} \mathrm{C}$ for 3 hours. The mixture was then precipitated in methanol yielding $(0.65 \mathrm{~g}, 25 \%$ conversion, $\mathrm{M}_{n}-24300 \mathrm{~g} \mathrm{~mol}^{-1}$, PDI-1.71) white flaky powder. ${ }^{1} \mathrm{H} \mathrm{NMR}\left(\mathrm{CDCl}_{3}\right) \delta$ (ppm) $1.48\left(\mathrm{br}, \mathrm{CH}_{2}\right), 1.75(\mathrm{br}, \mathrm{CH}), 3.06-3.35\left(\mathrm{~m}, \mathrm{CH}_{2}\right), 4.18-4.38\left(\mathrm{~m}, \mathrm{CH}_{2}\right), 4.82(\mathrm{~m}$, $\mathrm{CH}), 6.32-7.30(\mathrm{br}, \mathrm{CH}).), 8.22(\mathrm{~s}, \mathrm{H}-\mathrm{C}=\mathrm{O})$.

\section{Copolymerization of styrene with a protected thiazolidine $\mathbf{( 2 0 b )}$}

Styrene ( $2.7 \mathrm{~g}, 26.0 \mathrm{mmol}), 19$ (0.22 g, $0.72 \mathrm{mmol})$, toluene $(2 \mathrm{~mL})$ and a stir bar were added to $25 \mathrm{~mL}$ round bottom flask. Benzoyl peroxide (BPO) (32.3 $\mathrm{mg}, 0.13 \mathrm{mmol}$ ) and DMF $(2 \mathrm{~mL})$ were added to the mixture. The mixture purged with nitrogen for 20 minutes and then heated at $80^{\circ} \mathrm{C}$ for 3 hours. The reaction was then precipitated into methanol yielding (1.32 g, $52 \%$ conversion, $\mathrm{M}_{n}-22100 \mathrm{~g} \mathrm{~mol}^{-1}$, PDI-1.67) white flaky powder. ${ }^{1} \mathrm{H}$ NMR $\left(\mathrm{CDCl}_{3}\right) \delta(\mathrm{ppm}) 1.48\left(\mathrm{br}, \mathrm{CH}_{2}\right), 1.75(\mathrm{br}, \mathrm{CH}), 3.06-3.35\left(\mathrm{br}, \mathrm{CH}_{2}\right)$, 4.18-4.38 (br, $\mathrm{CH}_{2}$ ), 4.82 (br, $\left.\mathrm{CH}\right), 6.32-7.30$ (br, $\left.\mathrm{CH}\right)$ ), 8.22 (br, $\left.\mathrm{H}-\mathrm{C}=\mathrm{O}\right)$.

Synthesis of 3-formyl-2,2-dimethyl-N-(prop-2-yn-1-yl)thiazolidine-4-carboxamide (21)

Triethylamine (1.3 g, $12.8 \mathrm{mmol}), 11$ (2.5 g, $13.24 \mathrm{mmol})$, dichloromethane $(35 \mathrm{~mL}$ ) and a stir bar was added to $200 \mathrm{~mL}$ round bottom flask. The solution of methyl chloroformate $(1.245 \mathrm{~g}, 13 \mathrm{mmol})$ in dichloromethane $(\mathrm{mL})$ was added to the mixture. Salt was formed so additional dichloromethane $(20 \mathrm{~mL})$ was added. The solution of 
propargyl amine $(0.723 \mathrm{~g}, 13.1 \mathrm{mmol})$ in dichloromethane $(6 \mathrm{~mL})$ was added to $25 \mathrm{~mL}$ vial and placed in the freezer for 10 minutes prior to the addition to the mixture. The reaction was stirred at room temperature for 2.5 hours. Next, dichloromethane $(20 \mathrm{~mL})$ was added to the mixture. The mixture then washed with $5 \% \mathrm{HCl}(20 \mathrm{~mL})$, saturated sodium bicarbonate $(10 \mathrm{~mL})$, and $\mathrm{DI}$ water $(15 \mathrm{~mL})$. The organic layer then obtained and dried with anhydrous sodium sulfate, filtered, and excess solvent was removed via rotary evaporation. The solvent was further removed under reduced pressure. Yield (1.65 g, 55 \%) as opaque liquid. ${ }^{1} \mathrm{H} \mathrm{NMR}\left(\mathrm{CDCl}_{3}\right) \delta(\mathrm{ppm}) 1.77-1.85\left(2 \mathrm{~s}, \mathrm{CH}_{3}\right), 2.23(\mathrm{~s}, \mathrm{CH}), 3.18$ $3.75\left(2 \mathrm{~d}\right.$ of d, $\left.\mathrm{CH}_{2}\right), 4.04\left(\mathrm{~m}, \mathrm{CH}_{2}\right), 5.02(\mathrm{~m}, \mathrm{CH}), 7.09(\mathrm{~s}, \mathrm{NH}), 8.4(\mathrm{~s}, \mathrm{H}-\mathrm{C}=\mathrm{O})$.

Synthesis of 3-formyl-2,2-dimethyl-N-((1-(4-vinylbenzyl)-1H-1,2,3-triazol-4yl)methyl)thiazolidine-4-carboxamide (22).

A stir bar, 21 (0.618 g, $2.73 \mathrm{mmol})$, and 17b (0.435 g, $2.73 \mathrm{mmol})$ was added to $50 \mathrm{~mL}$ round bottom flask followed by the mixture of t-butanol $(6 \mathrm{~mL})$ and DI water $(6$ $\mathrm{mL})$. L-sodium ascorbate $(0.0538 \mathrm{~g}, 0.27 \mathrm{mmol})$ and copper sulfate pentahydride $(0.008$ $\mathrm{g}, 0.03 \mathrm{mmol})$. The reaction was stirred at room temperature for 48 hours. Ice-cold DI water $(25 \mathrm{~mL})$ was added to the mixture and a white precipitate formed. The precipitate was filtered via vacuum filtration and dried for 24 hours. Yield (0.32 g, $30 \%)$ obtained as a white powder. ${ }^{1} \mathrm{H}$ NMR $\left(\mathrm{CDCl}_{3}\right) \delta(\mathrm{ppm}) 1.48-1.53\left(2 \mathrm{~s}, \mathrm{CH}_{3}\right), 2.50\left(\mathrm{~s}, \mathrm{CH}_{2}\right), 3.15-3.38$ (m, $\left.\mathrm{CH}_{2}\right), 4.38\left(\mathrm{~d}, \mathrm{CH}_{2}\right), 4.71-4.85(\mathrm{~m}, \mathrm{CH}), 5.25-5.3(\mathrm{~d}, \mathrm{CH}), 6.70\left(\mathrm{~s}, \mathrm{CH}_{2}\right), 5.80-5.91(\mathrm{~d}$, $\mathrm{CH}), 6.70-6.80(\mathrm{~m}, \mathrm{CH}), 7.33-7.51(2 \mathrm{~d}, \mathrm{CH}), 7.93(\mathrm{~s}, \mathrm{CH}), 8.35(\mathrm{~s}, \mathrm{H}-\mathrm{C}=\mathrm{O})$. 


\subsection{Conclusion}

The initial attempt to synthesize a cysteine containing from styrene/styrene oxide proved to require multiple columns and was not facile enough for high throughput. To circumvent this issue L-cysteine hydrochloride was used as a starting material. L-cysteine $\mathrm{HCl}$ could not be used directly to ligate to a polymer as there are too many functional groups that could interfere with ligation (mercaptan, thiol, carboxylic acid). Additionally the solubility of the salt severely limited the amount of reactions that could be attempted.

Initially it was though that a synthesis similar to Grinstaff et al. could be employed. The first reaction with L-cysteine $\mathrm{HCl}$ with acetone was found to proceed with quantitative conversion to the thiazolidine salt. The boc protection of the secondary amine within the thiazolidine ring proved to be challenging. Alternative uses of the thiazolidine salt were attempted including the reduction of the carboxylic acid. However the salt nature of the thiazolidine made reactions heterogeneous and unable to proceed. It was thought that a more hydrophobic aldehyde or ketone could help improve the solubility of the thiazolidine, however simply placing a hydrophobic ketone with Lcysteine $\mathrm{HCl}$ did not proceed.

It was found that a high yielding formylation of the secondary amine could be achieved. This now fully protected thiazolidine could become solubilized in a wide range of organic solvents in the presence of a base. Esterification of the carboxylic acid was successful, however the ester proved to be unstable under acidic conditions. Amide formation using DCC was unsuccessfully attempted, however another mixed anhydride of the protected cysteine could be reacted with a primary amine to yield an amide. This reaction was high yielding and worked with a variety of amines, notably 4-vinylbenzyl 
amine and propargyl amine. The ligated 4-vinylbenzyl amide was successfully polymerized and incorporated into the polymer, however IR analysis proved difficult to see differences in the protected vs. non-protected polymer due to low incorporation of the functional monomer into the polymer. Propargyl amine allowed for the facile click of protected thiazolidine to a 4-vinylbenzyl azide.

The triazole formed from 4-vinylbenzyl azide and the fully protected cysteine was subjected to a kinetic test to see if the thiazolidine linkages are reversible. It was found that the addition of an acid releases acetone that was initially incorporated into the cysteine residue indicating that latent cysteine residues can be made. Additionally the ligation of the protected cysteine to propargyl amine allows for it to be clicked onto any polymer with pendent azides in addition to direct ligation to a monomer.

Future work includes clicking the protected thiazolidine to polystyrene with terminal azides. Additionally the photolabile bonds of ortho-nitrobenzyl ester create aldehydes upon ultraviolet (UV) stimuli (see Figure 3.3.1). The use of thiazolidine chemistry to react with the produced aldehyde has not been reported. This could become an important way of repurposing a material that has been designed to be cleaved upon exposure to UV.

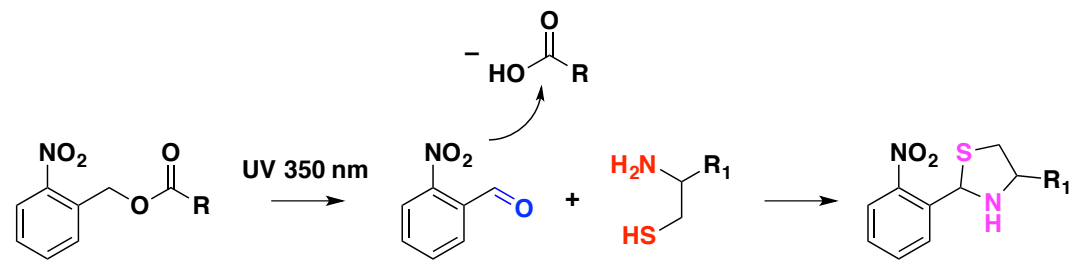

Figure 3.4.1. Incorporation of thiazolidine chemistry as a way to functionalize a photocleavable molecule.

Additional work is the use of other click reactions with the alkyne such as thiolene/yne reactions. This in combination with RAFT, could be useful in creating 
dimers with a central cysteine residue (Figure 3.3.2). The potential applications for this chemistry have yet to be attempted as thiazolidine chemistry has slowly began to win popularity among chemists.

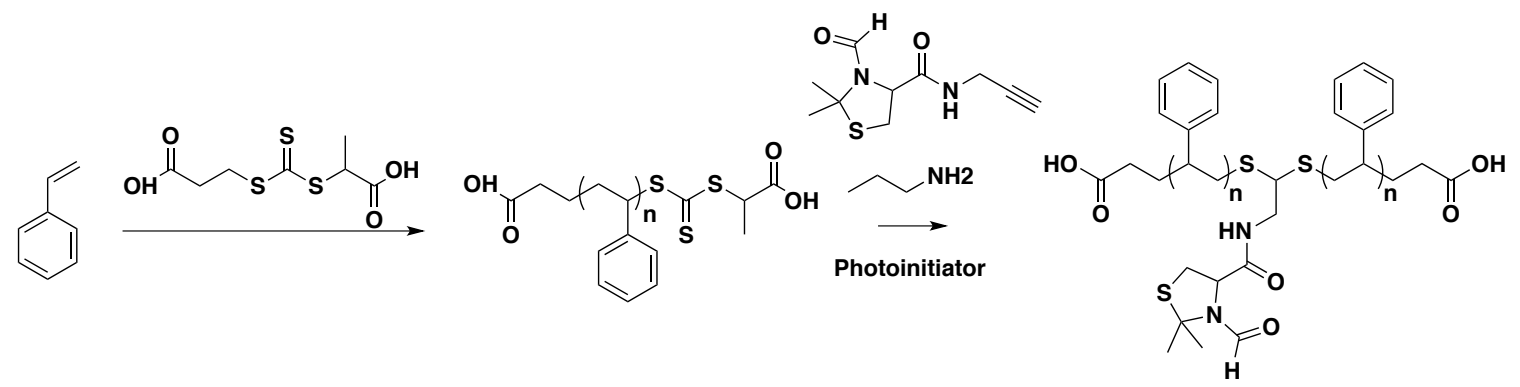

Figure 3.4.2. Use of thiolyne click to create a dimer with a central protected thiazolidine. 


\section{References}

(1) Wagh, M. P.; Joshi, O. U.; Patel, J. S.; Jain, V. R. Thiomers: a new generation of mucoadhesive polymers. Research J Pharm and ... 2009.

(2) Li, W.; Lu, Y.; Wang, Z.; Dalton, J. T.; Miller, D. D. Synthesis and antiproliferative activity of thiazolidine analogs for melanoma. Bioorganic \& Medicinal Chemistry Letters 2007, 17, 4113-4117.

(3) Armarego, W. L. F.; Chai, C. L. L. Purification of laboratory chemicals; 6 ed. Butterworth Heinemann, 2009.

(4) Amantini, D.; Fringuelli, F.; Piermatti, O.; Tortoioli, S.; Vaccaro, L. Nucleophilic ring opening of 1, 2-epoxides in aqueous medium. Arkivoc 2002, 11, 293-311.

(5) Wathier, M.; Jung, P. J.; Carnahan, M. A.; Kim, T.; Grinstaff, M. W. Dendritic macromers as in situ polymerizing biomaterials for securing cataract incisions. $J$. Am. Chem. Soc. 2004, 126, 12744-12745.

(6) Onen-Bayram, F. E.; Durmaz, I.; Scherman, D.; Herscovici, J.; Cetin-Atalay, R. A novel thiazolidine compound induces caspase-9 dependent apoptosis in cancer cells. Bioorganic \& Medicinal Chemistry 2012, 20, 5094-5102.

(7) Sheehan, J. C.; Yang, D.-D. H. A New Synthesis of Cysteinyl Peptides. J. Am. Chem. Soc. 1958, 80, 1158-1164.

(8) Goodman, M. Synthesis of peptides and peptidomimetics; Thieme, 2002; pp. 517533.

(9) Fringuelli, F.; Pizzo, F.; Vaccaro, L. Cobalt (II) chloride-catalyzed chemoselective sodium borohydride reduction of azides in water. Synthesis 2000, 2000, 646-650. 


\section{Conclusion}

Using multiple post polymerization modifications, a polymer prepared via RAFT was shown to have latent cysteine residues. It was determined that the amount of dithiothreitol, solvent selection, and potassium carbonate in solution directly affects the coupling efficiency. It seems that an eventual optimization of reaction conditions to achieve a high degree of coupling of polymers prepared via RAFT is possible. A more promising direction is to generate the free thiol in situ and react it immediately as opposed to protecting it with MTS. This would eliminate a deprotection step and make the reaction more economically viable. It has been shown previously that minimal coupling due to disulfide bond formation can be observed in the aminolysis of the polymer without the use of a protecting group. ${ }^{1}$ If the free thiol attached to the polymer could then be clicked to a protected cysteine via thiol-ene/yne chemistry then it would provide a facile method for the attachment of cysteine residues onto the polymer without multiple post polymerization modifications.

A range of synthetic reactions were attempted to find a facile method to create a molecule that protects cysteine as well incorporates usable functionality to ligate the compound onto a monomer or polymer. It was found that by using a mixed anhydride approach the cysteine could be fully protected as well as incorporated into an alkyne for future click reactions. It was proven that the thiazolidine reaction is reversible in acidic conditions via ${ }^{1} \mathrm{H}$ NMR. Now that the molecule with the potential to perform thiazolidine linkages has been made, it can be incorporated into a variety of polymers regardless of the polymer backbone. Future studies will include the incorporation of thiazolidine linkages into thermally responsive, water soluble, and biocompatible polymers. 


\section{References:}

(1) Konkolewicz, D.; Gray-Weale, A.; Perrier, S. Hyperbranched polymers by thiolyne chemistry: from small molecules to functional polymers. J. Am. Chem. Soc. 2009, 131, 18075-18077. 